Aus der Klinik für Nephrologie und Rheumatologie

(Prof. Dr. med. M. Zeisberg)

der Medizinischen Fakultät der Universität Göttingen

\title{
Einfluss von salzreicher Ernährung auf die hyperperfundierte Niere nach \\ Uninephrektomie bei hereditären Nierenerkrankungen wie dem Alport-Syndrom im Mausmodell
}

\author{
INAUGURAL-DISSERTATION \\ zur Erlangung des Doktorgrades \\ der Medizinischen Fakultät der \\ Georg-August-Universität zu Göttingen
}

vorgelegt von

Stefan Benda

aus

Hildesheim

Göttingen 2020 
Dekan:

\section{Betreuungsausschuss}

Betreuer

Ko-Betreuer

\section{Prüfungskommission}

Referent

Ko-Referent:

Promotor:

Datum der mündlichen Prüfung:
Prof. Dr. med. W. Brück

\author{
Prof. Dr. O. Gross
}

PD. Dr. W. Krick

Prof. Dr. O. Gross

Prof. Dr. C. Mühlhausen

Prof. Dr. R. Dressel 
Hiermit erkläre ich, die Dissertation mit dem Titel "Einfluss von salzreicher Ernährung auf die hyperperfundierte Niere nach Uninephrektomie bei hereditären Nierenerkrankungen wie dem Alport-Syndrom im Mausmodell" eigenständig angefertigt und keine anderen als die von mir angegebenen Quellen und Hilfsmittel verwendet zu haben.

Göttingen, den 


\section{Inhaltsverzeichnis}

Abbildungsverzeichnis ......................................................................................... III

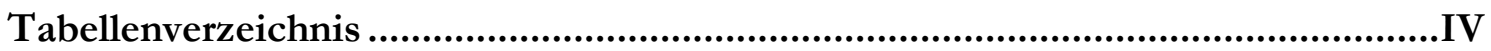

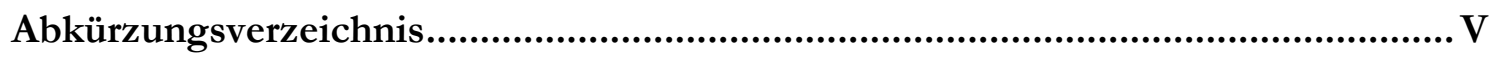

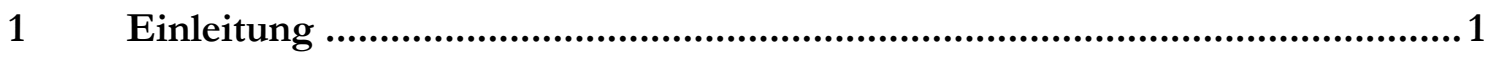

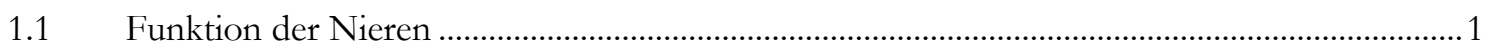

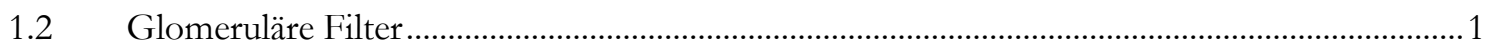

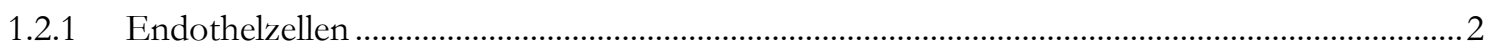

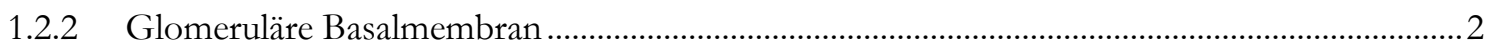

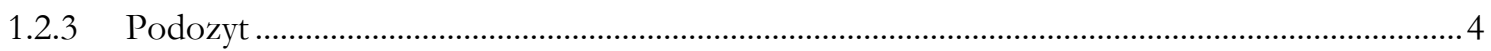

1.3 Alport-Syndrom..................................................................................................

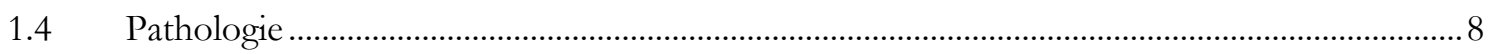

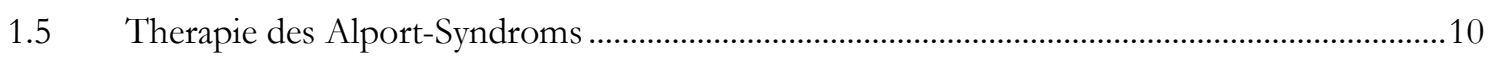

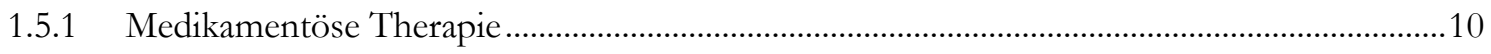

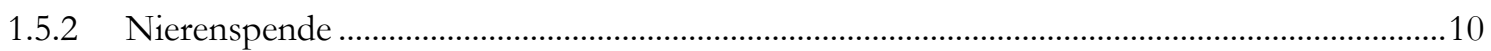

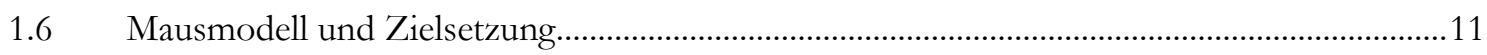

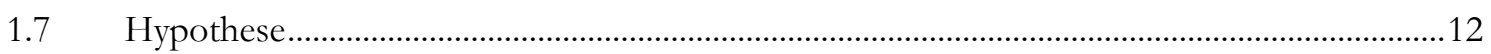

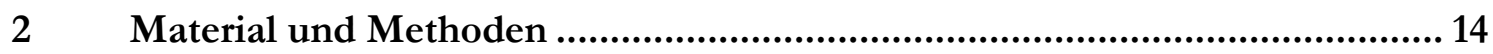

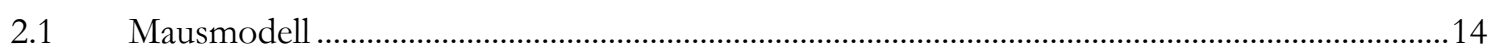

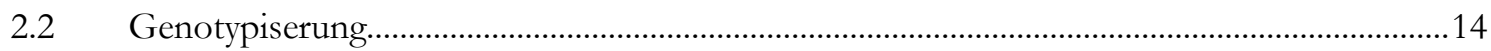

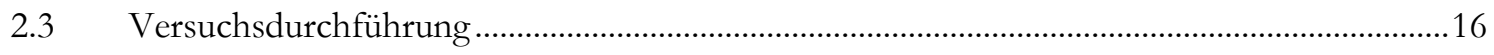

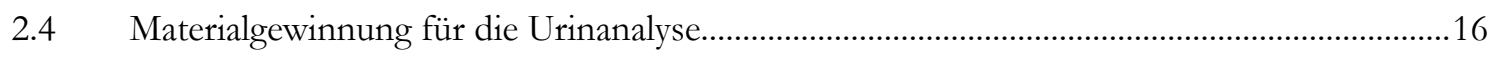

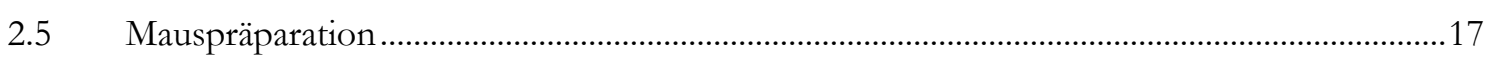

2.5.1 Herstellung von Paraffinschnitten...................................................................................... 17

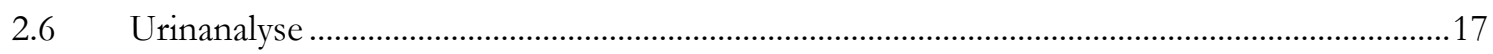

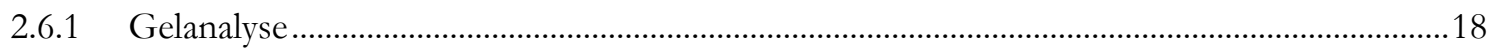

2.7 Herstellung von Schnitten für lichtmikroskopische Beurteilung................................................18

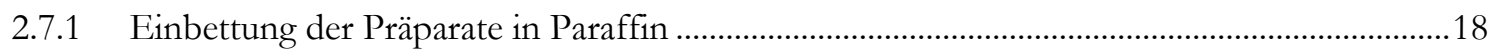

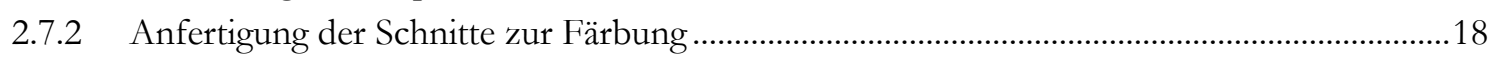

2.8 Färbung der Präparate für die lichtmikroskopische Beurteilung.............................................19

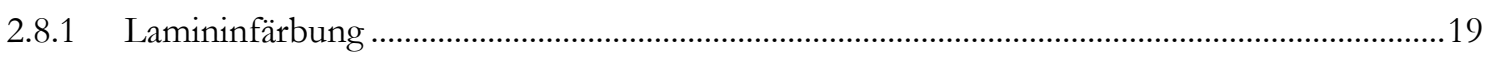

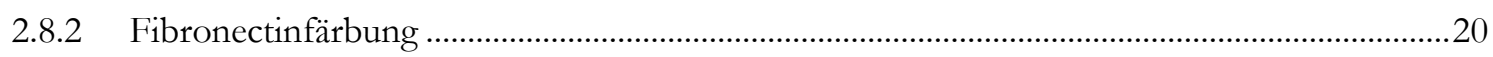

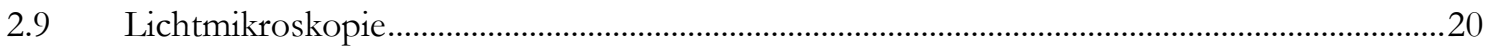

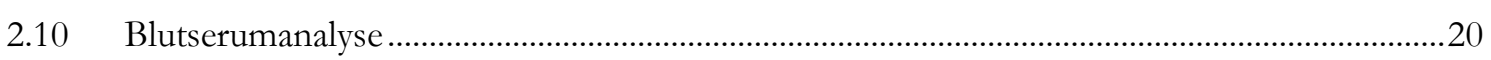




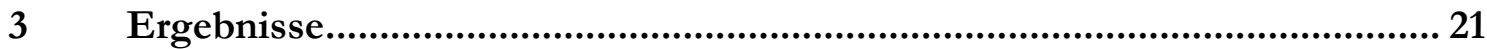

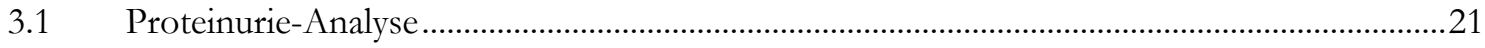

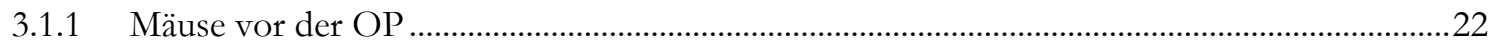

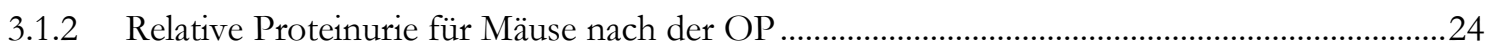

3.1.3 Absolute Proteinurie für Mäuse nach der OP ……………………………………………......29

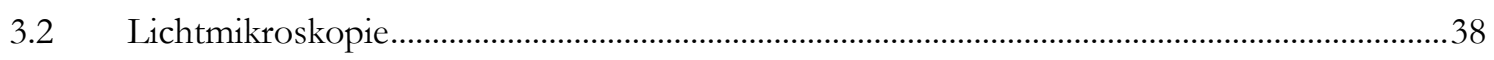

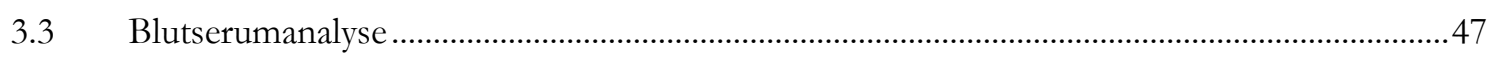

3.4 Analyse des Körpergewichts der Mäuse .................................................................................50

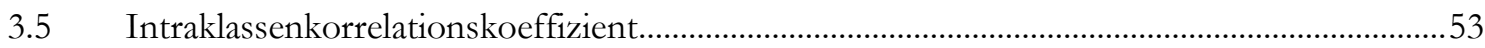

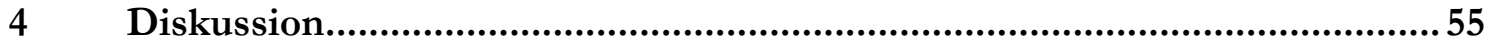

4.1 Grundlegende Überlegungen für die Analyse......................................................................... 55

4.2 Übertragbarkeit der tierexperimentellen Daten auf den Menschen ..........................................58

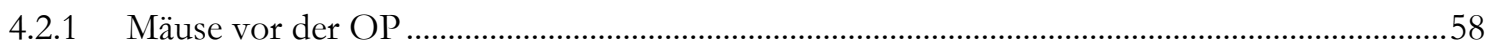

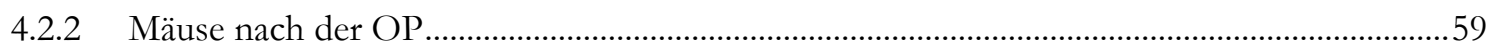

4.3 Reproduzierbarkeit der Ergebnisse (Intraklassenkorrelationskoeffizient) ................................65

4.4 Bewertung und Ausblick ...................................................................................................65

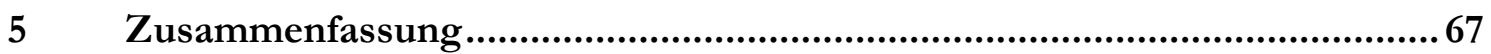

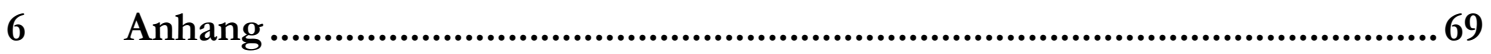

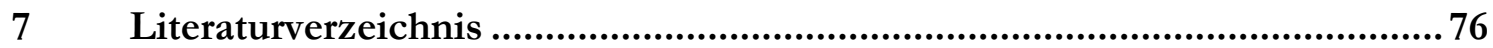




\section{Abbildungsverzeichnis}

Abbildung 1 - Übersicht des glomerulären Filters.

Abbildung 2 - Beispiel einer semiquantitativen Proteinuriebestimmung mittels Protein-Gelelektrophorese

Abbildung 3 - Proteinurie für Proteine gleicher Größe wie Albumin vor der OP ………….....23

Abbildung 4 - Proteinurie für Proteine größer als Albumin vor der OP ......................................24

Abbildung 5 - relative Proteinurie für Proteine gleicher Größe wie Albumin bei weiblichen Mäusen ab einem Alter von 120 Lebenstagen................................................25

Abbildung 6 - relative Proteinurie für Proteine größer als Albumin bei weiblichen Mäusen ab einem Alter von 120 Lebenstagen ....................................................................26

Abbildung 7 - relative Proteinurie für Proteine gleicher Größe wie Albumin bei männlichen Mäusen ab einem Alter von 120 Lebenstagen.............................................2

Abbildung 8 - relative Proteinurie für Proteine größer als Albumin bei männlichen Mäusen ab einem Alter von 120 Lebenstagen

Abbildung 9 - Proteinurie für Proteine gleicher Größe wie Albumin bei weiblichen Mäusen ab einem Alter von 120 Lebenstagen

Abbildung 10 - Proteinurie für Proteine größer als Albumin bei weiblichen Mäusen ab einem Alter von 120 Lebenstagen

Abbildung 11 - Proteinurie für Proteine gleicher Größe wie Albumin bei männlichen Mäusen ab einem Alter von 120 Lebenstagen

Abbildung 12 - Proteinurie für Proteine größer als Albumin bei männlichen Mäusen ab einem Alter von 120 Lebenstagen

Abbildung 13 - Fibronectinfärbung in 10-facher Vergrößerung; beispielhafte Bilder für jeweilige Behandlungsgruppe und Genotyp

Abbildung 14 - Fibronectinfärbung in 40-facher Vergrößerung; beispielhafte Bilder für jeweilige Behandlungsgruppe und Genotyp

Abbildung 15 - Lamininfärbung in 10-facher Vergrößerung; beispielhafte Bilder für jeweilige Behandlungsgruppe und Genotyp

Abbildung 16 - Lamininfärbung in 40-facher Vergrößerung; beispielhafte Bilder für jeweilige Behandlungsgruppe und Genotyp

Abbildung 17 - Fibronectin-Score jeweils in 10- und 40-facher Vergrößerung ............................ 45

Abbildung 18 - Laminin-Score jeweils in 10- und 40-facher Vergrößerung …………………...... 46

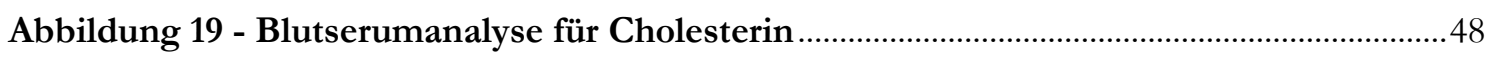

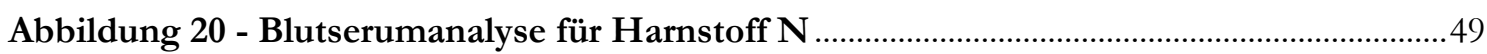

Abbildung 21 - Gewichtsveränderung: 60. Lebenstag bis zur OP .............................................51

Abbildung 22 - Gewichtsveränderung: ab OP für weibliche Tiere.............................................52

Abbildung 23 - Gewichtsveränderung: ab OP für männliche Tiere...........................................53 


\section{Tabellenverzeichnis}

Tabelle 1 - Verarbeitungsschema für die Top Taq PCR

Tabelle 2 - Amplifizierungsprogramm der DNA im Biometra'Tprofessional .........................15

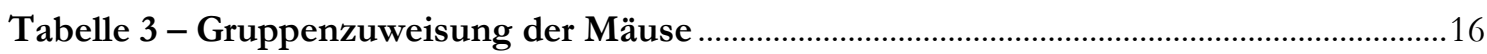

Tabelle 4 - Zusammensetzung der Probe für die Chloroform-Methanol-Fällung .................117

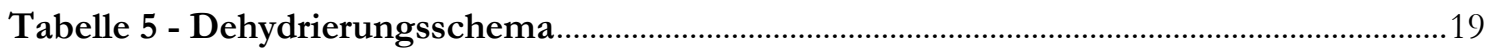

Tabelle 6 - Übersicht der Proteinuriemittelwerte und Standardabweichungen für weibliche Tiere im Alter von 180 Tagen.

Tabelle 7 - Übersicht der Proteinuriemittelwerte und Standardabweichungen für männliche Tiere im Alter von 180 Tagen. ...................................................................... 36

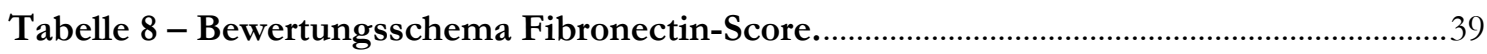

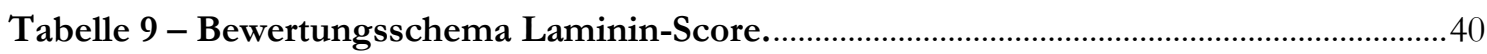

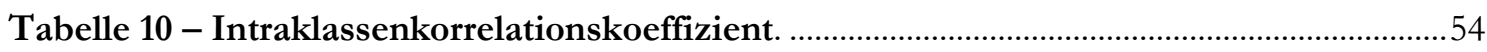




\section{Abkürzungsverzeichnis}

$\begin{array}{ll}\text { ACE } & \text { angiotensin converting enayme } \\ \text { ANOVA } & \text { analysis of variance } \\ \text { BDA } & \text { Bio-Doc-Analyse } \\ \text { BSA } & \text { bovine serum albumin } \\ \text { COL4 } & \text { Kollagen IV } \\ \text { DNA } & \text { Desoxyribonukleinsäure } \\ \text { EDTA } & \text { Ethylendiamintetraacetat } \\ \text { EtOH } & \text { Ethanol } \\ \text { GBM } & \text { Glomeruläre Basalmembran } \\ \text { GFR } & \text { Glomeruläre Filtrationsrate } \\ \text { HSPHG } & \text { Heparansulfatproteoglykane } \\ \text { Neph } & \text { Operation mit Uninephrektomie } \\ \text { NPHS1 } & \text { Nephrin-Gen } \\ \text { NPHS2 } & \text { Podocin-Gen } \\ \text { OP } & \text { Operation } \\ \text { PBS } & \text { phosphate-buffered saline } \\ \text { PCR } & \text { Polymerasekettenreaktion } \\ \text { PFA } & \text { Paraformaldehyd } \\ \text { pi } & \text { Pixel } \\ \text { RAAS } & \text { Renin-Angiotensin-Aldosteron-System } \\ \text { rpm } & \text { rounds per minute/Umdrehungen pro Minute } \\ \text { s. c. } & \text { subkutan } \\ \text { SD } & \text { Standardabweichung } \\ \text { Sham } & \text { Operation ohne Uninephrektomie } \\ \text { TAE } & \text { Tris-Acetat-EDTA-Puffer } \\ \text { TBS } & \text { tris-buffered saline } \\ & \end{array}$




\section{$1 \quad$ Einleitung}

\subsection{Funktion der Nieren}

Die Nieren liegen im Retroperitonealraum des Abdomens. Sie haben hauptsächlich regulatorische Aufgaben. Hierbei sind vor allem die Homöostase im Elektrolyt- und Säure-BaseHaushalt und weiterhin auch ihre Bedeutung im Vitaminhaushalt und Knochenstoffwechsel zu erwähnen. Sowohl Suleiman et al. (2013) als auch Tryggvason und Wartiovaara (2005) beschreiben die zentrale Aufgabe der Niere so, dass die Niere mit ihren Funktionseinheiten, den Nephronen, sowie der Filtrationseinheit, dem Glomerulum, dafür verantwortlich ist, dass niedrigmolekulare Plasmaprodukte aus dem Blut gefiltert werden können. Jede Niere besteht aus ungefähr einer Million Nephrone. Den niedrigmolekularen Plasmaprodukten wird eine ungehinderte Passage von der Blut- auf die Urinseite ermöglicht. Proteine, die gleich groß oder größer als Albumin sind, sollen durch den Filter zurückgehalten werden.

Tryggvason und Wartiovaara (2005) beschrieben die Urinproduktion in der Niere mit einer täglichen Bildung von ungefähr 180 Litern Primärurin und einer Modifizierung des Primärharns in dem sich an das Glomerulum anschließenden Teil des Nephrons, sodass physiologischerweise täglich 1 - 1,5 Liter Urin produziert werden.

\subsection{Glomeruläre Filter}

Innerhalb des Glomerulums befindet sich ein dreigeteilter Filter. Dieser Filter ist wohl einer der komplexesten im menschlichen Körper (Haraldsson et al. 2008). Wie von Funk et al. (2018) beschrieben wurde, liegt in der Mitte des Filters die glomeruläre Basalmembran (GBM), welche auch als flächendeckende extrazelluläre Matrix angesehen werden kann. Auf der Urinseite sind spezialisierte Endothelzellen vorhanden, sogenannte Podozyten. Auf der Blutseite findet sich das fenestrierte Endothel. Die GBM wird von Podozyten und Endothelzellen gebildet (Abrahamson 1985). Der glomeruläre Filter ist größen- und ladungsabhängig (Rennke und Venkatachalam 1977; Rennke et al. 1975).

Proteine werden an der Größe von Albumin bemessen. Albumin ist ein ungefähr 65 Kilodalton (kDa) großes Protein (Carter et al. 1989). Der Moleküldurchmesser von Albumin beträgt 3,6 Nanometer (nm) (Lüllmann-Rauch 2012). Im Urin werden Proteine in drei verschiedene Größen unterteilt: kleiner als Albumin, gleich groß wie Albumin und größer als Albumin. Albumin kann teilweise den glomerulären Filter passieren und wird danach im sich anschließenden Tubulusabschnitt reabsorbiert (Birn und Christensen 2006). Die grö- 
ßenabhängige Filtration findet in der GBM statt. Hier können Moleküle kleiner 1,8 nm den Filter frei passieren, wohingegen Moleküle größer 4,4 nm zurückgehalten werden (Lüllmann-Rauch 2012). Da große Teile des Filters negativ geladen sind, können negativ geladene Proteine den Filter deutlich schlechter passieren.

Diese Arbeit beschäftigt sich mit einer Erkrankung der GBM: dem Alport-Syndrom. Vorab werden daher die an dem Filter beteiligten drei Strukturen (Endothel, Basalmembran und Podozyt) näher in ihrer physiologischen Zusammensetzung betrachtet.

\subsubsection{Endothelzellen}

Die Hauptaufgabe der Endothelzellen ist es, den Tonus und somit den Blutfluss durch das Glomerulum zu regulieren (Calles-Escandon und Cipolla 2001).

Tryggvason und Wartiovaara (2005) beschrieben den Aufbau der Endothelzellen im Bereich des Glomerulums: Die Endothelzellen haben von Zelle zu Zelle Fenster mit einem 50 - 100 nm großen Durchmesser. Diese Fenster dienen nicht primär als Öffnung für Makromoleküle des Plasmas. Die negative Ladung der Endothelzellen entsteht durch ihre Glykokalix mit ihren Glykosaminoglykanen.

Haraldsson et al. (2008) beschrieben ergänzend: Die Endothelzellen können in ihrer Funktion im glomerulären Filter allgemein als negativ geladen angesehen werden. Albumin mit einem Durchmesser von ungefähr 3,6 nm sollte theoretisch problemlos das fenestrierte Endothel passieren können. Da dies nicht der Fall ist, kann als Ursache die Ladungsabhängigkeit des Filters angenommen werden.

Endothelzellen spielen vor allem eine Rolle in der Pathogenese von diabetischer Nephropathie (Cheng und Harris 2014).

\subsubsection{Glomeruläre Basalmembran}

Nach Tryggvason und Wartiovaara (2005) ist die GBM eine 300 bis $350 \mathrm{~nm}$ dicke, extrazelluläre Struktur. Ihre strukturellen Hauptkomponenten sind Laminin, Kollagen IV, Nidogen und die Heparansulfatproteoglykane (HSPHG) Perlecan und Agrin (Pozzi et al. 2017). Sowohl Yurchenco und O'Rear (Yurchenco und O'Rear 1994) als auch Miner und Sanes (Miner und Sanes 1994) beschrieben die GBM als zwei unabhängige Netzwerke aus Kollagen IV und Laminin. Beide Netzwerke sind über Verbindungsmoleküle innerhalb der GBM verbunden. Hier entfalten die beiden weiteren Hauptkomponenten (Nidogen und HSPHG) neben weiteren kleineren Molekülen ihre Bedeutung für die GBM.

Miner (2011) publizierte, dass die Zusammenfügung der glomerulären Basalmembran nicht aller Bestandteile bedarf. So führt eine Mutation im Kollagen IV (COL4) oder im Agrin nicht zu einer fehlerhaften Entwicklung. Die Bildung einer GBM ist zwar ohne Kollagen möglich, jedoch leidet hierunter deren Stabilität (Poschl et al. 2004). 
Wegen der wichtigen Rolle der GBM in der Pathogenese des Alport-Syndroms werden die vier Hauptkomponenten der Membran im Folgenden genauer betrachtet.

\subsubsection{Kollagen}

Der Aufbau des Kollagens IV ist mittlerweile weit erforscht. Funk et al. (2018) fassten zusammen: COL4 ist der Hauptbestandteil der GBM. Die Kollagen IV-Familie besteht aus sechs alpha-Ketten $(\alpha 1-\alpha 6)$, wobei jede dieser Ketten durch ein eigenes Gen kodiert wird. Diese alpha-Ketten haben immer die gleiche Abfolge von Aminosäuren (Glycin-X-Y). Somit ist es ihnen möglich, die Struktur einer Triplehelix anzunehmen.

Es gibt drei bekannte COL4-Heterotrimere: $\alpha 1 \alpha 2 \alpha 1, \alpha 3 \alpha 4 \alpha 5$ und $\alpha 5 \alpha 6 \alpha 5$, welche eine gewebespezifische Verteilung haben (Hudson 2004). Die Zusammenlagerung der Heterotrimere erfolgt über ihre NC1-Domäne (Kang et al. 2008). Die Interaktion der unterschiedlichen Domänen beschrieb Hudson (2004) wie folgt: Im Bereich der NC1-Domäne lagern sich jeweils zwei Heterotrimere zusammen. Am anderen Ende der Aminosäurekette liegt die 7S-Domäne. In diesem Bereich lagern sich jeweils vier Heterotrimere zusammen. Da dies im Bereich der GBM geschieht, werden zunächst nur Protomere in die extrazelluläre Matrix sezerniert.

In der Entwicklung befindet sich zunächst Kollagen $\alpha 1 \alpha 2 \alpha 1$ (IV) in der GBM. Erst im Verlauf kommt es zu einem Wechsel der Kollagenketten von $\alpha 1 \alpha 2 \alpha 1$ (IV) zu $\alpha 3 \alpha 4 \alpha 5$ (IV). Der Wechsel der Kollagenketten scheint die GBM widerstandsfähiger gegenüber mechanischem und chemischem Stress zu machen (Kalluri et al. 1997). Verschiedene Arbeiten beschrieben die Regulation der Kollagen IV Heterotrimere (Abrahamson et al. 2009; Funk et al. 2018; Heidet et al. 2000; Suleiman et al. 2013): Kollagen $\alpha 1 \alpha 2 \alpha 1$ (IV) wird von den Endothelzellen, Mesangiumzellen und Podozyten gebildet und befindet sich physiologischerweise herunterreguliert in der gesunden GBM des Erwachsenen durch das ausreichende Vorhandensein von Kollagen $\alpha 3 \alpha 4 \alpha 5$ (IV) in der Nähe der Endothelzellen. Kollagen $\alpha 3 \alpha 4 \alpha 5$ (IV) wird ausschließlich von Podozyten gebildet. Ein Grund für die erhöhte Widerstandsfähigkeit von Kollagen $\alpha 3 \alpha 4 \alpha 5$ (IV) ist das vermehrte Vorkommen von Disulfidbrücken zwischen den Kollagenfasern (Gunwar et al. 1998).

Kollagen IV befindet sich in der Niere nicht nur in der GBM, sondern auch im Mesangium und in der Bowman'schen Kapsel (Miner 1999).

\subsubsection{Laminin}

In der Entwicklung der GBM spielt Laminin, welches allein für die Integrität verantwortlich ist, eine besondere Rolle (Miner 2011). Laminin wurde von Tryggvason und Wartiovaare (2005) als ein großes heterotrimeres Glykoprotein beschrieben, welches wichtige Aufgaben in der zellulären Differenzierung und Adhäsion sowie in der Strukturgebung hat. Es wird im Gegensatz zum Kollagen IV in der reifen GBM von Endothelzellen und Podozyten gebildet (St John und Abrahamson 2001) und kommt ubiquitär vor. Laminin wird in 
Form von $\alpha \beta \gamma$-Heterotrimeren sezerniert. Sie setzen sich aus $5 \alpha, 4 \beta$ und $3 \gamma$ Ketten zusammen. Die Namensgebung erfolgt anhand der einzelnen Ketten. Eine Stabilisierung erfolgt durch Disulfidbrücken (Miner 2012). Physiologischerweise besteht das Laminin in der Basalmembran beim Adulten aus $\alpha 5 \beta 2 \gamma 1$ (L-521 - Laminin 11) (Miner 2005). Dem gegenüber steht eine Vielfalt von Lamininen, die während der Embryogenese in der GBM zu finden sind und durch Laminin-521 in ihrem Verlauf ersetzt werden (Miner und Li 2000). Hierbei findet im Großen und Ganzen ein Ersatz von Laminin $1(1 \alpha 1 \beta 1 \gamma)$ über Laminin 10 $(5 \alpha 1 \beta 1 \gamma)$ in Laminin 11 statt (Miner 1998).

\subsubsection{Nidogen}

Nidogen verbindet in der GBM Laminin und Kollagen (Fox et al. 1991). Es gibt zwei verschiedene Arten von Nidogen: Nidogen-1 und Nidogen-2. Eine Mutation beziehungsweise ein Fehlen in einem der beiden Nidogen-Gene führt nicht zwangsläufig zu einem Schaden der GBM (Murshed et al. 2000; Schymeinsky et al. 2002). Bader et al. (2005) konnten feststellen, dass eine Mutation in einem der beiden Nidogen-Gene zwar zu einer Ausbildung der GBM führt, jedoch ist die Mutation in beiden Genen nicht mit dem Leben vereinbar. Es kommt zum perinatalen Tod.

\subsubsection{Agrin}

Das größte HSPHG in der GBM ist Agrin. Wie alle HSPHG ist es negativ geladen. Da die GBM ebenfalls negativ geladen ist, kann vermutet werden, dass Agrin einen großen Anteil an deren negativer Ladung hat (Kanwar et al. 2007). Harvey et al. (2007) legten dar, dass Agrin weder für die Bildung noch für die Aufrechterhaltung der GBM benötigt wird. Die ladungsabhängige Filterfunktion steht ebenfalls nicht im Zusammenhang mit Agrin.

\subsubsection{Podozyt}

Bei dem Podozyten handelt es sich um spezialisierte Epithelzellen auf der Urinseite des glomerulären Filters (Bouchireb et al. 2014). Die Entstehung der Schlitzmembran beschrieb Kerjaschki (2001): Im Podozyten werden eine Vielzahl von Molekülen gebildet, die an der Bildung des Filters beteiligt sind. Die Ausläufer der Podozyten - die Podozytenfußfortsätze - verlaufen oktopusartig und greifen wie zwei Hände ineinander.

Die Podozytenfortsätze lassen zwischen sich 30 bis $45 \mathrm{~nm}$ Platz, der durch die Schlitzmembran aufgefüllt wird (Rodewald und Karnovsky 1974). Diese wird durch verschiedene Moleküle gebildet, die miteinander interagieren; hierzu zählt unter anderem Nephrin (NPHS1) (Pavenstadt et al. 2003). In den Blickpunkt der Forschung um Veränderungen der Podozyten- bzw. Schlitzmembranintegrität sind vor allem zwei Gene geraten: NPHS1 und NPHS2, letzteres kodiert für Podocin. Sie sind die beiden Hauptgene, die zum Steroidresistenten nephrotischen Syndrom führen (Bouchireb et al. 2014). Allgemein scheint der Podozyt in der Pathogenese von glomerulären Erkrankungen wie beispielsweise der fokal segmentalen Glomerulosklerose eine Schlüsselrolle einzunehmen (Kerjaschki 2001). 
Bouchireb et al. (2014) beschrieben Podocin: Bei NPHS2 handelt es sich um ein $42 \mathrm{kDa}$ großes, aus 383 Aminosäuren bestehendes Protein aus der Stomatinprotein-Familie, welches einzig vom Podozyten exprimiert wird. Es stellt ein wichtiges Verbindungsmolekül zwischen der Schlitzmembran und dem Zytoskelett des Podozyten dar.

Untersuchungen zeigten NPHS2 als einen Regulator für die Integrität der Schlitzmembran, welches die Lücke zwischen den Fußfortsätzen der Podozyten durch Zell-Zell-Kontakte überbrückt (Funk et al. 2018).

Eine Mutation im NPHS2 kann zu einer Verschlechterung bzw. zu einem rasanteren Fortschreiten einer Proteinurie führen. Somit spielt dieses Gen möglicherweise eine Rolle als ein Modifiergen in der Progression des Alport-Syndroms (Voskarides et al. 2012). Roselli et al. (2004) zeigten, dass es bei Podocin-Knockoutmäusen (NPHS2 ${ }^{-/}$) zu einer fokal segmentalen Glomerulosklerose kommt. Diese Mäuse entwickelten ebenfalls eine Proteinurie. Es kann davon ausgegangen werden, dass das NPHS2 ein Modifier von glomerulären Krankheiten ist. Des Weiteren zeigten diese Mäuse eine mesangiale Sklerosierung, Verschmelzungen der Podozytenfußfortsätze und letztlich einen Verlust der GBM.

Mutationen in diesem Gen konnten beim familiären idiopathischen nephrotischen Syndrom und bei fokal segmentaler Glomerulosklerose nachgewiesen werden (Boute et al. 2000). Hierbei spielt vor allem die R229Q-Mutation des NPHS2-Gens eine besondere Rolle und korreliert mit der Stärke der Proteinurie (Tonna et al. 2008). Das Vorliegen einer compound-heterozygoten p.R229Q-Mutation führt zu einem Auftreten der Proteinurie im Rahmen eines Steroid-resistenten nephrotischen Syndroms im höheren Lebensalter (Machuca et al. 2009). Verschiedene Mutationen in verschiedenen Genen der Schlitzmembran können zu einem kongenitalen nephrotischen Syndrom, zu einem Steroid-resistenten nephrotischen Syndrom oder zu einer fokal segmentalen Glomerulosklerose führen (Grahammer et al. 2013). Tonna et al. (2008) schlussfolgerten, dass die R229Q-Mutation einen genetischen Risikofaktor für eine Proteinurie darstellt. Dies gilt auch für einen Schaden an der GBM bei Vorliegen einer thin basement membrane nephropathy. Der hierfür ursächliche Mechanismus ist allerdings noch unklar.

Es wird vermutet, dass die R229Q-Mutation ein guter prognostischer Marker für Patienten mit einer Hämaturie in jungen Jahren ist (Voskarides et al. 2012). 


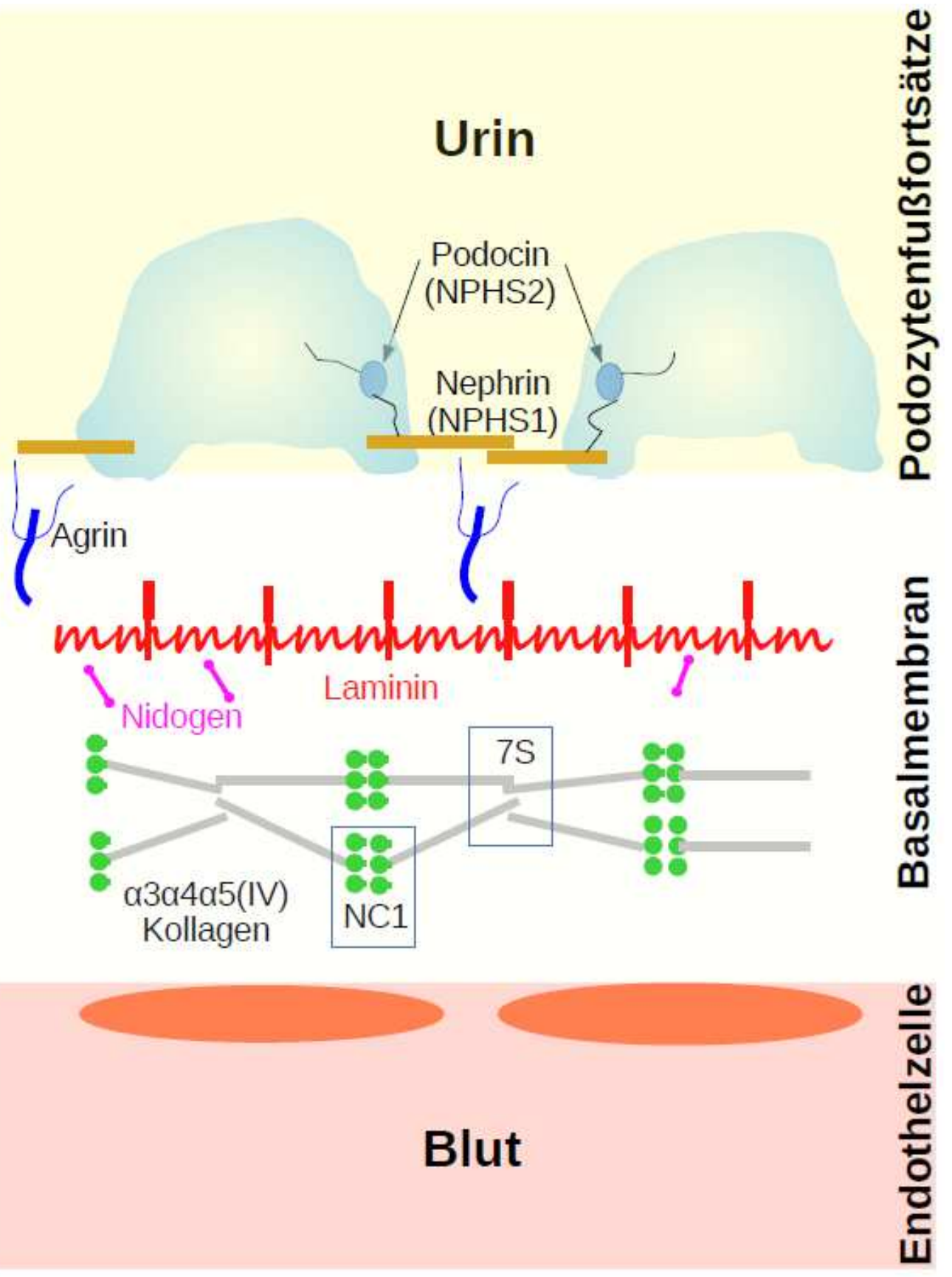

Abbildung 1 - Übersicht des glomerulären Filters NC1 = NC1-Domäne; 7S = 7SDomäne, modifiziert nach Chew und Lennon (2018); die Abbildung wurde unter der Creative-Commons-Lizenz: Creative-Commons-Namensnennung (abgekürzt: CC BY 4.0) in der 4. Version vom 26. August 2020 auf https:// creativecommons.org/licenses/by/4.0/legalcode. de nachzulesen veröffentlicht.

\subsection{Alport-Syndrom}

Das Alport-Syndrom führt in variabler Ausprägung durch die Mutationen im Kollagen IV (COL4A3/4/5-Genen) in der GBM zu Nierenversagen, Schwerhörigkeit und Augenveränderungen (Alport 1927). Die Häufigkeiten und das Vererbungsmuster beschrieben Kashtan et al. in verschiedenen Arbeiten (Kashtan 2018; Kashtan et al. 2001): Das Alport-Syndrom 
ist eine genetische Erkrankung und wird in 80 bis $85 \%$ der Fälle durch eine Mutation in COL4A5 X-chromosomal übertragen. Allerdings gibt es auch ein autosomal (rezessiv oder dominant) vererbtes Alport-Syndrom. Hierbei sind die Gene COL4A3 und COL4A4 betroffen. Somit kann jede Mutation, die zu einer Fehlbildung der Bestandteile für das Kollagen $\alpha 3 \alpha 4 \alpha 5$ (IV) führt, auch in einem Alport-Syndrom resultieren (Funk et al. 2018). Allein im COL4A5-Gen sind über 700 Mutationen bekannt, die zum Alport-Syndrom führen (Savige et al. 2014). Miner (2012) publizierte, dass es bei einer Mutation im Kollagen $\alpha 3 \alpha 4 \alpha 5$ (IV) zu einer kompensatorischen Expression von Kollagen $\alpha 1 \alpha 2 \alpha 1$ (IV) kommt. Somit wird scheinbar die Architektur der GBM zeitweise aufrechterhalten. Hierdurch lässt sich ein Teil der Pathogenese des Alport-Syndroms durch die Annahme erklären, dass Kollagen $\alpha 1 \alpha 2 \alpha 1$ (IV) weniger widerstandsfähig gegenüber proteolytischen Einflüssen ist als Kollagen $\alpha 3 \alpha 4 \alpha 5$ (IV) (Kalluri et al. 1997).

Kashtan et al. (2001) führten in Bezug auf das Alport-Syndrom aus, dass es neben den Veränderungen im Kollagen IV zu Veränderungen in der Lamininzusammenlagerung innerhalb der GBM kommt. Hierbei entsteht eine ektope Akkumulation von Laminin $\alpha 2$ in Form von Laminin $4(\alpha 2 \beta 2 \gamma 1)$ in menschlichen, am Alport-Syndrom erkrankten Nieren.

Im Mausmodell ist beim Vergleich von gesunden Mäusen mit Alport-Mäusen eine Akkumulation von Lamininen, wie z.B. Laminin 111 und Laminin $211 \mathrm{zu}$ sehen (Cosgrove et al. 2000). In der GBM von Alport-Mäusen kommt die $\alpha 5$-Kette des Laminins vermehrt vor (Abrahamson et al. 2007). Die Abwesenheit von Kollagen $\alpha 3 \alpha 4 \alpha 5$ (IV) reaktiviert die im reifen Glomerulum inhibierte Expression von Laminin-111 (Abrahamson et al. 2003). In einer weiteren Arbeit zeigten Abrahamson et al. (2007), dass Laminin-111 vor allem in den verdickten Bereichen der GBM akkumuliert. Des Weiteren belegte diese Arbeit, dass insbesondere dort die Filterleistung verringert ist. Somit kann davon ausgegangen werden, dass es vor allem in diesen Abschnitten der GBM zu einer Proteinurie kommt. Weiterführend wird angenommen, dass die Akkumulation von Laminin in der GBM einer der ersten pathologischen Schritte in der Manifestation des Alport-Syndroms ist (Abrahamson et al. 2003).

Aus den oben genannten Gründen wurden die lichtmikroskopischen Schnitte auf Laminin als Veränderungsmarker der GBM gefärbt.

Auch elektronenmikroskopisch sind diese Veränderungen in der Zusammensetzung der Basalmembran sichtbar. So bilden sich im Rahmen des Alport-Syndroms typischerweise eine aufgespaltene und verdickte Basalmembran sowie eine Fußfortsatzverschmelzung aus (Kruegel et al. 2013).

In dieser Arbeit soll das heterozygote Vorliegen einer Alport-Mutation untersucht werden.

Mittlerweile wird auch das heterozygote Vorliegen einer Mutation der COL4A3/A4/A5Gene unter dem Oberbegriff Alport-Syndrom geführt (Kashtan et al. 2018). Bisher wurden heterozygote Mutationen in den COL4A3- bzw. COL4A4-Genen als thin basement membrane 
nephropathy bezeichnet. Im Folgenden wird daher nur noch vom heterozygoten AlportSyndrom gesprochen. Hierbei ist die ehemals sogenannte thin basement membrane nephropatby gemeint. Das heterozygote Alport-Syndrom wird durch eine heterozygote Mutation in den Genen COL4A3 oder COL4A4 hervorgerufen (Savige et al. 2003). Es wird vermutet, dass ungefähr $1 \%$ der Weltbevölkerung heterozygoter Anlageträger für ein autosomales AlportSyndrom (Mutation in COL4A3/COL4A4-Gen) ist (Gross et al. 2003). Man kann das heterozygote Vorliegen des Alport-Syndroms auch als eine Art Carrier für das AlportSyndrom ansehen. Diese Patienten fallen, wenn überhaupt, erst im höheren Lebensalter mit Symptomen auf (Jais et al. 2003). Der Phänotyp wurde von Kashtan (2003) so beschrieben, dass bei beiden Formen des Alport-Syndroms eine Hämaturie bereits in der Kindheit als ein erstes Krankheitszeichen beobachtet werden kann. Dies kann ein Grund dafür sein, dass die Krankheiten in Anfangsstadien schwer zu unterscheiden sind.

Früher wurde diese Hämaturie im Rahmen des heterozygoten Alport-Syndroms auch als benigne familiäre Hämaturie bezeichnet. Allerdings ist der Name irreführend, denn eine benigne familiäre Hämaturie ist nicht immer gutartig. Es besteht eine Verbindung zwischen heterozygoten Mutationen in den COL4A3/COL4A4-Genen und fokal segmentaler Glomerulosklerose sowie der Entwicklung einer Proteinurie und letztlich einem terminalen Nierenversagen (Pierides et al. 2009; Voskarides et al. 2007).

Der Verlauf des heterozygoten Alport-Syndroms weist nach Deltas et al. (2015) eine große Varianz auf. Patienten mit einem heterozygoten Alport-Syndrom erleiden in ungefähr $35 \%$ der Fälle ein terminales Nierenversagen im Alter von ca. 70 Jahren. Das Alter, in dem die terminale Niereninsuffizienz erreicht wird, schwankt allerdings sehr stark. Demgegenüber stehen 20 bis $25 \%$ der Patienten mit einem heterozygoten Alport-Syndrom, die nur eine Mikrohämaturie mit oder ohne Proteinurie bekommen.

\subsection{Pathologie}

Der genaue Pathomechanismus hinter dem Alport-Syndrom ist unbekannt. Es kann lediglich aus verschiedenen Vermutungen ein möglicher Pathomechanismus skizziert werden.

Im Folgenden werden einige bekannte Veränderungen des Alport-Syndroms beschrieben: Charakteristisch für glomeruläre Erkrankungen sind eine mesangiale Zellproliferation und eine vermehrte extrazelluläre Ablagerung (Sethi et al. 2016). Diese Veränderungen in der GBM in Verbindung mit biomechanischem Stress führen zu einer Reaktion (Meehan et al. 2009). Dadurch und in Verbindung mit einem erhöhten Abstand zwischen GBM und Podozyt entsteht typischerweise eine Glomerulosklerose (Ding et al. 2017; Wickman et al. 2016). Weiterhin führen alle glomerulären Erkrankungen zu einer interstitiellen Fibrose (Cosgrove und Liu 2017). Im Verlauf der Alport-Erkrankung entsteht eine fokal segmentale Glomerulosklerose (Funk et al. 2018). Es konnte für verschiedene Bestandteile der GBM ein kompensatorischer Mechanismus bei Verlust einzelner Bestandteile gezeigt werden. 
Hierzu gehören Nidogene (Miosge et al. 2002), Laminin-B2 (Noakes et al. 1995) und Kollagen IV (Miner und Sanes 1996).

Außerdem zeigte sich, dass eine Verringerung der GBM zu einer milden Proteinurie führt, wohingegen der Verlust beziehungsweise die Verschmelzung der Podozytenfußfortsätze in einer massiven Proteinurie resultiert (Hamano et al. 2002). Bei der Fußfortsatzverschmelzung werden die Zwischenzellkontakte durch tight junctions ersetzt. Im gesunden Glomerulum werden die tight junctions hingegen nur sehr selten gesehen. Der physiologische Zwischenzellkontakt der Schlitzmembran wird durch Nephrin gebildet (Grahammer et al. 2013; Pricam et al. 1975).

Das Alport-Syndrom offenbart sich durch verschiedene Symptome. Hierbei soll nur eine Auswahl der typischen renalen Symptome aufgezeigt werden. Wie bereits herausgearbeitet, handelt es sich bei einer Proteinurie um ein genotypunabhängiges, typisches Symptom des Alport-Syndroms. Die Abfolge des Auftretens von renalen Symptomen beim AlportSyndrom beschrieben Kruegel et al. (2013): Zunächst kommt es zu einer mikroskopischen Hämaturie. Als nächster Schritt kann eine größer werdende Proteinurie beobachtet werden. Letztlich kommt es zur Abnahme der glomerulären Filtrationsrate (GFR) und zu einem terminalen Nierenversagen.

Weiterhin steigen bei Patienten mit einem Nierenversagen Retentionsparameter, wie zum Beispiel Harnstoff an. Als weiterer, im Blut nachweisbarer Parameter bei nephrotischen Patienten gilt ein erhöhtes Cholesterin.

Inzwischen wird die Hämaturie als ein Risikofaktor für die Entwicklung einer Niereninsuffizienz angesehen (Kashtan 2004).

Mit dieser Arbeit soll als möglicher Umwelteinfluss eine salzreiche Ernährung auf eine vorgeschädigte GBM untersucht werden. Weitere Promotionsarbeiten in unserer Arbeitsgruppe beschäftigen sich bei gleichem Versuchsaufbau mit dem Umweltfaktor Fett beziehungsweise fettreicher Ernährung oder mit dem Einfluss des bisherigen Standardmedikaments zum Aufhalten der Krankheitsprogression (Renin-Angiotensin-Aldosteron-System [RAAS]-Blockade, s.u.).

Es konnte in Versuchen gezeigt werden, dass bereits ab einer geringen Salzkonzentration im Trinkwasser Effekte wie eine Glomerulosklerose zu sehen sind und diese mit der Menge des Salzes zunehmen (Hamming et al. 2006). Eine salzreiche Ernährung von AlportMäusen führt auch zu einem erhöhten Blutdruck und einer gesteigerten Proteinurie (Meehan et al. 2009).

Da es beim Alport-Syndrom zu einer Glomerulosklerose kommt, wurden die lichtmikroskopischen Schnitte der Mausnieren unter anderem auf Fibronectin gefärbt. Fibronectin ist ein 270 kDa großes Glykoprotein, welches einen Marker für Sklerose beziehungsweise Fibrinosierung darstellt. Die Menge an Fibronectin in der GBM wird durch die Stärke des mechanischen Einflusses reguliert (Chew und Lennon 2018). Eine vermehrte Fibronectinabla- 
gerung in der GBM kann das Entstehen eines terminalen Nierenversagens begünstigen (Strom et al. 1995).

\subsection{Therapie des Alport-Syndroms}

\subsubsection{Medikamentöse Therapie}

Für die meisten Patienten ist die Therapie der Wahl des Alport-Syndroms die Inhibierung des RAAS (Gross et al. 2012; Kashtan et al. 2013; Savige et al. 2013). Eine frühzeitig begonnene Therapie mit einer RAAS-Blockade bringt auch einen längeren und größeren Erfolg (Gross et al. 2012). Sie führt zu einer Proteinuriereduktion, welche den Hauptfaktor der Nephroprotektion darstellt (Hamming et al. 2006).

\subsubsection{Nierenspende}

Zwar kann durch das beschriebene Hinauszögerung des terminalen Nierenversagens mittels RAAS-Blockade der Zeitraum bis zur Dialysepflichtigkeit des Patienten verlängert werden, dennoch werden nahezu alle Patienten dialysepflichtig. Die Dialyse stellt im Fall eines terminalen Nierenversagens eine sehr gute Therapieoption dar. Allerdings ist die Therapie nicht frei von Nebenwirkungen und schränkt den Patienten zum Teil sehr stark in seiner Alltagsgestaltung ein. Als beste Therapieoption gilt daher die Nierentransplantation (Gillion et al. 2018).

In diesem Versuch soll die Auswirkung einer möglichen Spende auf den Spender simuliert und analysiert werden.

Hierzu ist es zunächst notwendig, sich die Gruppe der möglichen Spender anzuschauen. In Deutschland besteht lediglich die Möglichkeit der postmortalen Spende oder der Lebendspende unter Verwandten bzw. nahen Angehörigen. Als Spender kommen häufig aus genetischen und gesetzlichen Gründen Eltern von betroffenen Kindern in Frage.

Das Outcome einer Lebendspende ist für Patienten mit einem Alport-Syndrom im Vergleich zu anderen Krankheiten, die den Empfang eines Spenderorgans notwendig machen, sehr gut (Kashtan 2018; Kashtan et al. 1995). Als eine sehr seltene, aber schwerwiegende Komplikation bei einer Spende kann es aber beim Empfänger zu einer Anti-GBM Nephritis kommen (Kashtan 2018). Der Verlauf ist dabei nicht von der Schwere der Mutation abhängig; dies gilt sowohl für das Transplantatüberleben als auch für die Wahrscheinlichkeit einer Anti-GBM Nephritis (Gillion et al. 2018).

Die große Varianz im Phänotyp des Alport-Syndroms spielt für die Therapie durch Lebendspende eine entscheidende Rolle. So kann es unter Umständen durchaus schwierig sein, einen geeigneten Spender zu finden. Hierbei spielt u.a. die Mutation im Kollagen IV eine Rolle. 
Patienten mit einem X-chromosomalen Alport-Syndrom haben eine Mutation im COL4A5-Gen. Diese zeichnet sich durch eine sehr hohe Penetranz aus, sodass es bisher keine Fallbeschreibung eines männlichen Betroffenen ohne Hämaturie gibt (Kashtan 2006). Bei Frauen liegt ebenfalls eine hohe Penetranz vor, sodass über $90 \%$ der Frauen mit Xchromosomalem Alport-Syndrom eine Hämaturie aufweisen (Jais et al. 2003). Somit besteht für alle betroffenen Männer eine Kontraindikation zur Nierenspende (Kashtan 2006). Frauen mit einem X-chromosomalen Alport-Syndrom werden als schlechteste Spendergruppe angesehen und Frauen, die vor dem 45. Lebensjahr Symptome des Xchromosomalen Alport-Syndroms zeigen, gelten als ungeeignete Spender (Kashtan 2006, 2018).

Mutationen in den COL4A3- und COL4A4-Genen resultieren in einem autosomalen Alport-Syndrom. Hierbei kann zwischen einem rezessiven und dominanten Alport-Syndrom unterschieden werden. Bei diesen Mutationen kommt es, wie bereits beschrieben, zu einer großen Varianz der möglichen Symptome (Kashtan et al. 2018). Eine Eignung der Patienten als mögliche Spender kann nicht pauschal bestimmt werden. Ein Spender mit einer heterozygoten Mutation sollte nur dann generell von einer Spende ausgeschlossen werden, wenn diese in der Familie oder in der Literatur mit einem Nierenversagen assoziiert werden kann (Kashtan 2018).

Potenzielle Spender sollen selbstverständlich vor Spätfolgen einer Spende geschützt werden. Über Spätfolgen für Spender einer Niere mit einer heterozygoten COL4A3- oder COL4A4-Mutation ist bisher sehr wenig bekannt (Kashtan 2006).

Ziel dieser Arbeit ist es, mögliche Risikofaktoren, die bereits vor der Spende erkannt werden können, für den Spender zu identifizieren und den Schaden eines möglicherweise erhöhten Salzkonsums nach der Spende herauszuarbeiten.

\subsection{Mausmodell und Zielsetzung}

Cosgrove et al. (1996) beschrieben, dass COL4A3-Knockout Mäuse einen ähnlichen Phänotyp des Alport-Syndroms zeigen wie Menschen. Diese Mäuse entwickelten innerhalb von 14 Wochen ein terminales Nierenversagen. Weiterhin konnte unterstützend durch Miner und Sanes (1996) belegt werden, dass diese Mäuse einen Schwund von $\alpha 3 \alpha 4 \alpha 5$ Kollagen IV haben. Darüber hinaus wiesen die Knockout-Mäuse lediglich ein isoliertes Fehlen des COL4A3-Gens auf. Die anderen Gene der Kollagen IV-Ketten lagen unverändert vor. Auch die weitere Zusammensetzung der glomerulären Basalmembran bei diesen Tieren zeigte Veränderungen, die denen beim Menschen sehr ähnlich sind. Durch diese sekundären Veränderungen kann es letztlich zu dem terminalen Nierenversagen kommen, welches das Alport-Syndrom in der Niere charakterisiert (Cosgrove et al. 1996; Gross et al. 2004; Sampson et al. 2001). 
Heterozygote Mäuse mit einer COL4A3-Mutation erwiesen sich in Versuchen als ein gutes Modell für ein heterozygotes Alport-Syndrom (Beirowski et al. 2006).

Es gibt Grund für die Vermutung, dass NPHS2 ein Modifiergen in der Pathogenese von glomerulären Erkrankungen insbesondere beim Alport-Syndrom ist (Roselli et al. 2004). In diesem Versuch wurde das heterozygote Vorliegen einer Mutation im NPHS2-Gen und deren Auswirkungen auf GBM simuliert. Mäuse mit einer NPHS2 ${ }^{+/ R 140 Q}$ Mutation stellen ein valides Modell für einen Polymorphismus im Podocin-Gen dar (Tabatabaeifar et al. 2017). Da diese Mutation bereits lange im Mausmodell erprobt und etabliert wurde (Roselli et al. 2004), ist sie in Kombination mit der COL4A3-Mutation für den Versuch ausgewählt worden. Philippe et al. (2008) legten dar, dass Mäuse mit einer heterozygoten NPHS2Mutation keinen Phänotyp entwickeln und somit keine Proteinurie aufweisen, wohingegen homozygote Mäuse für dieses Gen innerhalb weniger Tage starben. Bei den homozygoten Mäusen war außerdem eine Fußfortsatzverschmelzung nachzuweisen. Darüber hinaus kam es bei diesen Mäusen zu histologischen Befunden, die zu einem zunehmenden Nierenversagen passen, wie zum Beispiel eine mesangiale Sklerosierung.

Das menschliche NPHS2-Gen hat zwei Aminosäuren weniger als das entsprechende Gen der Maus. Es konnte ein Mausmodell erzeugt werden, in dem die R140Q-Mutation der R138Q-Mutation des Menschen entspricht (Philippe et al. 2008; Roselli et al. 2004). Bei der hier wichtigen Patientengruppe mit einem heterozygoten Alport-Syndrom zeigte sich im Vergleich zu anderen Mutationen die R229Q-Veränderung am häufigsten (Tonna et al. 2008). Bei der R138Q Mutation wird vermindert Podocin exprimiert (Huber et al. 2003). Eine der Hauptaufgaben des NPHS2 ist die Bindung an NPHS1. Es konnte gezeigt werden, dass beim R229Q-Polymorphismus eine verringerte Bindung des NPHS2 an NPHS1 im Vergleich zum Wildtyp vorliegt (Tsukaguchi et al. 2002). Da bei beiden Mutationen (R138Q und R229Q) sowohl eine Punktmutation also auch eine verminderte Bindung von NPHS2 und NPHS1 vorliegt, kann von einer Ähnlichkeit der Mutationen ausgegangen werden.

Versuche mit dem COL4A3 $3^{+/} / / \mathrm{NPHS}^{+/ \mathrm{R} 140 \mathrm{Q}}-$ Mausmodell wurden in unserer Arbeitsgruppe bereits durchgeführt und somit als Methode etabliert. Hierbei zeigten erste Versuche unter der Fragestellung des Einflusses des Modifiergens NPHS2 auf die Pathogenese von Kollagen IV-Erkrankungen, dass die Proteinurie bei doppelt heterozygoten Mäusen altersabhängig zunimmt genauso wie der Grad der Podozytenfortsatzverschmelzung.

\subsection{Hypothese}

Die Symptomspanne des heterozygoten Alport-Syndroms kann nur unzureichend durch Genotypen erklärt werden (Bekheirnia et al. 2010; Jais et al. 2003). Aus diesem Grund werden Modifiergene diskutiert. Es konnte gezeigt werden, dass der R229Q-Polymorphismus eine Auswirkung auf den Phänotyp und somit auf die Proteinurie bei Patienten mit heterozygotem Alport-Syndrom hat (Tonna et al. 2008; Voskarides et al. 2012). 
Die Hypothese dieser Arbeit lautet daher: Welchen Einfluss haben Modifiergene, in diesem Fall das NPHS2-Gen, Umwelteinfluss (salzreiche Ernährung) und Hyperperfusion nach Uninephrektomie auf eine vorgeschädigte GBM (hier: heterozygotes Alport-Syndrom). In unserem Mausmodell soll die Lebendspende einer Niere bei einer genetisch vorgeschädigten GBM simuliert werden (Uninephrektomie). Es wird die Hypothese aufgestellt, dass nach erfolgter Spende die Proteinurie ansteigt und diese durch eine erhöhte Salzzufuhr nochmals gesteigert wird. Zusätzlich ist die fortschreitende Nierenschädigung an weiteren Parametern zu detektieren: dem Gewicht, der histologischen Ausprägung des Nierenschadens und dem Serumgehalt von Cholesterin und Harnstoff-N. 


\section{$2 \quad$ Material und Methoden}

\subsection{Mausmodell}

Für den Versuch wurden Inzucht-Mäuse vom SvJ-Stamm verwendet. Diese Mäuse haben ein Knock-out im COL4A3-Gen (internationale Bezeichnung 129-COL4A3 tm1Dec/J) (Cosgrove et al. 1996). Weiterhin wurden Tiere mit einer Mutation im NPHS2-Gen (129Nphs2 ${ }^{+/ R 140 Q}$ ) verwendet (siehe Einleitung).

Mit diesem Tierstamm wurden schon mehrere Versuche durchgeführt, sodass dieser als erprobt angesehen werden kann.

Die Tiere waren heterozygoter Anlageträger für COL4A3-Mutationen mit und ohne heterozygoter Podocinmutation (NPHS2 - R140Q). Daher erfolgte der Versuch mit einer Einteilung der Mäuse in vier Gruppen (Wildtyp: COL4A3 ${ }^{+/+} \mathrm{NPHS}^{+/+}$Tiere; COL4A3 heterozygot: $\mathrm{COL}_{4} \mathrm{A3}^{+/-} \mathrm{NPHS}^{+/+}$Tiere; NPHS2 heterozygot: COL4A3 ${ }^{+/+} \mathrm{NPHS}^{+/ \mathrm{R} 140 \mathrm{Q}}$ Tiere; COL4A3 NPHS2 doppelt heterozygot: COL4A3 ${ }^{+/-}$NPHS2 $2^{+/ R 1400}$ Tiere). Es erfolgte eine Positivkontrolle mit Mäusen mit dem Alport-Syndrom (COL4A3 ${ }^{-/-} \mathrm{NPHS}^{+/+}$Tiere).

\subsection{Genotypiserung}

Der Genotyp wurde anhand von Schwanzbiopsien (ca. 0,5 cm lang) bestimmt. Es wurde hierbei die DirectPCR (Polymerasekettenreaktion) Lysis Reagent Tail nach Angaben des Herstellers verwendet. Als Abwandlung des vom Hersteller angegeben Programms erfolgte die Verdauung der Schwanzbiopsie für eine Stunde (Std) bei 55 Grad Celsius $\left({ }^{\circ} \mathrm{C}\right)$ und 1400 rounds per minute (rpm) im Eppendorf Thermomixer Compact. Es schloss sich eine Ruhephase von 45 Minuten bei $85^{\circ} \mathrm{C}$ im Liebisch TR-L 288 an. Daraufhin wurden die Proben in der Mikro200R Hettich Zentrifuge für 30 Sekunden, bei $25^{\circ} \mathrm{C}$ und $15000 \mathrm{rpm}$ zentrifugiert. Der Überstand wurde in ein neues Reaktionsgefäß pipettiert.

Die weitere Verarbeitung erfolgte nach der Top Taq PCR für COL4 und für NPHS2: 
Tabelle 1 - Verarbeitungsschema für die Top Taq PCR

\begin{tabular}{|c|c|c|c|}
\hline \multicolumn{2}{|r|}{ COL4A3 } & \multicolumn{2}{|r|}{ Podocin } \\
\hline Menge & Substanz & Menge & Substanz \\
\hline $0,5 \mu \mathrm{l}$ & Desoxyribonukleinsäure (DNA) & $0,5 \mu l$ & DNA \\
\hline $17,4 \mu \mathrm{l}$ & destilliertes Wasser $\left(\mathrm{dH}_{2} \mathrm{O}\right)$ & $17,9 \mu l$ & $\mathrm{dH}_{2} \mathrm{O}$ \\
\hline $2,5 \mu l$ & 10 x Puffer (Top'Taq PCR Puffer, 10x) & $2,5 \mu l$ & $10 \times$ Puffer \\
\hline $2,5 \mu \mathrm{l}$ & $10 \mathrm{x}$ Corel Load ${ }^{\mathrm{TM}}$ (Concentrate, $\left.10 \mathrm{x}\right)$ & $2,5 \mu l$ & Corel Load \\
\hline $0,5 \mu l$ & Primer 1 forward & $0,5 \mu l$ & Podocin 3 forward (20pM) \\
\hline $0,5 \mu l$ & Primer 2 reverse & $0,5 \mu \mathrm{l}$ & Podocin 3 reverse $(20 \mathrm{pM})$ \\
\hline $0,5 \mu l$ & Primer 3 mutant & $0,5 \mu l$ & Nuki (je $10 \mathrm{mM}$ ) \\
\hline $0,5 \mu l$ & Nuki (je 10 millimolar [mM] & $0,1 \mu l$ & TopTaq \\
\hline $0,1 \mu l$ & Taq-Polymerase & & \\
\hline \multicolumn{2}{|c|}{ Gesamt: $=25 \mu \mathrm{l}$} & \multicolumn{2}{|c|}{ Gesamt: $=25 \mu \mathrm{l}$} \\
\hline
\end{tabular}

Es erfolgte die Amplifizierung der DNA im BiometraTprofessional unter folgendem Programm:

Tabelle 2 - Amplifizierungsprogramm der DNA im BiometraTprofessional

\begin{tabular}{|l|l|l|l|}
\hline \multicolumn{1}{|c|}{ Gradanzahl } & \multicolumn{1}{|c|}{ Dauer } & \multicolumn{1}{c|}{ Zweck } & Wiederholungen \\
\hline $94{ }^{\circ} \mathrm{C}$ & 3 Minuten (Min.) & & \\
\hline $94^{\circ} \mathrm{C}$ & 30 Sekunden (Sek.) & Denaturierung & \multirow{2}{*}{$35 \times$} \\
\hline $60{ }^{\circ} \mathrm{C}$ & 30 Sek. & Annealing & \\
\hline $72{ }^{\circ} \mathrm{C}$ & $1 \mathrm{Min}$. & Elongation & \\
\hline $72{ }^{\circ} \mathrm{C}$ & $10 \mathrm{Min}$. & & \\
\hline
\end{tabular}

Zur Auswertung erfolgte die Auftrennung des PCR-Produkts mittels DNAGelelektrophorese. Hierzu wurde ein 1,5\%iges Agarose-Gel verwendet. Für die Herstellung dieses Gels bitte Anhang beachten.

Im Anschluss lief das Gel für ungefähr 40 bis 60 Min. bei 75 Volt (V).

Die Auswertung der Gele erfolgte auf einem Ultraviolett (UV) -Transsimulator mittels Fotografie (Bio Doc Analyse (BDA) Live). 


\subsection{Versuchsdurchführung}

Nach der Genotypisierung wurden die Mäuse der jeweils zugehörigen Genotyp-Gruppe zugeordnet. Jede Maus einer dieser Genotyp-Gruppen wurde dann wiederum einer von fünf Behandlungsgruppen zugeteilt:

Tabelle 3 - Gruppenzuweisung der Mäuse

\begin{tabular}{|l|l|l|}
\hline \multicolumn{1}{|c|}{ Gruppennummer } & \multicolumn{1}{|c|}{ Behandlungsgruppe } & \multicolumn{1}{c|}{ Bezeichnung im Versuch } \\
\hline 1 & Operation (OP) ohne Uninephrektomie & „Sham“ \\
\hline 2 & OP mit Uninephrektomie & „Neph“ \\
\hline 3 & $\begin{array}{l}\text { OP mit Uninephrektomie }+ \text { Angitotensin } \\
\text { Converting Enzyme (ACE)-Hemmer }\end{array}$ & $\begin{array}{l}\text { andere Promotion dieser Ar- } \\
\text { beitsgruppe }\end{array}$ \\
\hline 4 & $\begin{array}{l}\text { OP mit Uninephrektomie }+0,9 \% \text { iger Natrium- } \\
\text { chlorid (NaCl)-Trinkwassergabe }\end{array}$ & „Salz“ \\
\hline 5 & OP mit Uninephrektomie + Protein/Fett & $\begin{array}{l}\text { andere Promotion dieser Ar- } \\
\text { beitsgruppe }\end{array}$ \\
\hline
\end{tabular}

In jeder Behandlungsgruppe waren vier Mäuse aus einer Genotyp-Gruppe. Weiterhin fand eine geschlechterspezifische Untersuchung mit je vier männlichen und vier weiblichen Mäusen statt.

In regelmäßigen Abständen wurde das Gewicht der Tiere kontrolliert. Bis zur OP erfolgte die Gewichtskontrolle alle 30 Tage. Nach der OP verringerte sich dieser Abstand auf wöchentliche Gewichtskontrollen. Ergänzend erfolgten weitere Kontrollen nach Auflage durch das zuständige Landesamt und nach Bedarf.

Bei den Tieren wurde im Alter von 138 Tagen durch Frau Diplom-Biologin Diana Rubel die Uninephrektomie entsprechend der Gruppenzuteilung durchgeführt.

Im Rahmen der OP unter Isofluran-Narkose wurde an den Mäusen prä- und postoperativ eine Analgesie durchgeführt. Präoperativ erhielten sie Buprenorphin subkutan (s. c.) in einer Dosierung von $50 \mu \mathrm{l} / 10 \mathrm{Gramm}$ (g) Körpergewicht der Maus, postoperativ am Tag der OP einmalig Metamizol + Buprenorphin s. c. (50 $\mu \mathrm{l} / 10 \mathrm{~g}$ Körpergewicht der Maus). An Tag 1 und Tag 2 postoperativ bekamen sie zweimal täglich Metamizol + Buprenorphin s. c. $(50 \mu \mathrm{l} / 10 \mathrm{~g}$ Körpergewicht der Maus). An den Tagen 3 bis 7 post-OP erfolgte eine Analgesie nach Bedarf bis zu zweimal täglich mit Metamizol s. c. (50 $\mu \mathrm{l} / 10 \mathrm{~g}$ Körpergewicht der Maus).

\subsection{Materialgewinnung für die Urinanalyse}

Um den Grad der Proteinurie bestimmen zu können, wurde bei den Mäusen ab einem Alter von 30 Tagen alle 30 Tage Urin gesammelt und zwar jeweils drei Tage vor und nach dem bestimmten Termin. 


\subsection{Mauspräparation}

\subsubsection{Herstellung von Paraffinschnitten}

Zunächst wurde die Maus durch zervikale Dislokation getötet. Es folgte die Entnahme von Urin, Blut und Niere zur weiteren Analyse. Das gewonnene Blut gerann für ca. 60 Minuten. Durch zweifache Zentrifugation wurde das Serum zur weiteren Analyse (Harnstoff-N und Cholesterin) gewonnen.

Die Nieren wurden nach der Präparation aus dem Situs in eine Universalkassette gelegt. Eine Hälfte wurde über Nacht in $4 \%$ igem Paraformaldehyd (PFA) bei $4{ }^{\circ} \mathrm{C}$ gelagert. Am nächsten Morgen wurde die Niere dann für eine Stunde in phosphate-buffered Saline (PBS) bei $4{ }^{\circ} \mathrm{C}$ im Kühlschrank gewaschen und anschließend bis zum Ausgießen in $70 \%$ igen Ethanol (EtOH) bei $4{ }^{\circ} \mathrm{C}$ gelagert.

\subsection{Urinanalyse}

Zur Urinanalyse wurde zunächst eine Chloroform-Methanol-Fällung durchgeführt. Hierzu wurden die Reaktionsgefäße mit den gesammelten Urinen aus dem Gefrierschrank genommen und bei geringer Kältezufuhr etwas aufgetaut.

Die Proben wurden bei $3200 \mathrm{rpm}$ bei $4{ }^{\circ} \mathrm{C}$ über 5 Minuten zentrifugiert.

Tabelle 4-Zusammensetzung der Probe für die Chloroform-Methanol-Fällung

\begin{tabular}{|l|l|}
\hline \multicolumn{1}{|c|}{ Menge } & \multicolumn{1}{c|}{ Substanz } \\
\hline Probe: $100 \mu \mathrm{l}(20 \mu \mathrm{l}$ Urin $+80 \mu \mathrm{l} \mathrm{dH} 2 \mathrm{O}$ & Methanol \\
\hline $400 \mu \mathrm{l}$ & Chloroform \\
\hline $100 \mu \mathrm{l}$ & $\mathrm{dH}_{2} \mathrm{O}$ \\
\hline $300 \mu \mathrm{l}$ &
\end{tabular}

Das Gemisch wurde für eine Minute bei $15.000 \mathrm{rpm}$ bei $21{ }^{\circ} \mathrm{C}$ zentrifugiert.

Anschließend wurde die obere Phase abpipettiert und erneut $400 \mu$ l Methanol zur Probe gegeben. Danach wurde das Gemisch für zwei Minuten bei $15.000 \mathrm{rpm}$ und $21^{\circ} \mathrm{C}$ zentrifugiert. Auch hier wurde die obere Phase wieder entnommen. Es erfolgte die weitere Zugabe von $400 \mu \mathrm{l}$ Methanol. Nach einer erneuten Zentrifugation (zwei Minuten bei 15.000 $\mathrm{rpm}$ und $21^{\circ} \mathrm{C}$ ) wurde wieder die obere Phase entnommen. Die Probe wurde anschließend offen gelagert, sodass das restliche Methanol verdunsten konnte.

Nach dem Trocknen wurden zu jeder Probe $25 \mu$ Probenpuffer gegeben. Die Proben inklusive dem bovine serum albumin (BSA)-Standard wurden nun für zwei Minuten bei $85{ }^{\circ} \mathrm{C}$ erhitzt und danach sofort auf Eis gekühlt. 
Anschließend wurden das Gel und die Laufkammer vorbereitet. Vor dem Befüllen der Kammern wurden die Proben bei 8000 rpm für wenige Sekunden zentrifugiert.

In die erste Kammer wurden $10 \mu$ l des Markers gefüllt.

Das Gel lief bei $80 \mathrm{~V}$ für 15 Min und dann für ca. 1,5 Std. bei $106 \mathrm{~V}$. Anschließend wurde das Gel aus der Kammer herausgelöst und in ca. $25 \mathrm{ml}$ InstantBlue ${ }^{\mathrm{TM}}$ in einer Plastikbox über Nacht geschüttelt. Am nächsten Morgen wurde das Gel mit $\mathrm{dH}_{2} \mathrm{O}$ mehrfach gespült und bis zur Analyse im Kühlschrank in $\mathrm{dH}_{2} \mathrm{O}$ gelagert.

\subsubsection{Gelanalyse}

Die Analyse des Gels erfolgte mit Hilfe des Bio Rad und dem Computerprogramm Image Lab. Es wurden zwei Aufnahmen eines jeden Gels angefertigt (Gray und Coomassie).

Die anschließende Auswertung der Banden erfolgte mit Hilfe von Fiiji Image_J. Hierbei wurden folgende Bandengrößen gewählt:

Proteine $<$ Albumin $\quad 80 \times 200$ Pixel (pi)

Albumin $\quad 80 \times 66$ pi

Proteine $>$ Albumin $\quad 80 \times 510$ pi

Es erfolgte die Analyse relativiert zum BSA-Standard (semiquantitative Proteinbestimmung).

\subsection{Herstellung von Schnitten für lichtmikroskopische Beurteilung}

\subsubsection{Einbettung der Präparate in Paraffin}

Die in 70\%igem EtOH gelagerten Präparate wurden einen Tag vor dem Ausgießen in den Einbettautomaten gelegt.

Zum Ausgießen wurden die Einbettkassetten mit den Präparaten in Paraffin gelegt. Anschließend wurde das Paraffin auf einer Kühlplatte gehärtet.

Nach dem Aushärten wurden die Präparate bei $4{ }^{\circ} \mathrm{C}$ bis zur weiteren Verarbeitung gelagert.

\subsubsection{Anfertigung der Schnitte zur Färbung}

Die Schnitte für die lichtmikroskopische Beurteilung der Nieren wurden mit einer LEICA RM 2165 angefertigt. Die Schnitte waren 0,3 SPECT/ $\mu$ m dick. Sie wurden auf MenzelGläser Superfrost Plus aufgetragen. Anschließend erfolgte die Ablösung der Schnitte in einem Wasserbad bei $40{ }^{\circ} \mathrm{C}$ Wassertemperatur. Danach wurden sie auf eine Wärmeplatte bei $45^{\circ} \mathrm{C}$ für ca. 30 Minuten getrocknet.

Abschließend wurden die Objektträger im Wärmeschrank bei $37^{\circ} \mathrm{C}$ über Nacht getrocknet. 
Die weitere Lagerung erfolgte im Trockenen bei Raumtemperatur.

\subsection{Färbung der Präparate für die lichtmikroskopische Beurteilung}

\subsubsection{Lamininfärbung}

Bei jeder Färbung wurde eine Negativ-Kontrolle mitgefärbt, um den Erfolg der Färbung zu beurteilen.

Zunächst wurden die Proben dreimal für jeweils 10 Minuten in $>96 \%$ igen Xylol gewaschen. Danach erfolgte die Dehydrierung mit EtOH nach folgendem Schema:

Tabelle 5 - Dehydrierungsschema

\begin{tabular}{|l|l|}
\hline \multicolumn{1}{|c|}{ Dauer } & \multicolumn{1}{|c|}{ Substanz } \\
\hline $2 \times 5$ Min. & $100 \%$ iges EtOH \\
\hline $1 \times 5$ Min. & $96 \%$ iges EtOH \\
\hline $1 \times 5$ Min. & $70 \%$ iges EtOH \\
\hline $1 \times 5$ Min. & $50 \%$ iges EtOH \\
\hline $1 \times 5$ Min. & $\mathrm{dH}_{2} \mathrm{O}$ \\
\hline
\end{tabular}

Die Objektträger wurden mit einem KimTechTuch trockengewischt. Es schloss sich die Verdauung mit Proteinase $\mathrm{K}$ in 0,05 Tris-Salzsäure (Tris-HCl) mit einer Verdünnung von $1 / 50$ an. Dann wurden $50 \mu l$ verdünnte Proteinase K pro Schnitt aufgetragen.

Die Schnitte wurden über fünf Minuten bei $37^{\circ} \mathrm{C}$ mit Proteinase $\mathrm{K}$ inkubiert. Anschließend erfolgte das Waschen der Objektträger in 1 x tris-buffered saline (TBS) für 3 x 10 Minuten. Das TBS wurde während der gesamten Färbung nach jeweils 10 Minuten entsorgt.

Im nächsten Schritt wurden die Objektträger mit jeweils $50 \mu 1$ 5\% BSA/TBS pro Schnitt über eine Stunde bei Raumtemperatur geblockt.

Nun wurde der erste Antikörper in einer Verdünnung von 1/25 in 5\% BSA/TBS zu je 50 $\mu \mathrm{l} /$ Schnitt aufgetragen. Auf die Negativkontrolle wurde kein Antikörper, sondern erneut 50 $\mu \mathrm{l}$ 5\% BSA/TBS aufgetragen.

Nach einer Stunde bei $37^{\circ} \mathrm{C}$ wurden die Objektträger erneut in TBS für 3 x 10 Minuten gewaschen.

Der zweite Antikörper wurde in einer Verdünnung von 1/200 in 5\% BSA/TBS zu je $50 \mu \mathrm{l}$ pro Schnitt aufgetragen. Da der zweite Antikörper lichtempfindlich ist, fand die weitere Verarbeitung im Dunklen bzw. vor direkter Lichteinstrahlung geschützt statt. Die Inkubationszeit des zweiten Antikörpers betrug eine Stunde. 
Vor dem Eindeckeln mit Fluoreszent Mounting Medium und Deckgläschen wurden die Objektträger erneut für 3 x 10 Minuten in TBS gewaschen.

Die Objektträger wurden über Nacht im Dunklen getrocknet und bis zur Mikroskopie bei $4{ }^{\circ} \mathrm{C}$ dunkel gelagert.

\subsubsection{Fibronectinfärbung}

Die Färbung erfolgte analog zur Laminin-Färbung. Es wurden folgende Antikörper verwendet:

Der erste Antikörper wurde in einer Verdünnung von 1/100 in $5 \%$ BSA/TBS aufgetragen. Auch hier wurde bei der Negativkontrolle auf den Antikörper verzichtet.

Der zweite Antikörper wurde in einer Verdünnung 1/1000 in 5 \% BSA/TBS aufgetragen.

\subsection{Lichtmikroskopie}

Die gefärbten Präparate für die Lichtmikroskopie wurden mit dem Mikroskop Axiocam 503 mono von Zeiss mikroskopiert.

Am Computer wurde das Präparat mit dem Programm Zen2.6 blue edition betrachtet.

Es wurden pro Färbung und Maus jeweils sechs Bilder in 10-facher Vergrößerung vom Rindenbereich und sechs Bilder in 40-facher Vergrößerung von den Glomerula gemacht. Je nach Färbung erfolgte die Betrachtung mit einem speziellen Filter. So wurde für die Laminin-Färbung ein FITC44-Filter verwendet und die Belichtung wurde für die 10-fache Vergrößerung bei ca. 600 Millisekunden (ms) und für die 40-fache Vergrößerung bei ca. 300 ms eingestellt. Bei der Fibronectin-Färbung wurde ein TexRed-Filter verwendet. Die Belichtungszeit lag bei 10-facher Vergrößerung bei ca. 800 ms und bei 40-facher Vergrößerung bei ca. $600 \mathrm{~ms}$.

Die Bilder erfassten den gesamten Nierenrindenbereich.

\subsection{Blutserumanalyse}

Das Blut der Mäuse wurde im Labor der Klinischen Chemie der Universitätsmedizin Göttingen auf den Gehalt von Harnstoff $\mathrm{N}$ und Cholesterin analysiert. 


\section{Ergebnisse}

Um den Einfluss von Modifiergene, in diesem Fall das NPHS2-Gen, Umwelteinfluss (salzreiche Ernährung) und Hyperperfusion nach Uninephrektomie auf eine vorgeschädigte GBM (hier: heterozygotes Alport-Syndrom) zu untersuchen, wurden die gesammelten Daten (Proteinurie, Gewicht, die histologische Ausprägung des Nierenschadens und der Serumgehalt von Cholesterin und Harnstoff-N) statistisch mit Hilfe des Programms SPSS der Firma IBM Deutschland GmbH ausgewertet.

Das Alpha-Fehler-Niveau für einen Fehler 1. Art liegt bei $5 \%$ und wurde gegebenenfalls entsprechend dem Test angepasst.

Bei allen Analysen wurden die Daten zunächst auf Normalverteilung nach Shapiro-Wilk getestet. Lag diese vor, wurde ein Homogenitätstest nach Levene durchgeführt. Bei Homogenität wurden die Daten anhand einer analysis of variance (ANOVA) verglichen. Waren die Daten nicht homogen verteilt, erfolgte die Analyse durch eine Welch-ANOVA. Bei nicht normalverteilten Daten kam der Kruskal-Wallis-Test zur Anwendung. Nach statistischer Beratung durch das Institut für Medizinische Statistik der Universitätsmedizin Göttingen wurden folgende Post-hoc-Tests durchgeführt: Bonferroni und Tukey-HSD für homogene und normalverteilte Daten, Dunnett-T3 für heterogene und normalverteilte Daten und für nicht normalverteilte Daten wurde ebenfalls ein Bonferroni Post-hoc-Test angewendet.

Es wurden pro Gruppe und Geschlecht mindestens drei Tiere zur Analyse herangezogen.

Wildtyp-Tiere können als nierengesunde Tiere angenommen werden und symbolisieren einen normalen Verlauf für die Parameter.

\subsection{Proteinurie-Analyse}

Die Analyse der Proteinurie fand nach einer semiquantitativen Proteinuriebestimmung mittels Protein-Gelelektrophorse wie in 2.6 beschrieben statt.

Es wurde die Proteinurie für Proteine der gleichen Größe von Albumin $(65 \mathrm{kDa})$ und für Proteine, die größer sind als Albumin bestimmt. Ein Beispiel für größere Proteine als Albumin sind Immunglobuline, die ein Molekulargewicht von ca. $188 \mathrm{kDa}$ aufweisen.

Da die Fragestellung auf eine mögliche Schädigung des glomerulären Filters abzielt, wurde auf die Analyse der Gesamtproteinurie und auf die Analyse von Proteinen kleiner als Albumin verzichtet.

Die Analyse der Proteinuriewerte basiert immer auf Mittelwerten.

Hierbei fand die Auswertung mittels Fiiji Image_J nach folgendem Schema statt (siehe Abbildung 2): 


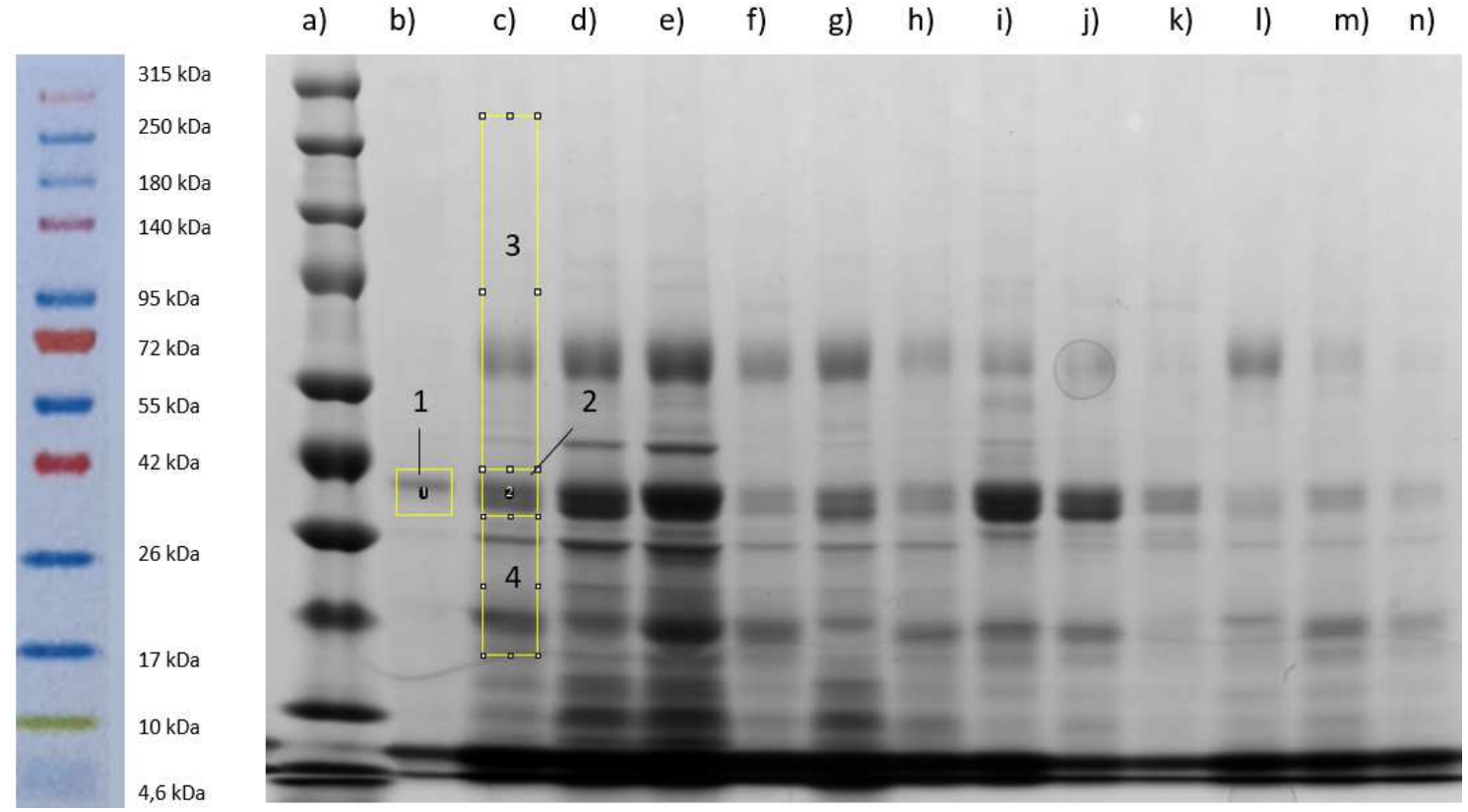

Abbildung 2 - Beispiel einer semiquantitativen Proteinuriebestimmung mittels Protein-Gelelektrophorese. a) zeigt ProSieve ${ }^{\circledR}$ QuadColor ${ }^{\mathrm{TM}}$ Protein Marker, b) zeigt Albuminstandard, c) bis n) zeigen $\mathrm{COL}_{4} \mathrm{~A} 3^{+/-} \mathrm{NPHS} 2^{+/ \mathrm{R} 140 \mathrm{Q}}$ Mäuse, c) bis e) zeigen Behandlungsgruppe „Neph“ (Uninephrektomie) 120 bis 180 Tage, f) bis $\mathbf{n}$ ) zeigen drei Mäuse der Behandlungsgruppe „Salz“ (Uninephrektomie mit anschließender 0,9\%iger NaCl-Trinkwassergabe) jeweils 120 bis 180 Tage. 1 zeigt Albuminstandard, 2 zeigt als Albumin identifizierbare Bande, 3 zeigt Bande für Proteine größer als Albumin, 4 zeigt Bande für Proteine kleiner als Albumin.

\subsubsection{Mäuse vor der OP}

Die Proteinurie der Mäuse wurde an den Lebenstagen 60, 90 und 120 analysiert. Die Analyse erfolgte für die jeweiligen Genotypen nach Geschlechtertrennung. 


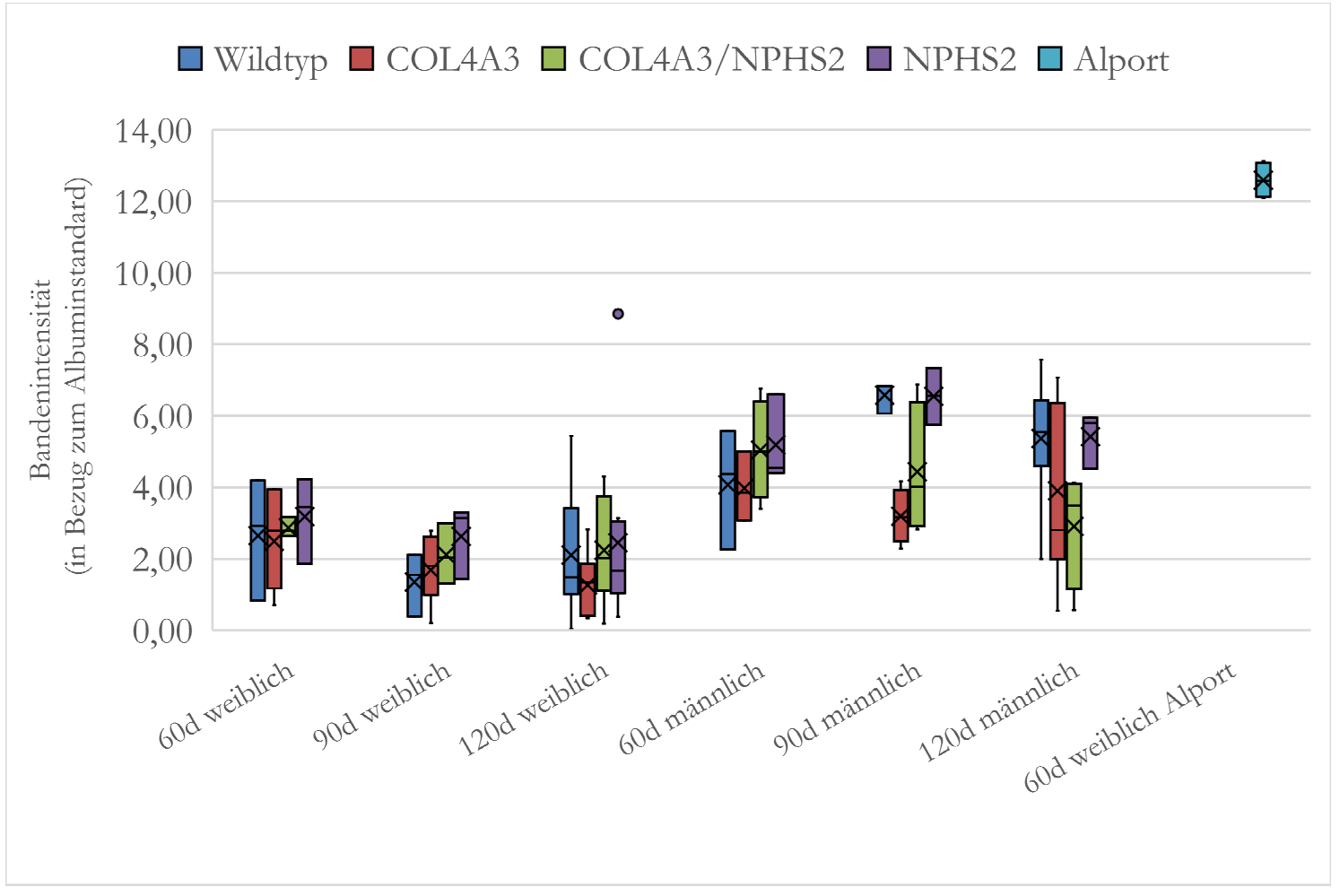

Abbildung 3 - Proteinurie für Proteine gleicher Größe wie Albumin vor der OP. Wildtyp $=$ COL4A3 $3^{+/+} \mathrm{NPHS}^{+/+} ;$COL4A3 $=\mathrm{COL}_{4} \mathrm{~A}^{+/-} \mathrm{NPHS}^{+/+} ;$COL4A3 $/ \mathrm{NPHS} 2=\mathrm{COL}_{4} \mathrm{~A}^{+/}$ $\mathrm{NPHS}^{+/ \mathrm{R} 140 \mathrm{Q}} ; \mathrm{NPHS} 2=\mathrm{COL}_{\mathrm{A}} 3^{+/+} \mathrm{NPHS}^{+/ \mathrm{R} 140 \mathrm{Q}} ;$ Alport $=\mathrm{COL}^{2} \mathrm{~A}^{-/-} \mathrm{NPHS}^{+/+} ; \mathrm{d}=$ Tage. Punkt zeigt signifikanten Ausreißer an. Kreuz zeigt Mittelwert.

In der Analyse der Proteinurie für Proteine gleicher Größe wie Albumin ergeben sich für weibliche Tiere keine signifikanten Unterschiede zwischen den Genotypen. Im Verlauf des Beobachtungszeitraums von $60 \mathrm{zu} 120$ Lebenstagen kann eine Abnahme der Proteinuriemittelwerte für Proteine gleicher Größe wie Albumin innerhalb eines Genotyps beobachtet werden.

Bei männlichen Tieren kommt es im Vergleich von 60 zu 120 Lebenstagen für die beiden Genotypen Wildtyp (COL4A3 ${ }^{+/+} \mathrm{NPHS}^{+/+}$) und NPHS2 $\left(\mathrm{COL}_{4} \mathrm{A3}^{+/+} \mathrm{NPHS}^{+/ \mathrm{R} 140 \mathrm{Q}}\right.$ ) zu einer Zunahme der Proteinuriemittelwerte für COL4A3 $\left(\mathrm{COL} 4 \mathrm{~A} 3^{+/-} \mathrm{NPHS}^{+/+}\right.$) und bei COL4A3/NPHS2 $\left(\right.$ COL4A3 $\left.^{+/-} \mathrm{NPHS}^{+/ \mathrm{R} 140 \mathrm{Q}}\right)$ nehmen dagegen die Mittelwerte leicht ab. Wie in Abbildung 3 zu sehen ist, nimmt an Lebenstag 120 die Spannweite der Proteinuriewerte für COL4A3-Tiere zu und der Proteinuriemittelwert für NPHS2- und Wildtyp-Tiere sinkt ab. Bei den Proteinuriemittelwerten ist im Vergleich von 90 zu 120 Lebenstagen bei allen Genotypen bis auf COL4A3 eine Abnahme der Mittelwerte zu sehen. An den Beobachtungstagen 90 und 120 zeigt der Wildtyp jeweils die höchsten Mittelwerte aller Genotypen.

Für alle Werte ist geschlechtsunabhängig zu erkennen, dass sie deutlich unter dem Mittelwert der Alport-Vergleichsgruppe im Alter von 60 Lebenstagen liegen. 


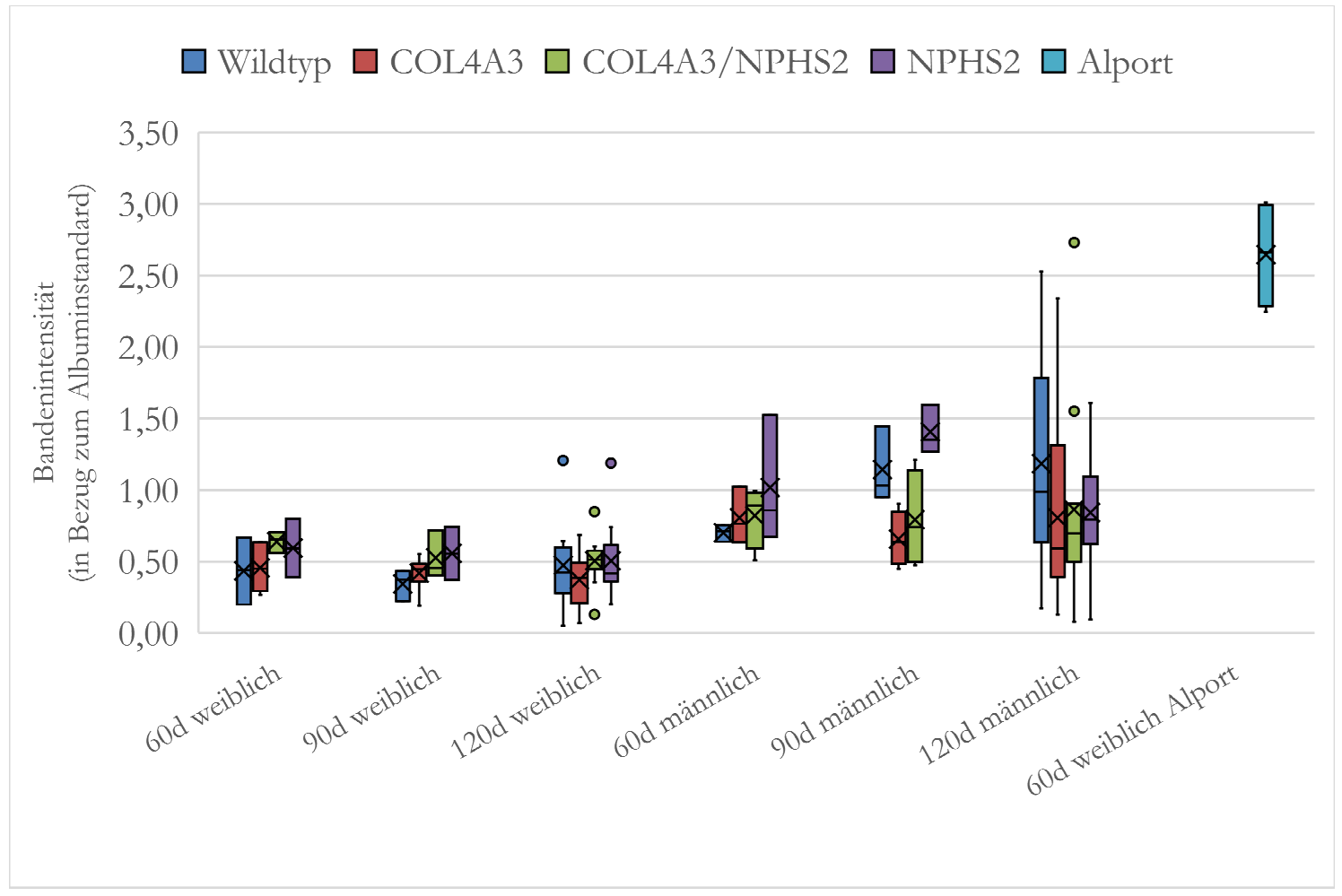

Abbildung 4 - Proteinurie für Proteine größer als Albumin vor der OP. Wildtyp = $\mathrm{COL}_{4} \mathrm{A3}^{+/+} \mathrm{NPHS}^{+/+} ; \mathrm{COL} 4 \mathrm{~A} 3=\mathrm{COL}_{4} \mathrm{~A}^{+/-} \mathrm{NPHS}^{+/+} ; \mathrm{COL} 4 \mathrm{~A} 3 / \mathrm{NPHS} 2=\mathrm{COL}_{4} \mathrm{~A}^{+/-}$ $\mathrm{NPHS}^{+/ \mathrm{R} 140 \mathrm{Q}} ; \mathrm{NPHS} 2=\mathrm{COL}_{\mathrm{A}} 3^{+/+} \mathrm{NPHS}^{+/ \mathrm{R} 140 \mathrm{Q}} ;$ Alport $=$ COL4A3 ${ }^{-/} \mathrm{NPHS}^{+/+} ; \mathrm{d}=$ Tage. Punkte zeigen signifikante Ausreißer. Kreuz zeigt Mittelwert.

Für weibliche Tiere ergeben sich keine signifikanten Unterschiede zwischen den einzelnen Genotypen für Proteine größer als Albumin. Die Mittelwerte für 120 Tage alte Mäuse liegen in einer Spannweite von 0,4 für COL4A3 bis 0,54 für COL4A3/NPHS2.

Männliche Tiere haben an Lebenstag 90 signifikant höhere Proteinuriemittelwerte nach Durchführung einer ANOVA für NPHS2-mutierte Mäuse (Mittelwert 1,4 mit einer Standardabweichung $(\mathrm{SD}) \pm 0,17$ ) im Vergleich zu COL4A3 (Mittelwert 0,65 mit einer SD \pm 0,18). An Tag 120 weist der Wildtyp den höchsten Mittelwert auf.

Auch hier sieht man durchgängig deutlich niedrigere Mittelwerte im Vergleich zu 60 Tage alten Alport-Mäusen.

\subsubsection{Relative Proteinurie für Mäuse nach der OP}

Es wurden die Proteinuriewerte der Mäuse im Alter von 120 Lebenstagen gleich „„“ gesetzt und die relativen Veränderungen an den Lebenstagen 150 und 180 geschlechterspezifisch und geno- bzw. behandlungstypspezifisch ermittelt. 


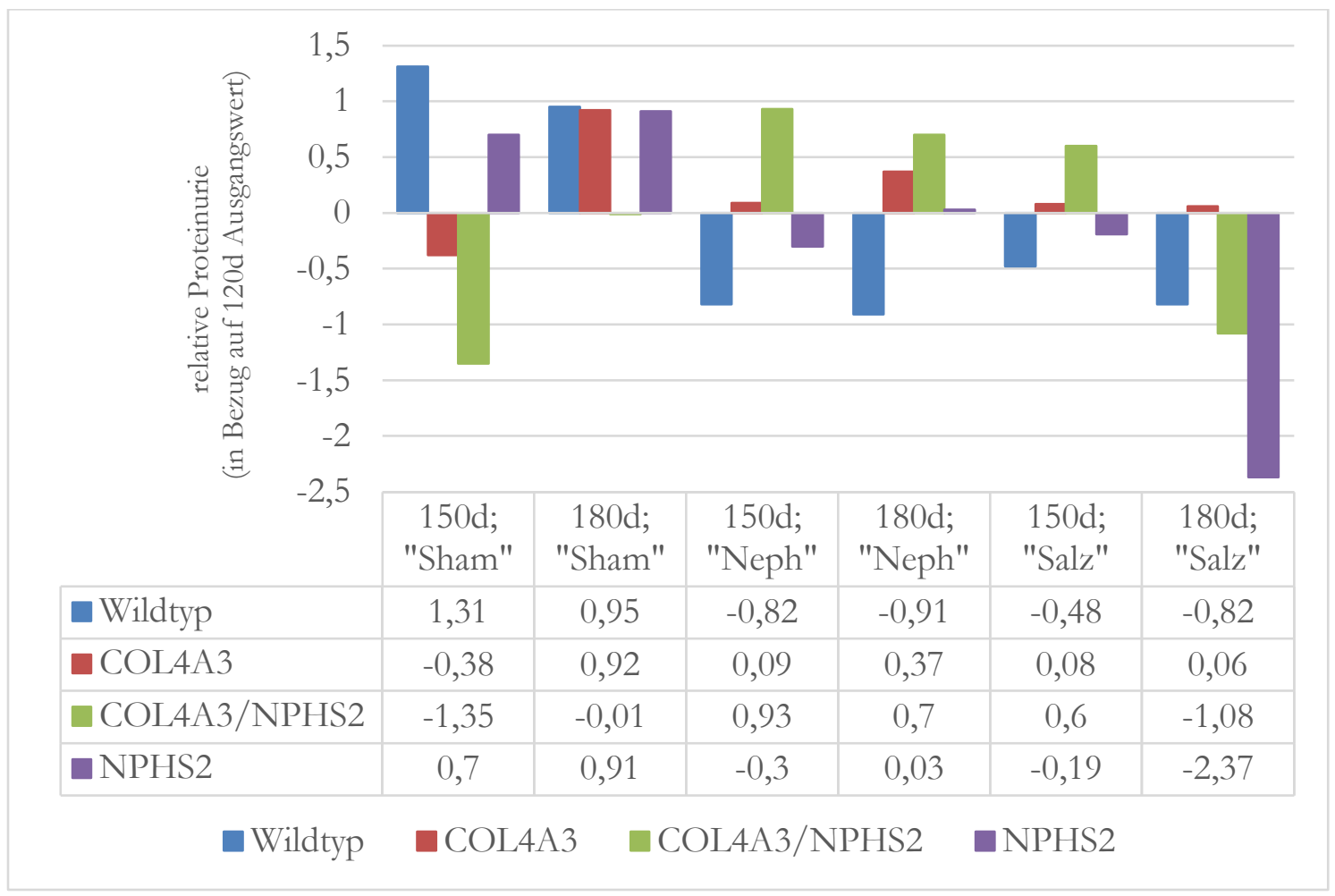

Abbildung 5 - relative Proteinurie für Proteine gleicher Größe wie Albumin bei weiblichen Mäusen ab einem Alter von 120 Lebenstagen. Wildtyp $=$ COL4A3 $3^{+/+}$

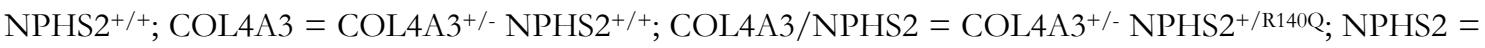

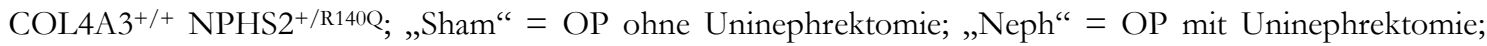
„Salz“ = OP mit Uninephrektomie + 0,9\%iger NaCl-Trinkwassergabe. Es sind die Mittelwerte angegeben.

In der Analyse der relativen Proteinurie für Proteine gleicher Größe wie Albumin sind keine signifikanten Unterschiede zwischen den einzelnen Genotypen festzustellen.

Für Proteine gleicher Größe wie Albumin weist die Behandlungsgruppe „Sham“ im Verlauf von 150 zu 180 Lebenstagen steigende Proteinuriewerte für alle Genotypen bis auf den Wildtyp auf. Letztlich hat kein Genotyp eine höhere relative Proteinausscheidung als der Wildtyp.

Bei uninephrektomierten Mäusen steigt bei COL4A3-Mäusen die Proteinausscheidung über den gesamten Beobachtungszeitraum. Für die anderen Genotypen sind die Proteinuriewerte immer im Vergleich von 150 zu 180 Lebenstagen stabil oder nehmen die Proteinuriemittelwerte ab.

Unter Salzbelastung lassen sich nur für COL4A3-Mäuse stabile Proteinuriewerte darstellen. Uninephrektomierte und 0,9\%iger NaCl-Trinkwassergabe ausgesetzte Mäuse haben häufig im Vergleich zum Lebenstag 120 abnehmende Proteinuriemittelwerte. Nur in der Behandlungsgruppe „Sham“ nehmen die Proteinuriemittelwerte regelmäßig zu. 


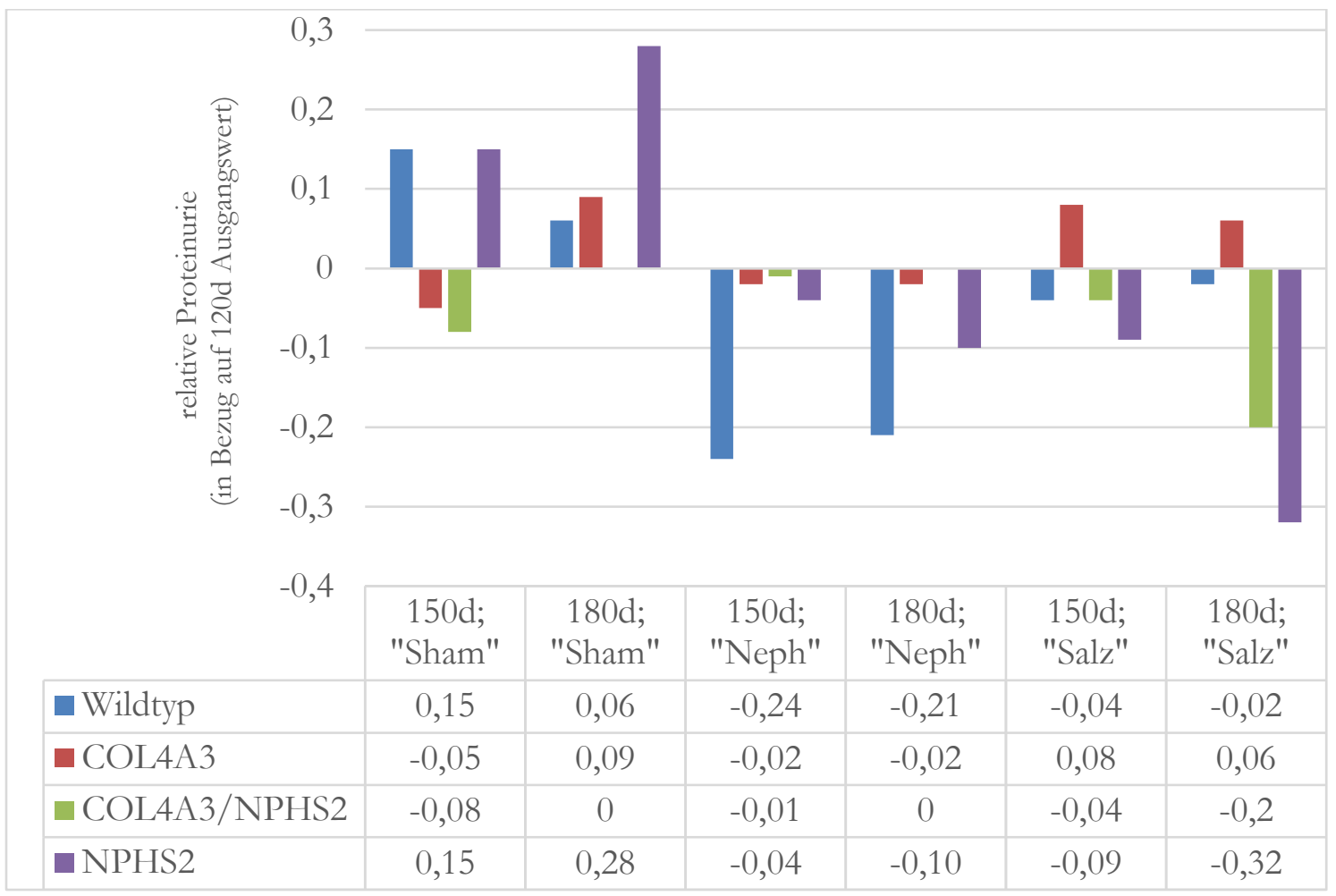

Abbildung 6 - relative Proteinurie für Proteine größer als Albumin bei weiblichen

Mäusen ab einem Alter von 120 Lebenstagen. Wildtyp $=$ COL4A3 $3^{+/+} \mathrm{NPHS}^{+/+} ;$COL4A $3=$

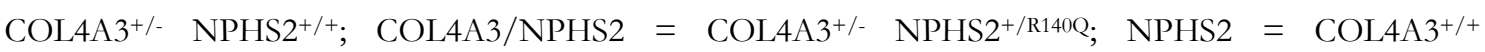
NPHS2+/R140Q; „Sham“ = OP ohne Uninephrektomie; „Neph“ = OP mit Uninephrektomie; „Salz“ = OP mit Uninephrektomie $+0,9 \%$ iger NaCl-Trinkwassergabe. Es sind die Mittelwerte angegeben.

Die relativen Proteinuriewerte der weiblichen Mäuse weisen für die Behandlungsgruppe „Sham“ einen signifikanten Unterschied für Proteine größer als Albumin am 150. Lebenstag auf. Die Post-hoc-Analyse nach Bonferroni und Tukey-HSD zeigt keine signifikanten Unterschiede zwischen einzelnen Genotypen. Alle Genotypen bis auf COL4A3/NPHS2 stellen im 120 zu 180 Tage-Vergleich eine Zunahme der Proteinurie dar.

Für die Behandlungsgruppe „Neph“ sind keine signifikanten Unterschiede zu sehen. Es ist auffällig, dass kein Genotyp im Vergleich zum 120 Tage-Wert im Mittel eine Zunahme der Proteinurie für Proteine größer als Albumin aufweist.

In der Behandlungsgruppe „Salz“ kann bei weiblichen Mäusen ein signifikanter Unterschied nach ANOVA zwischen den Genotypen COL4A3 (Mittelwert 0,06 mit einer SD \pm 0,17 ) und NPHS2 (Mittelwert -0,32 mit einer SD \pm 0,2) an Lebenstag 180 in der ANOVA festgestellt werden. In dieser Behandlungsgruppe weisen alle Genotypen bis auf COL4A3 eine Abnahme der Proteinurie im Mittel auf. Bei COL4A3 ist im Vergleich zum Lebenstag 150 am Lebenstag 180 ebenfalls eine Abnahme der Proteinurie zu sehen.

Beim Genotyp COL4A3/NPHS2 hat die Behandlungsgruppe „Salz“ (Mittelwert -0,2 mit einer $\mathrm{SD} \pm 0,03$ ) signifikant niedrigere Werte in der ANOVA als die Behandlungsgruppen 
„Neph“ (Mittelwert 0,00 mit einer SD \pm 0,3) und „Sham“ (Mittelwert 0,00 mit einer SD \pm $0,04)$.

Insgesamt lässt sich im Vergleich zum Ausgangswert an Lebenstag 120 insbesondere für die Gruppen „Neph“ und „Salz“ häufig eine Abnahme der Proteinurie ermitteln.

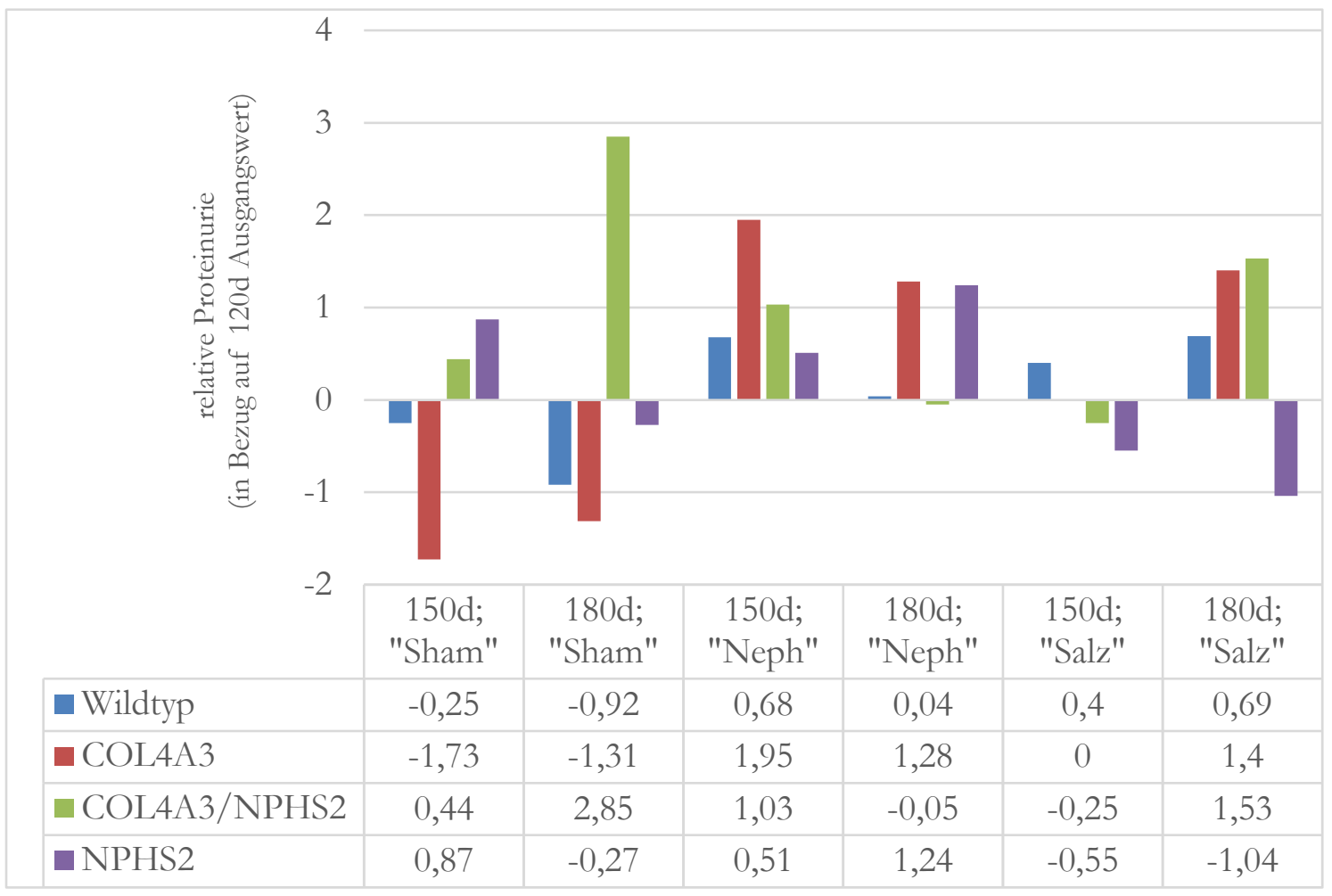

Abbildung 7 - relative Proteinurie für Proteine gleicher Größe wie Albumin bei männlichen Mäusen ab einem Alter von 120 Lebenstagen. Wildtyp $=$ COL4A3 $3^{+/+}$ $\mathrm{NPHS}^{+/+} ; \mathrm{COL} 4 \mathrm{~A} 3=\mathrm{COL}_{4} 3^{+/-} \mathrm{NPHS}^{+/+} ; \mathrm{COL} 4 \mathrm{~A} 3 / \mathrm{NPHS} 2=\mathrm{COL}_{4} 3^{+/-} \mathrm{NPHS}^{+/ \mathrm{R} 140 \mathrm{Q}} ; \mathrm{NPHS} 2=$

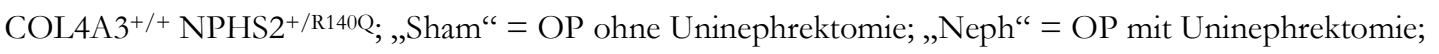
„Salz“ = OP mit Uninephrektomie + 0,9\%iger NaCl-Trinkwassergabe. Es sind die Mittelwerte angegeben.

Die in Abbildung 7 dargestellten Werte zeigen untereinander keine Signifikanzen.

Bei der relativen Proteinurie für Proteine gleicher Größe wie Albumin zeigen sich nur einzelne Genotypen mit einer stetigen Zunahme der Proteinurie („Sham“ COL4A3/NPHS2; „Neph“ NPHS2 und „Salz“ Wildtyp). Nur uninephrektomierte Mäuse zeigen an Lebenstag 150 für alle Genotypen eine Zunahme der Proteinurie.

Auffällig ist der Genotyp COL4A3/NPHS2, bei dem häufig besonders stark die Proteinurie zunimmt (180 Lebenstage „Sham“ und 180 Lebenstage „Salz“).

Es ist keine klare Tendenz für einen Genotypen oder eine bestimmte Behandlungsgruppe erkennbar. Im Vergleich zu weiblichen Mäusen kommt es allerdings häufiger zu einer Zunahme der Proteinuriemittelwerte. 


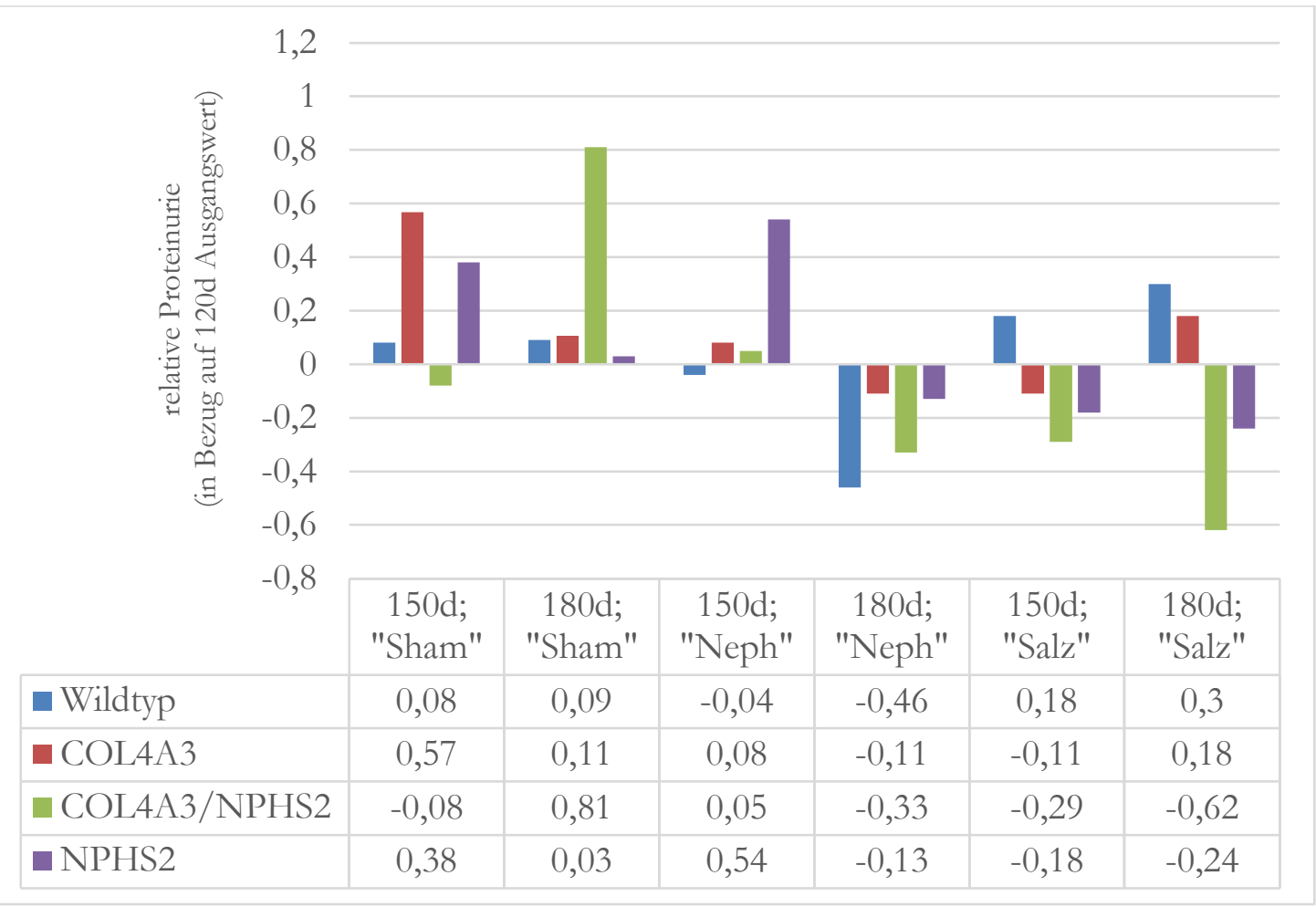

Abbildung 8 - relative Proteinurie für Proteine größer als Albumin bei männlichen Mäusen ab einem Alter von 120 Lebenstagen. Wildtyp $=$ COL4A3 $3^{+/+} \mathrm{NPHS}^{+/+} ;$COL4A $3=$ $\mathrm{COL}_{4 \mathrm{~A}} 3^{+/-} \mathrm{NPHS}^{+/+} ; \mathrm{COL} 4 \mathrm{~A} 3 / \mathrm{NPHS} 2=\mathrm{COL}^{2} 3^{+/-} \mathrm{NPHS}^{+/ \mathrm{R} 140 \mathrm{Q}} ; \mathrm{NPHS} 2=\mathrm{COLAA3}^{+/+}$ NPHS2+/R140Q; „Sham“ = OP ohne Uninephrektomie; „Neph“ = OP mit Uninephrektomie; „Salz“ = OP mit Uninephrektomie $+0,9 \%$ iger NaCl-Trinkwassergabe. Es sind die Mittelwerte angegeben.

Bei Betrachtung der männlichen Mäuse können keine signifikanten Unterschiede in Bezug auf den Genotyp oder die Behandlungsgruppe erkannt werden.

Die Behandlungsgruppe „Sham“ weist für COL4A3/NPHS2, wie bereits auch für Proteine gleicher Größe wie Albumin gezeigt, im Vergleich von 120 zu 180 Lebenstagen eine im Mittel deutliche Zunahme der Proteinuriewerte auf. Dagegen sind alle anderen Genotypen annähernd unverändert oder weisen in der Regel sogar eine Abnahme der Proteinurie auf.

Interessant ist der Kurvenverlauf der Behandlungsgruppe „Neph“. Hier konnte im Mittel für diese Tiere eine niedrigere Proteinurie am 180. Lebenstag als zum Zeitpunkt vor der OP ermittelt werden. In der „Neph“-Gruppe hat kein Genotyp stetig steigende Proteinuriewerte.

In der Gruppe von Tieren mit einer salzreichen Ernährung präsentiert vor allem der Wildtyp im Mittel bereits am Lebenstag 150 einen Anstieg der Proteinurie. Bei den übrigen Genotypen steigt die Proteinurie nicht flächenhaft, und wenn erst an Lebenstag 180 im Vergleich zu Lebenstag 120.

Im Vergleich weiblicher und männlicher Tiere schwankt bei den weiblichen Tieren die relative Proteinurie deutlich größer. 


\subsubsection{Absolute Proteinurie für Mäuse nach der OP}

\subsubsection{Vergleich ohne Alport-Vergleichsgruppe}

In diesem Abschnitt werden die Proteinuriewerte für die Lebenstage 120, 150 und 180 jeweils für Proteine der gleichen Größe wie Albumin und Proteine, die größer sind als Albumin, auch hier geschlechterspezifisch und geno- bzw. behandlungstypspezifisch betrachtet.

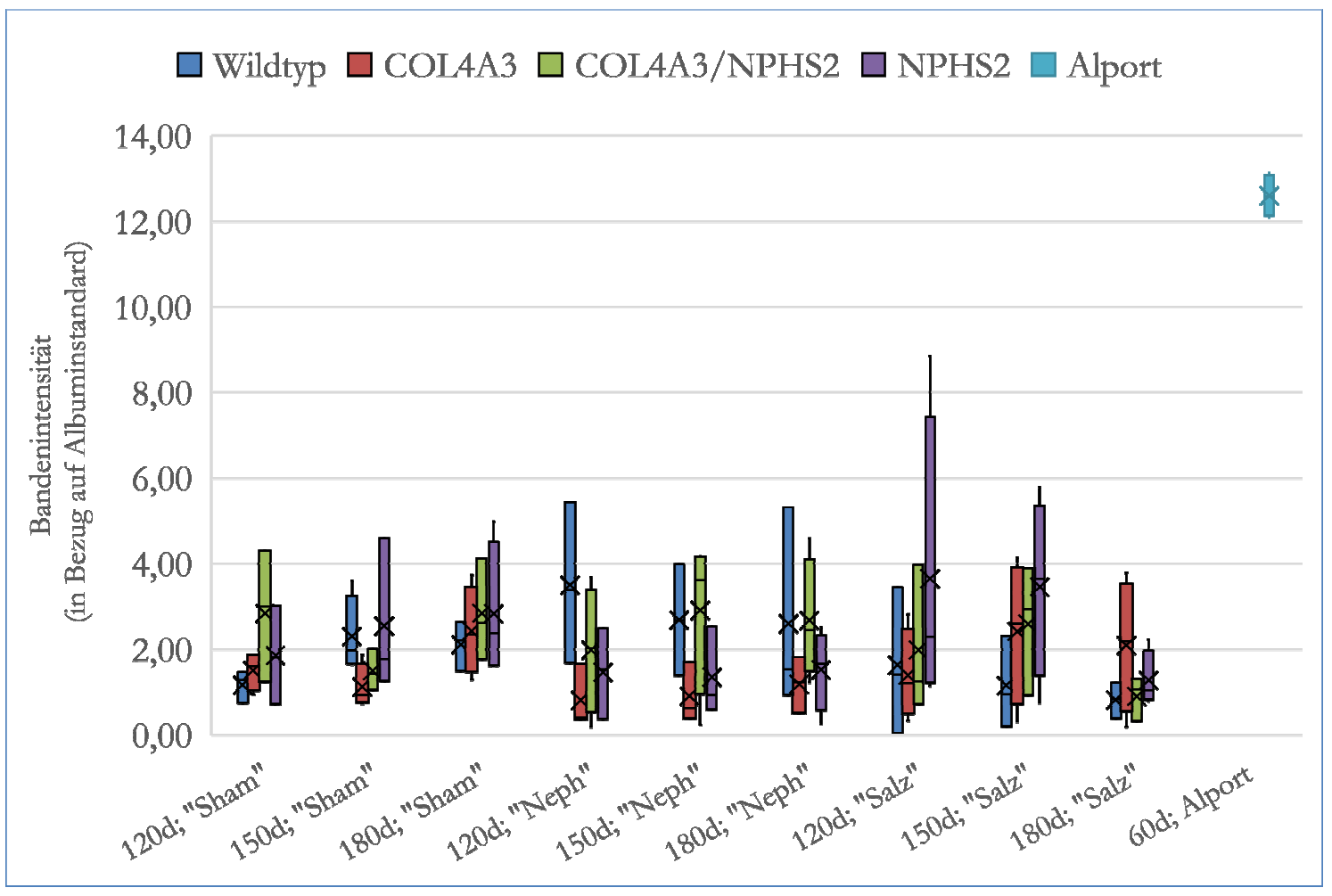

Abbildung 9 - Proteinurie für Proteine gleicher Größe wie Albumin bei weiblichen Mäusen ab einem Alter von 120 Lebenstagen. Wildtyp $=\mathrm{COLAA3}^{+/+} \mathrm{NPHS}^{+/+}$; COL4A $3=$

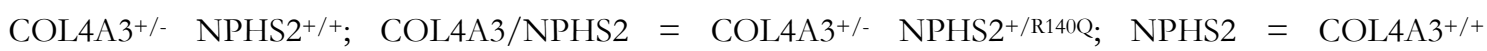
$\mathrm{NPHS}^{+/ \mathrm{R} 140 \mathrm{Q}}$; Alport $=$ COL4A3 ${ }^{-/}$NPHS2 $2^{+/+}$; „Sham“ $=$OP ohne Uninephrektomie; „Neph“ $=$OP mit Uninephrektomie; „Salz“ $=$ OP mit Uninephrektomie $+0,9 \%$ iger NaCl-Trinkwassergabe; $d=$ Tage. Kreuz zeigt Mittelwert.

In der Behandlungsgruppe „Sham“ zeigt sich am 180. Lebenstag der Wildtyp (COL4A3 ${ }^{+/+}$ $\mathrm{NPHS}_{2}^{+/+}$) im Vergleich zu allen anderen Genotypen die geringste Proteinurie (Mittelwert 2,11 mit einer SD \pm 0,57). Den höchsten Proteinuriewert weisen Mäuse mit einer COL4A3/NPHS2-Mutation auf (Mittelwert 2,83 mit einer SD $\pm 1,19$ ). Bereits vor der OP weist der Wildtyp die geringste Proteinurie auf. An Lebenstag 150 zeigen COL4A3- mutierte Mäuse die geringste Proteinurie.

Für die Behandlungsgruppe „Neph“ lassen sich keine signifikanten Unterschiede im Bezug auf den Genotyp ermitteln. Vor der OP zeigen Wildtyp-Mäuse die höchste Proteinurie (Mittelwert 3,5 mit einer SD \pm 1,87), an Lebenstag 150 tun dies COL4A3/NPHS2-Mäuse 
(Mittelwert 2,9 mit einer SD $\pm 1,84$ ) genauso wie zum Endpunkt des Versuches (Mittelwert $2,67$ mit einer $\mathrm{SD} \pm 1,4)$.

Allgemein kann bei der Behandlungsgruppe „Salz“ eine Abnahme der Proteinurie im Verlauf von Lebenstag 150 zu Lebenstag 180 beobachtet werden. Den größten Rückgang können hierbei COL4A3/NPHS2-mutierte Mäuse aufweisen (Mittelwert 2,58 [SD $\pm 1,51]$ an Lebenstag 150 und Mittelwert 0,89 [SD $\pm 0,51]$ an Lebenstag 180). Prozentual liegt hier ein Rückgang um 65,5 \% vor. Einen ähnlich starken Rückgang haben nur NPHS2-mutierte Mäuse im gleichen Zeitraum (63,19\%).

Im Vergleich der Mäuse postoperativ zeigt sich keine signifikante Zunahme der Proteinurie in Bezug auf die Behandlung. Hierbei sind teilweise geringere Proteinuriewerte für Mäuse der Behandlungsgruppe „Salz“ im Vergleich zu den beiden anderen Behandlungsgruppen zu sehen (beispielhaft COL4A3 ${ }^{+/-} \mathrm{NPHS}^{+/ \mathrm{R} 140 \mathrm{Q}}$ ).

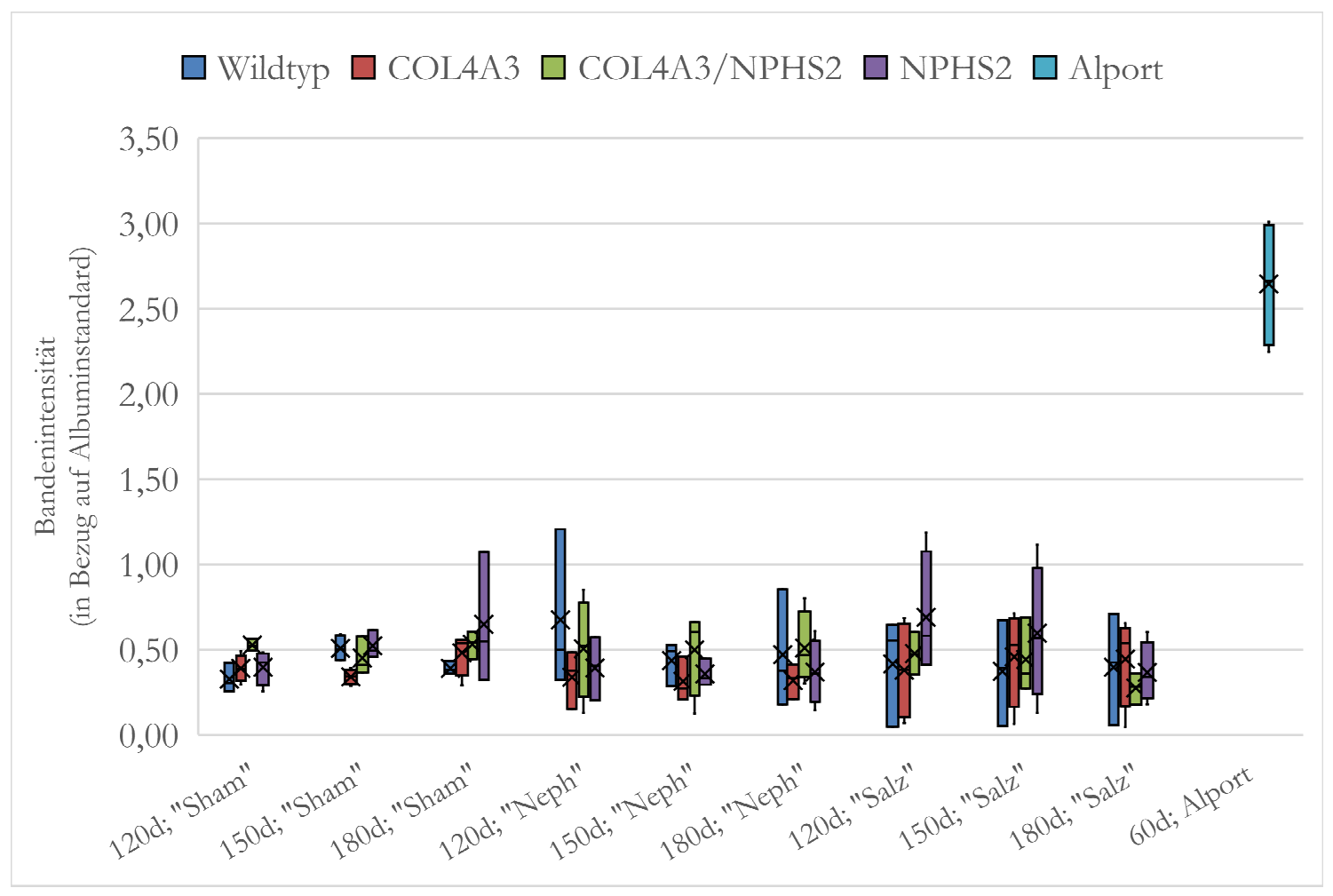

Abbildung 10 - Proteinurie für Proteine größer als Albumin bei weiblichen Mäusen ab einem Alter von 120 Lebenstagen. Wildtyp $=\mathrm{COL}_{4} 3^{+/+} \mathrm{NPHS}^{+/+} ; \mathrm{COL} 4 \mathrm{~A} 3=\mathrm{COL} 4 \mathrm{~A}^{+/-}$ $\mathrm{NPHS}^{+/+} ;$COL4A3/NPHS2 $=$COL4A3 ${ }^{+/-} \mathrm{NPHS}^{+/ \mathrm{R} 140 \mathrm{Q}} ; \mathrm{NPHS} 2=\mathrm{COL}_{\mathrm{AA}} 3^{+/+} \mathrm{NPHS}^{+/ \mathrm{R} 140 \mathrm{Q}} ;$ Alport $=$ COL4A3 $^{-/}$NPHS2 $^{+/+}$; „Sham“ = OP ohne Uninephrektomie; „Neph“ = OP mit Uninephrektomie; „Salz“ = OP mit Uninephrektomie + 0,9\%iger NaCl-Trinkwassergabe; $\mathrm{d}=$ Tage. Kreuz zeigt Mittelwert.

In Abbildung 10 können keine signifikanten Unterschiede ermittelt werden.

Für die Behandlungsgruppe „Sham“ zeigt sich eine Zunahme der Spannweite der Proteinuriewerte von NPHS2-mutierten Mäusen am Lebenstag 180. Dies gilt sowohl im Vergleich zu den übrigen Messpunkten dieser Mäuse als auch für andere Genotypen dieser Behandlungsgruppe. 
In der Behandlungsgruppe „Salz“ lässt sich lediglich für COL4A3-Mäuse eine Zunahme der Proteinurie unter salzreicher Ernährung ermitteln, wobei diese von Lebenstag $150 \mathrm{zu}$ 180 ebenfalls abnimmt. Weiterhin zeigen sich für die Behandlungsgruppe „Salz“ teilweise niedrigere Werte für die Proteinurie als in den anderen Behandlungsgruppen. Diese Beobachtung passt zu der Beobachtung für Proteine gleicher Größe wie Albumin.

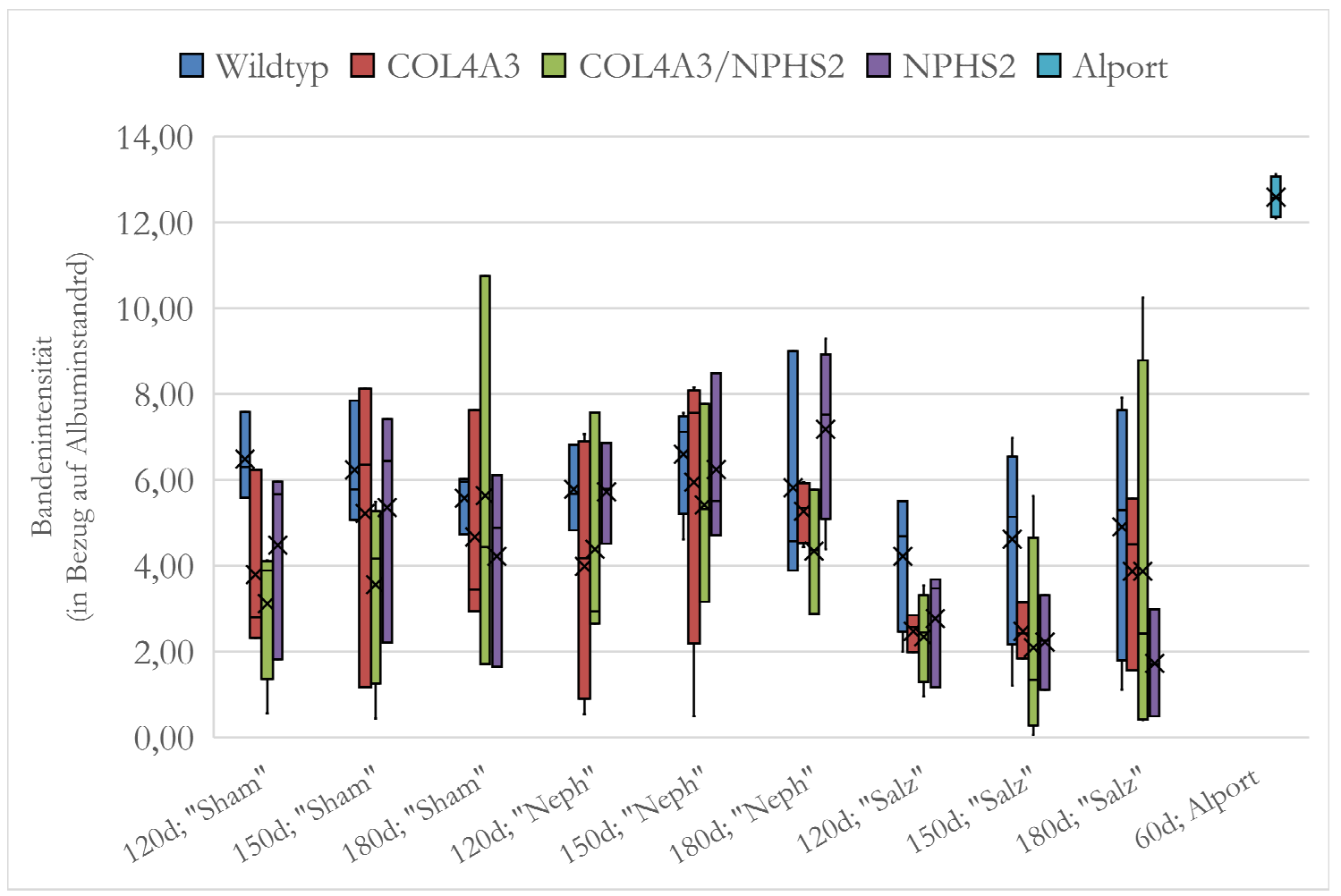

Abbildung 11 - Proteinurie für Proteine gleicher Größe wie Albumin bei männlichen Mäusen ab einem Alter von 120 Lebenstagen. Wildtyp $=\mathrm{COL}_{\mathrm{A}} 3^{+/+} \mathrm{NPHS}^{+/+}$; COL4A3 = $\mathrm{COL}_{4 \mathrm{~A}} 3^{+/-} \mathrm{NPHS}^{+/+} ; \mathrm{COL}_{4} \mathrm{~A} 3 / \mathrm{NPHS} 2=\mathrm{COL}_{4} 3^{+/-} \mathrm{NPHS}^{+/ \mathrm{R} 140 \mathrm{Q}} ; \mathrm{NPHS} 2=\mathrm{COL}_{4} 3^{+/+}$ NPHS2 $2^{+/ R 140 Q}$; Alport $=$ COL4A3 $-/-$ NPHS2 $^{+/+} ;$, ,Sham“ $=$OP ohne Uninephrektomie; „Neph“ $=$OP mit Uninephrektomie; „Salz“ = OP mit Uninephrektomie $+0,9 \%$ iger NaCl-Trinkwassergabe; $\mathrm{d}=$ Tage. Kreuz zeigt Mittelwert.

Männliche Tiere haben eine signifikant höhere Proteinurie nach Durchführung der ANOVA beim Genotyp COL4A3 ${ }^{+/+} \mathrm{NPHS}^{+/ \mathrm{R} 140 \mathrm{Q}}$ an Lebenstag 180 für Proteine gleicher GröBe wie Albumin in der Behandlungsgruppe „Neph“ (Mittelwert 7,17 mit einer SD $\pm 2,05$ ) als in der Behandlungsgruppe „Salz“ (Mittelwert 1,72 mit einer SD $\pm 1,24$ ). An den vorherigen Messpunkten sind bereits größere nicht signifikante Differenzen zwischen den Mittelwerten dieser Gruppen zu beobachten.

Wie in Abbildung 11 ersichtlich weist die Behandlungsgruppe „Salz“ tendenziell eher geringere Mittelwerte für die Proteinurie als die beiden anderen Behandlungsgruppen auf. Es kommt bei allen Genotypen bis auf NPHS2 zu einer Zunahme der Proteinurie bei salzreicher Ernährung. 
In allen drei Behandlungsgruppen weist der Wildtyp regelhaft die höchsten Proteinuriemittelwerte auf. Lediglich NPHS2-mutierte Tiere haben an Lebenstag 180 in der „Neph”Gruppe eine deutliche, allerdings nicht signifikante Mittelwertzunahme.

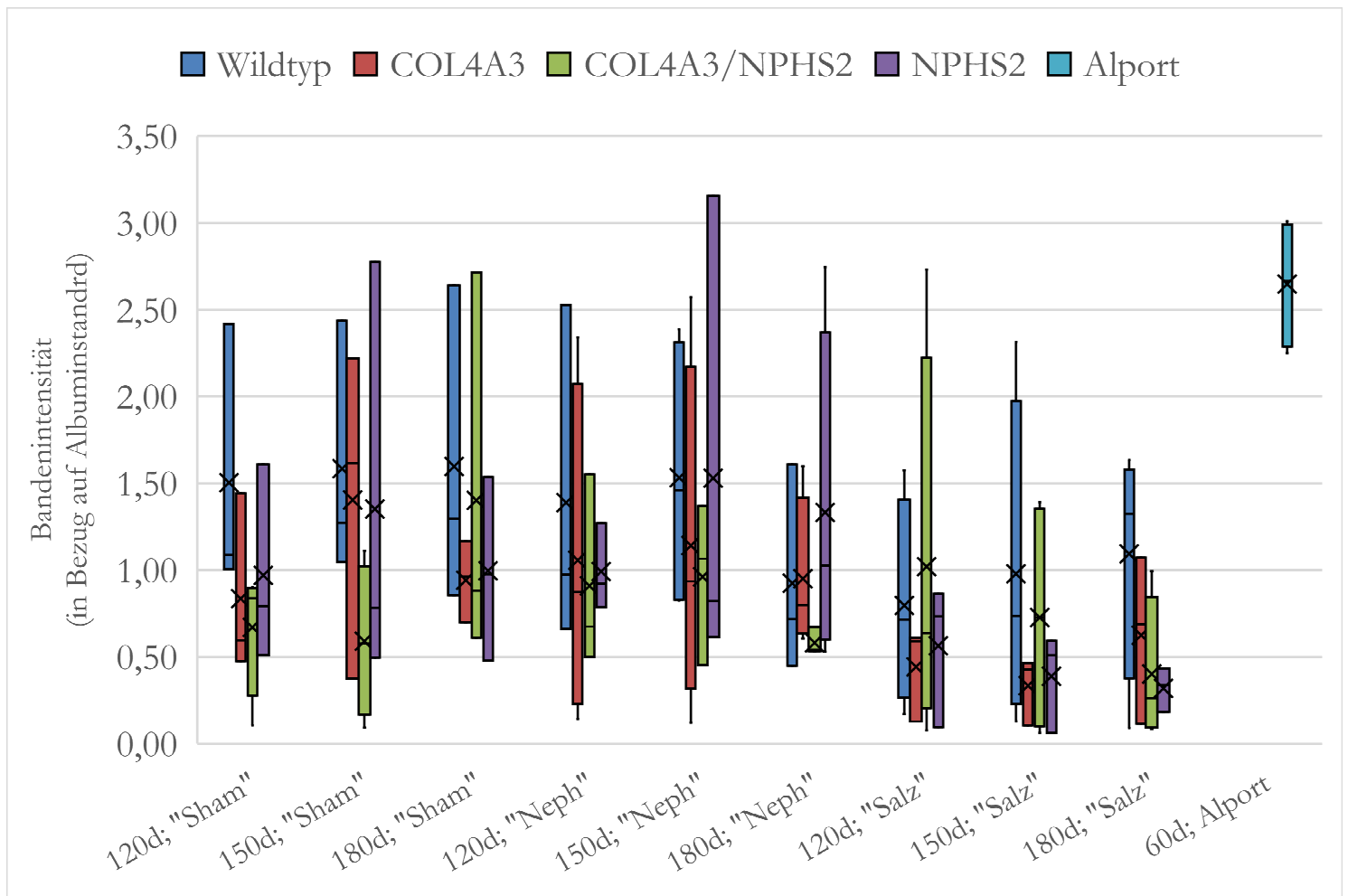

Abbildung 12 - Proteinurie für Proteine größer als Albumin bei männlichen Mäusen ab einem Alter von 120 Lebenstagen. Wildtyp $=\mathrm{COL}_{4} 3^{+/+} \mathrm{NPHS}^{+/+} ; \mathrm{COL} 4 \mathrm{~A} 3=\mathrm{COL}_{4} \mathrm{~A}^{+/-}$ $\mathrm{NPHS}^{+/+}$; COL4A3/NPHS2 $=$COL4A3 ${ }^{+/-} \mathrm{NPHS}^{+/ \mathrm{R} 140 \mathrm{Q}} ; \mathrm{NPHS} 2=\mathrm{COL}_{\mathrm{AA}} 3^{+/+} \mathrm{NPHS}^{+/ \mathrm{R} 140 \mathrm{Q}} ;$ Alport $=$ COL4A3 $^{--} \mathrm{NPHS}^{+/+}$; „Sham“ $=$OP ohne Uninephrektomie; „Neph“ = OP mit Uninephrektomie; „Salz“ = OP mit Uninephrektomie + 0,9\%iger NaCl-Trinkwassergabe; $\mathrm{d}=$ Tage. Kreuz zeigt Mittelwert.

Im gesamten Beobachtungszeitraum zeigen Wildtyp-Tiere die höchsten Mittelwerte in der Behandlungsgruppe „Sham“. Für die „Neph“-Gruppe kann ohne große Mittelwertverschiebungen ebenfalls diese Aussage unter Ausnahme für NPHS2-mutierte Tiere an Lebenstag 180 getroffen werden. Unter 0,9\%igen NaCl-Trinkwassergabe zeigt ebenfalls der Wildtyp die größten Mittelwerte. Die Wildtyp-Proteinuriemittelwerte sind regelhaft die höchsten im Vergleich der Behandlungsgruppen.

Die Genotypen COL4A3 ${ }^{+/-} \mathrm{NPHS}^{+/ \mathrm{R} 140 \mathrm{Q}}, \mathrm{COL}_{4} 3^{+/+} \mathrm{NPHS}^{+/ \mathrm{R} 140 \mathrm{Q}}$ und COL4A3 ${ }^{+/-}$ $\mathrm{NPHS}^{+/+}$haben im Vergleich der „Neph“- zur „Salz“-Gruppe für Tiere mit 0,9\%iger $\mathrm{NaCl}$-Trinkwassergabe niedrigere Proteinuriewerte über den gesamten hier gezeigten Zeitraum. Die Spannweite der Proteinuriewerte nimmt für die Behandlungsgruppen „Neph“ und „Salz“ von 150 Lebenstagen zu 180 Lebenstagen bei nahezu allen Genotypen ab. 
3.1.3.2 Vergleich mit Alport-Vergleichsgruppe

Nach den Abbildungen 9 bis 12 zeigt die Proteinanalyse der Mäuse am Lebenstag 180 bei geschlechterspezifischer und geno- bzw. behandlungstypspezifischer Betrachtung im Vergleich zu 60 Tage alten weiblichen Alport-Mäusen (COL4A3 ${ }^{-/} \mathrm{NPHS}^{+/+}$, Mittelwert für Proteine gleicher Größe wie Albumin 12,59 mit einer SD \pm 0,5; Mittelwert für Proteine größer als Albumin 2,64 mit einer SD \pm 0,37) folgende Ergebnisse, wobei wegen der Übersichtlichkeit die Mittelwerte sowie Standardabweichungen in einer Tabelle präsentiert werden: 
Tabelle 6 - Übersicht der Proteinuriemittelwerte und Standardabweichungen für weibliche Tiere im Alter von 180 Tagen.

\begin{tabular}{|c|c|c|c|c|c|}
\hline Gruppe & Mittelwert & $\begin{array}{l}\text { Standard- } \\
\text { abweichung }\end{array}$ & Gruppe & Mittelwert & $\begin{array}{l}\text { Standard- } \\
\text { abweichung }\end{array}$ \\
\hline \multirow{2}{*}{$\begin{array}{l}\text { weiblich; } \\
\text { Wildtyp; } \\
\text { „Sham“6 }\end{array}$} & $=\mathrm{A}: 2,11$ & $=\mathrm{A}: 0,57$ & \multirow{2}{*}{$\begin{array}{l}\text { weiblich; } \\
\text { Wildtyp; } \\
\text { „Salz““ }\end{array}$} & $=\mathrm{A}: 0,81$ & $=\mathrm{A}: 0,41$ \\
\hline & $>$ A: 0,39 & $>$ A: 0,03 & & $>$ A: 0,39 & $>\mathrm{A}: 0,32$ \\
\hline \multirow{2}{*}{$\begin{array}{l}\text { weiblich; } \\
\text { COL4A3; } \\
\text { „Sham“" }\end{array}$} & $=\mathrm{A}: 2,42$ & $=\mathrm{A}: 1,02$ & \multirow{2}{*}{$\begin{array}{l}\text { weiblich; } \\
\text { COL4A3; } \\
\text { „Salz“ }\end{array}$} & $=\mathrm{A}: 2,08$ & $=\mathrm{A}: 1,54$ \\
\hline & $>$ A: 0,48 & $>$ A: 0,12 & & $>$ A: 0,44 & $>$ A: 0,26 \\
\hline \multirow{2}{*}{$\begin{array}{l}\text { weiblich; } \\
\text { COL4A3/ } \\
\text { NPHS2; } \\
\text { „Sham“ }\end{array}$} & $=\mathrm{A}: 2,83$ & $=\mathrm{A}: 1,19$ & \multirow{2}{*}{$\begin{array}{l}\text { weiblich; } \\
\text { COL4A3/ } \\
\text { NPHS2; } \\
\text { „Salz“ }\end{array}$} & $=\mathrm{A}: 0,89$ & $=\mathrm{A}: 0,51$ \\
\hline & $>$ A: 0,52 & $>$ A: 0,08 & & $>$ A: 0,27 & $>$ A: 0,09 \\
\hline \multirow{2}{*}{$\begin{array}{l}\text { weiblich; } \\
\text { NPHS2; } \\
\text { „Sham“ }\end{array}$} & $=\mathrm{A}: 2,83$ & $=\mathrm{A}: 1,58$ & \multirow{2}{*}{$\begin{array}{l}\text { weiblich; } \\
\text { NPHS2; } \\
\text { „Salz“" }\end{array}$} & $=\mathrm{A}: 1,27$ & $=\mathrm{A}: 0,65$ \\
\hline & $>$ A: 0,6 & $>$ A: 0,32 & & $>\mathrm{A}: 0,36$ & $>\mathrm{A}: 0,17$ \\
\hline \multirow{2}{*}{$\begin{array}{l}\text { weiblich; } \\
\text { Wildtyp; } \\
\text { „Neph“ }\end{array}$} & $=\mathrm{A}: 2,59$ & $=\mathrm{A}: 2,37$ & & & \\
\hline & $>$ A: 0,47 & $>$ A: 0,34 & & & \\
\hline \multirow{2}{*}{$\begin{array}{l}\text { weiblich; } \\
\text { COL4A3; } \\
\text { „Neph“" }\end{array}$} & $=\mathrm{A}: 1,18$ & $=\mathrm{A}: 0,65$ & & & \\
\hline & $>\mathrm{A}: 0,31$ & $>$ A: 0,1 & & & \\
\hline \multirow{2}{*}{$\begin{array}{l}\text { weiblich; } \\
\text { COL4A3/ } \\
\text { NPHS2; } \\
\text { „Neph“ }\end{array}$} & $=\mathrm{A}: 2,67$ & $=\mathrm{A}: 1,4$ & & & \\
\hline & $>$ A: 0,5 & $>$ A: 0,1 & & & \\
\hline \multirow{2}{*}{$\begin{array}{l}\text { weiblich; } \\
\text { NPHS2; } \\
\text { „Neph“ }\end{array}$} & $=\mathrm{A}: 1,52$ & $=\mathrm{A}: 0,94$ & & & \\
\hline & $>A: 0,36$ & $>$ A: 0,19 & & & \\
\hline
\end{tabular}

Wildtyp = COL4A3+/+ NPHS2+/+-Tiere; COL4A3 = COL4A3+/- NPHS2+/+-Tiere; COL4A3/NPHS2 = COL4A3+/- NPHS2+/R140Q-Tiere; NPHS2 = COL4A3+/+ NPHS2+/R140Q-Tiere; „Sham“ = OP ohne Uninephrektomie; „Neph“ = OP mit Uninephrektomie; „Salz“ = OP mit Uninephrektomie + 0,9\%iger NaCl-Trinkwassergabe; =A entspricht Proteinen gleicher Größe wie Albumin; >A entspricht Proteinen größer als Albumin. 
Die weiblichen Mäuse der Behandlungsgruppen zeigen jeweils einen signifikanten Unterschied nach Dunnett-T3 (für die Welch-ANOVA) beziehungsweise Bonferroni oder Tukey-HSD (für die ANOVA) oder im Kruskal-Wallis-Test mit Bonferroni-Korrektur zur Alport-Vergleichsgruppe. Einzige Ausnahme hierbei ist die Behandlungsgruppe „Sham“. Hier gibt es keinen signifikanten Unterschied für Proteine größer als Albumin zwischen Wildtyp- und Alport-Mäusen.

Die Proteinurie der jeweiligen Genotypen und Behandlungen weist verglichen mit AlportMäusen stets signifikant niedrigere Mittelwerte mit Ausnahme der COL4A3-mutierten Mäuse für Proteine größer als Albumin auf. Diese Mäuse zeigen lediglich einen signifikanten Unterschied nach ANOVA zwischen den „Neph“- und den Alport-Mäusen.

Im Vergleich zur Alport-Vergleichsgruppe lässt sich für Alport-Mäuse für Proteine gleicher Größe wie Albumin eine mindestens um 344,88 \% höhere Proteinurie bestimmen (Vergleich „Sham“ COL4A3/NPHS2 und NPHS2 an Lebenstag 180 zur Alport-Gruppe an Lebenstag 60). Für Proteine größer als Albumin zeigen Alport-Mäuse eine sogar noch höhere Steigerung der Proteinurie (mindestens 340 \%; Vergleich „Sham“ NPHS2 an Lebenstag 180 zur Alport-Gruppe an Lebenstag 60). 
Tabelle 7 - Übersicht der Proteinuriemittelwerte und Standardabweichungen für männliche Tiere im Alter von 180 Tagen.

\begin{tabular}{|c|c|c|c|c|c|}
\hline Gruppe & Mittelwert & $\begin{array}{l}\text { Standard- } \\
\text { abweichung }\end{array}$ & Gruppe & Mittelwert & $\begin{array}{l}\text { Standard- } \\
\text { abweichung }\end{array}$ \\
\hline \multirow{2}{*}{$\begin{array}{l}\text { männlich; } \\
\text { Wildtyp; „Sham“ }\end{array}$} & $=\mathrm{A}: 5,56$ & $=\mathrm{A}: 0,72$ & \multirow{2}{*}{$\begin{array}{l}\text { männlich; } \\
\text { Wildtyp; } \\
\text { „Salz“ }\end{array}$} & $=\mathrm{A}: 4,9$ & $=\mathrm{A}: 3,05$ \\
\hline & $>\mathrm{A}: 1,59$ & $>$ A: 0,92 & & $>$ A: 1,09 & $>$ A: 0,68 \\
\hline \multirow{2}{*}{$\begin{array}{l}\text { männlich; } \\
\text { COL4A3; „Sham“ }\end{array}$} & $=\mathrm{A}: 4,66$ & $=\mathrm{A}: 2,57$ & \multirow{2}{*}{$\begin{array}{l}\text { männlich; } \\
\text { COL4A3; } \\
\text { „Salz“ }\end{array}$} & $=\mathrm{A}: 3,87$ & $=\mathrm{A}: 2,07$ \\
\hline & $>$ A: 0,94 & $>$ A: 0,23 & & $>$ A: 0,62 & $>$ A: 0,48 \\
\hline \multirow{2}{*}{$\begin{array}{l}\text { männlich; } \\
\text { COL4A3/NPHS2 } \\
\text {; „Sham“ }\end{array}$} & $=\mathrm{A}: 5,63$ & $=A: 4,63$ & \multirow{2}{*}{$\begin{array}{l}\text { männlich; } \\
\text { COL4A3/ } \\
\text { NPHS2; } \\
\text { „Salz“ }\end{array}$} & $=\mathrm{A}: 3,87$ & $=\mathrm{A}: 4,64$ \\
\hline & $>\mathrm{A}: 1,4$ & $>$ A: 1,14 & & $>$ A: 0,4 & $>$ A: 0,42 \\
\hline \multirow{2}{*}{$\begin{array}{l}\text { männlich; } \\
\text { NPHS2; „Sham“ }\end{array}$} & $=\mathrm{A}: 4,21$ & $=A: 2,3$ & \multirow{2}{*}{$\begin{array}{l}\text { männlich; } \\
\text { NPHS2; } \\
\text { „Salz“ }\end{array}$} & $=\mathrm{A}: 1,72$ & $=\mathrm{A}: 1,24$ \\
\hline & $>$ A: 0,99 & $>$ A: 0,53 & & $>$ A: 0,31 & $>$ A: 0,12 \\
\hline \multirow{2}{*}{$\begin{array}{l}\text { männlich; } \\
\text { Wildtyp; „Neph“ }\end{array}$} & $=\mathrm{A}: 5,81$ & $=\mathrm{A}: 2,77$ & & & \\
\hline & $>$ A: 0,92 & $>$ A: 0,6 & & & \\
\hline \multirow{2}{*}{$\begin{array}{l}\text { männlich; } \\
\text { COL4A3; „Neph“ }\end{array}$} & $=\mathrm{A}: 5,26$ & $=\mathrm{A}: 0,76$ & & & \\
\hline & $>$ A: 0,94 & $>$ A: 0,44 & & & \\
\hline \multirow{2}{*}{$\begin{array}{l}\text { männlich; } \\
\text { COL4A3/NPHS2 } \\
\text {; „Neph“ }\end{array}$} & $=\mathrm{A}: 4,33$ & $=\mathrm{A}: 1,44$ & & & \\
\hline & $>$ A: 0,58 & $>$ A: 0,07 & & & \\
\hline \multirow{2}{*}{$\begin{array}{l}\text { männlich; } \\
\text { NPHS2; „Neph“ }\end{array}$} & $=\mathrm{A}: 7,17$ & $=\mathrm{A}: 2,05$ & & & \\
\hline & $>$ A: 1,33 & $>$ A: 0,98 & & & \\
\hline
\end{tabular}

Wildtyp $=\mathrm{COL}_{4} 3^{+/+} \mathrm{NPHS}^{+/+}$-Tiere; COL4A3 $=\mathrm{COL}_{4} 3^{+/-} \mathrm{NPHS}^{+/+}$-Tiere; COL4A3/NPHS2 = $\mathrm{COL}_{4} 3^{+/-} \mathrm{NPHS}^{+/ \mathrm{R} 140 \mathrm{Q}-T i e r e}$; NPHS2 $=$ COL4A3 $^{+/+} \mathrm{NPHS}^{+/ \mathrm{R} 140 \mathrm{Q}-T i e r e}$; „Sham“ $=$ OP ohne Uninephrektomie; „Neph“ = OP mit Uninephrektomie; ,SSalz“ = OP mit Uninephrektomie $+0,9 \%$ iger $\mathrm{NaCl}$ Trinkwassergabe; =A entspricht Proteinen gleicher Größe wie Albumin; >A entspricht Proteinen größer als Albumin. 
Die Behandlungsgruppen für die männlichen Mäuse weisen im Vergleich zur weiblichen Alport-Vergleichsmaus folgende signifikante Unterschiede auf:

Die Behandlungsgruppe „Sham“ hat gegenüber der Alport-Vergleichsgruppe für Proteine größer als Albumin signifikant höhere Werte als COL4A3-mutierte Mäuse. Bei Proteinen gleicher Größe wie Albumin besteht der signifikante Unterschied zum Wildtyp. Die Unterschiede sind jeweils ermittelt nach der Welch-ANOVA.

In den Behandlungsgruppen „Neph“ und „Salz“ sind alle Genotypen nach ANOVA zur Vergleichsgruppe signifikant niedriger. Lediglich in der Behandlungsgruppe „Neph“ kann kein signifikanter Unterschied zwischen den $\mathrm{COL}_{4} \mathrm{~A}^{+/+}{ }^{+/} \mathrm{NPHS} 2^{+/ \mathrm{R} 140 \mathrm{Q}}$ Tieren und der Alport-Vergleichsgruppe für Proteine größer als Albumin gesehen werden.

Die Auswirkungen der Behandlung auf den jeweiligen Genotyp zeigen neben denen in 3.1.3 dargestellten Ergebnissen folgende signifikante Unterschiede:

Der Wildtyp hat einen niedrigeren Mittelwert für Proteine gleicher Größe wie Albumin zwischen der Behandlungsgruppe „Sham“ und der Alport-Vergleichsgruppe in der WelchANOVA. Für Proteine größer als Albumin zeigt sich beim gleichen Genotyp ein Unterschied in der ANOVA zwischen „Neph“ und „Salz“ jeweils zur Vergleichsgruppe.

Bei COL4A33 ${ }^{+/} \mathrm{NPHS}^{+/+}$-Mäusen kann für Proteine gleicher Größe wie Albumin nach Welch-ANOVA ein signifikanter Unterschied zwischen den Behandlungsgruppen „Neph“ und „Salz“ jeweils zur Alport-Vergleichsgruppe gesehen werden. Für größere Proteine als Albumin zeigt die ANOVA alle Behandlungsgruppen mit signifikant niedrigeren Proteinuriemittelwerten an.

Tiere mit einer COL4A3 ${ }^{+/-}$NPHS2 ${ }^{+/ R 140 Q}-$ Mutation weisen für beide Proteingrößen signifikante Unterschiede zwischen der Alport-Gruppe und jeweils den Behandlungsgruppen „Neph“ und „Salz“ auf. Für Proteine gleicher Größe wie Albumin ist dieser Unterschied in der ANOVA zu sehen und für Proteine größer Albumin in der Welch-ANOVA.

Für COL4A3 ${ }^{+/+}$NPHS2 ${ }^{+/ R 140 Q}-$ Mäuse kann bei der Proteinurie für Proteine gleicher Größe wie Albumin ein signifikanter Unterschied aller Behandlungsgruppen zur AlportVergleichsgruppe in der ANOVA ermittelt werden. Für Proteine, die größer als Albumin sind, sieht man dies nur für die Behandlungsgruppen „Sham“ und „Salz“ im Vergleich zur Alport-Gruppe in der ANOVA.

Männliche Tiere weisen eine allgemein höhere Proteinurie im Vergleich zu den weiblichen auf. Dennoch kommt es $\mathrm{zu}$ deutlich geringeren Proteinuriewerten als in der AlportVergleichsgruppe (für Proteine gleiche Größe wie Albumin um mindestens 75,59 \% [zwischen „Neph“ NPHS2 an Lebenstag 180 und Alport] sowie für Proteine größer als Albumin um mindestens 66,04 \% [zwischen „Sham“ Wildtyp an Lebenstag 180 und Alport]). 


\subsection{Lichtmikroskopie}

Es wurden je Genotyp und je Behandlungsgruppe drei Tiere ausgewählt. Beide Geschlechter wurden berücksichtigt. Die Schnitte wurden auf Fibronectin und Laminin gefärbt. Die Färbungen dienen zur Darstellung möglicher Nierenschäden. Fibronectin ist besonders als Sklerose- bzw. Fibrosemarker im Interstitium anfärbbar. Laminin zeigt Extrazellularmatrixablagerungerungen bzw. Matrixakkumulationen an. Explizit wurde Laminin 1 angefärbt. Als Kontrollgruppe wurden auch von drei Alport-Mäusen histologische Schnitte mit diesen Färbungen angefertigt. Es wurden nur die Behandlungsgruppen „Neph“ und „Salz“ berücksichtigt. 
Tabelle 8 - Bewertungsschema Fibronectin-Score.

\begin{tabular}{|c|c|c|}
\hline $\begin{array}{l}\text { Punkt- } \\
\text { wert }\end{array}$ & Beispielbild in 10-facher Vergrößerung & Tubulointerstitium \\
\hline 0 & & $\begin{array}{l}\text { Vereinzelte, zarte Signalanreicher- } \\
\text { ung um Glomerula und Gefäße } \\
\text { sowie Gewebsspalten }\end{array}$ \\
\hline 1 & & $\begin{array}{l}\text { Vermehrte Singnalanreicherung im } \\
\text { Interstitium, Fibroseinseln im Inter- } \\
\text { stitium }\end{array}$ \\
\hline 2 & & $\begin{array}{l}\text { Deutliche Fibrosebereiche im In- } \\
\text { terstitium, beginnende Verdräng- } \\
\text { ung des Nierengewebes }\end{array}$ \\
\hline 3 & & $\begin{array}{l}\text { Breite Vernarbung des Gewebes mit } \\
\text { starker Signalanreicherung unter } \\
\text { Aufhebung der tubulointerstitiellen } \\
\text { Architektur }\end{array}$ \\
\hline
\end{tabular}


Tabelle 9-Bewertungsschema Laminin-Score.

\begin{tabular}{|c|c|c|c|}
\hline $\begin{array}{l}\text { Punkt- } \\
\text { wert }\end{array}$ & $\begin{array}{l}\text { Beispielbild in } 10 \text {-facher Vergröße- } \\
\text { rung }\end{array}$ & Glomerulum & $\begin{array}{l}\text { Tubulo- } \\
\text { interstitium }\end{array}$ \\
\hline 0 & 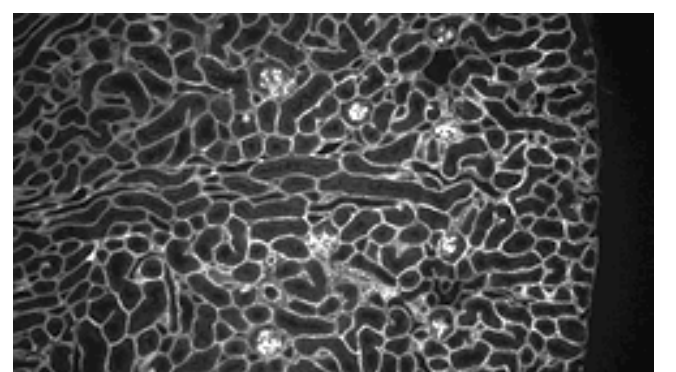 & $\begin{array}{l}\text { Klar erkennba- } \\
\text { re, feine Struk- } \\
\text { tur des Kapillar- } \\
\text { knäuels, freies } \\
\text { Lumen der } \\
\text { Bowmankapsel }\end{array}$ & $\begin{array}{l}\text { Klar erkennbare } \\
\text { Struktur, schmales } \\
\text { Interstitium ohne } \\
\text { fibröse Verbreite- } \\
\text { rung, keine Fibro- } \\
\text { seinseln }\end{array}$ \\
\hline 1 & & $\begin{array}{l}\text { Klar erkennbare } \\
\text { Struktur, Kapil- } \\
\text { lar-schlingen } \\
\text { aufgehellt, be- } \\
\text { ginnende Kap- } \\
\text { selbildung }\end{array}$ & $\begin{array}{l}\text { Regelmäßige struk- } \\
\text { turelle Anordnung } \\
\text { der Tubuli, breites } \\
\text { Interstitium mit } \\
\text { vereinzelten Fibro- } \\
\text { seinseln }\end{array}$ \\
\hline 2 & - & $\begin{array}{l}\text { Stark veränderte } \\
\text { Kapillarstruktur, } \\
\text { verschmälertes } \\
\text { Bowman- } \\
\text { Lumen }\end{array}$ & $\begin{array}{l}\text { Unregelmäßige } \\
\text { strukturelle Anord- } \\
\text { nung der Tubuli, } \\
\text { verbreitertes In- } \\
\text { terstitium mit dif- } \\
\text { fus verteilten Fib- } \\
\text { rosebereichen }\end{array}$ \\
\hline 3 & & $\begin{array}{l}\text { Keine Struktur } \\
\text { erkennbar, voll- } \\
\text { ständige glome- } \\
\text { ruläre Sklerose, } \\
\text { Verschmelzung } \\
\text { von Kapillar- } \\
\text { knäuel und } \\
\text { Kapsel }\end{array}$ & $\begin{array}{l}\text { Tubulointerstitielle } \\
\text { Struktur durch Fib- } \\
\text { rosierung auf- } \\
\text { gehoben, breite } \\
\text { bindegewebige } \\
\text { Durchsetzung des } \\
\text { Gewebes }\end{array}$ \\
\hline
\end{tabular}




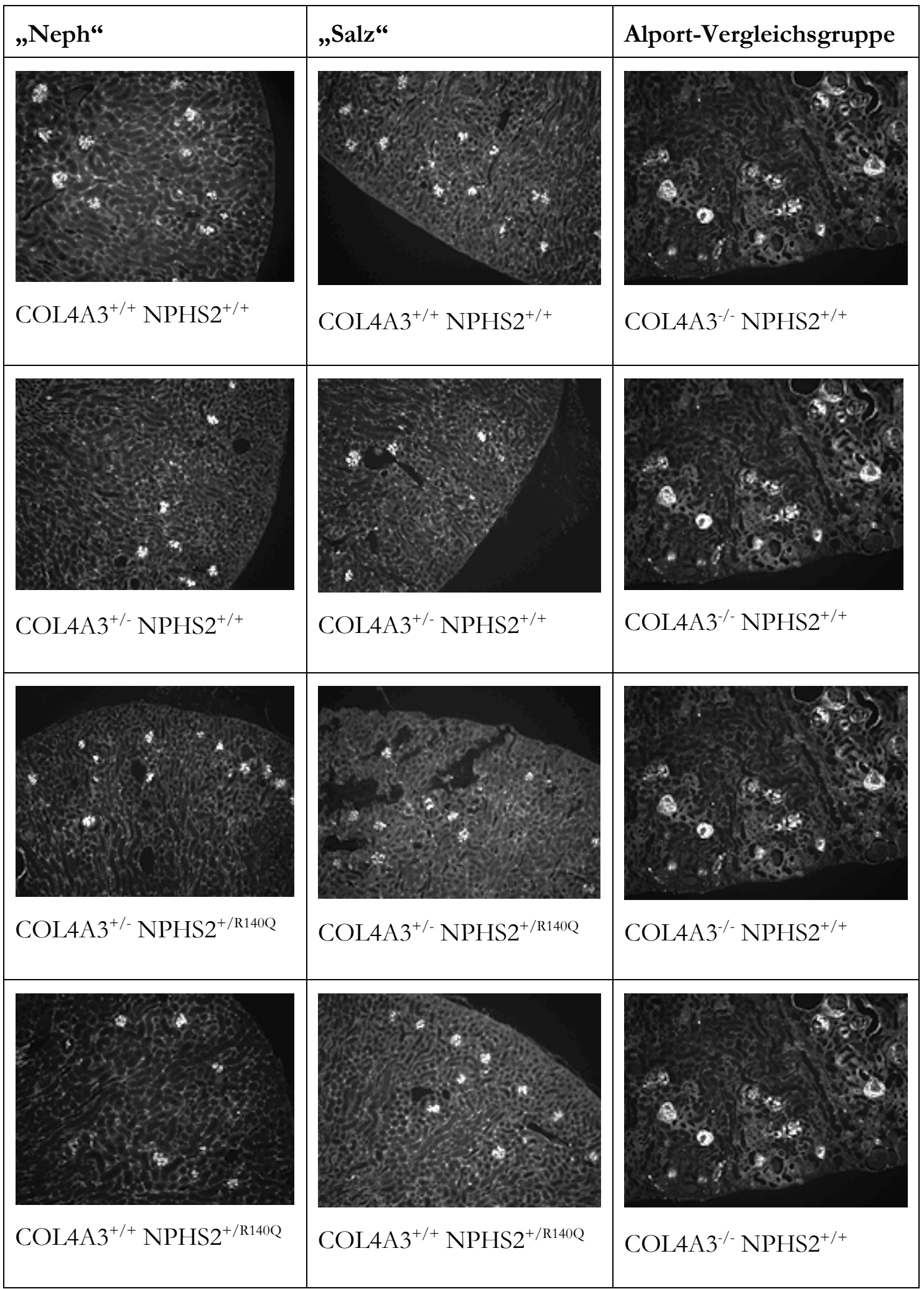

Abbildung 13 - Fibronectinfärbung in 10-facher Vergrößerung; beispielhafte Bilder für jeweilige Behandlungsgruppe und Genotyp. Wildtyp $=$ COL4A3 $3^{+/+} \mathrm{NPHS}^{+/+}-$Tiere; COL4A3 $=$ COL4A3 $3^{+/-} \mathrm{NPHS}^{+/+}{ }_{-}$Tiere; COL4A3/NPHS2 $=$COL4A3 $^{+/-} \mathrm{NPHS}^{+/ \mathrm{R} 140 \mathrm{Q}-\text { Tiere}}$; NPHS2 $=$

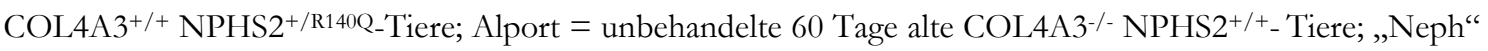
= OP mit Uninephrektomie; „Salz“ = OP mit Uninephrektomie + 0,9\%iger NaCl-Trinkwassergabe. 


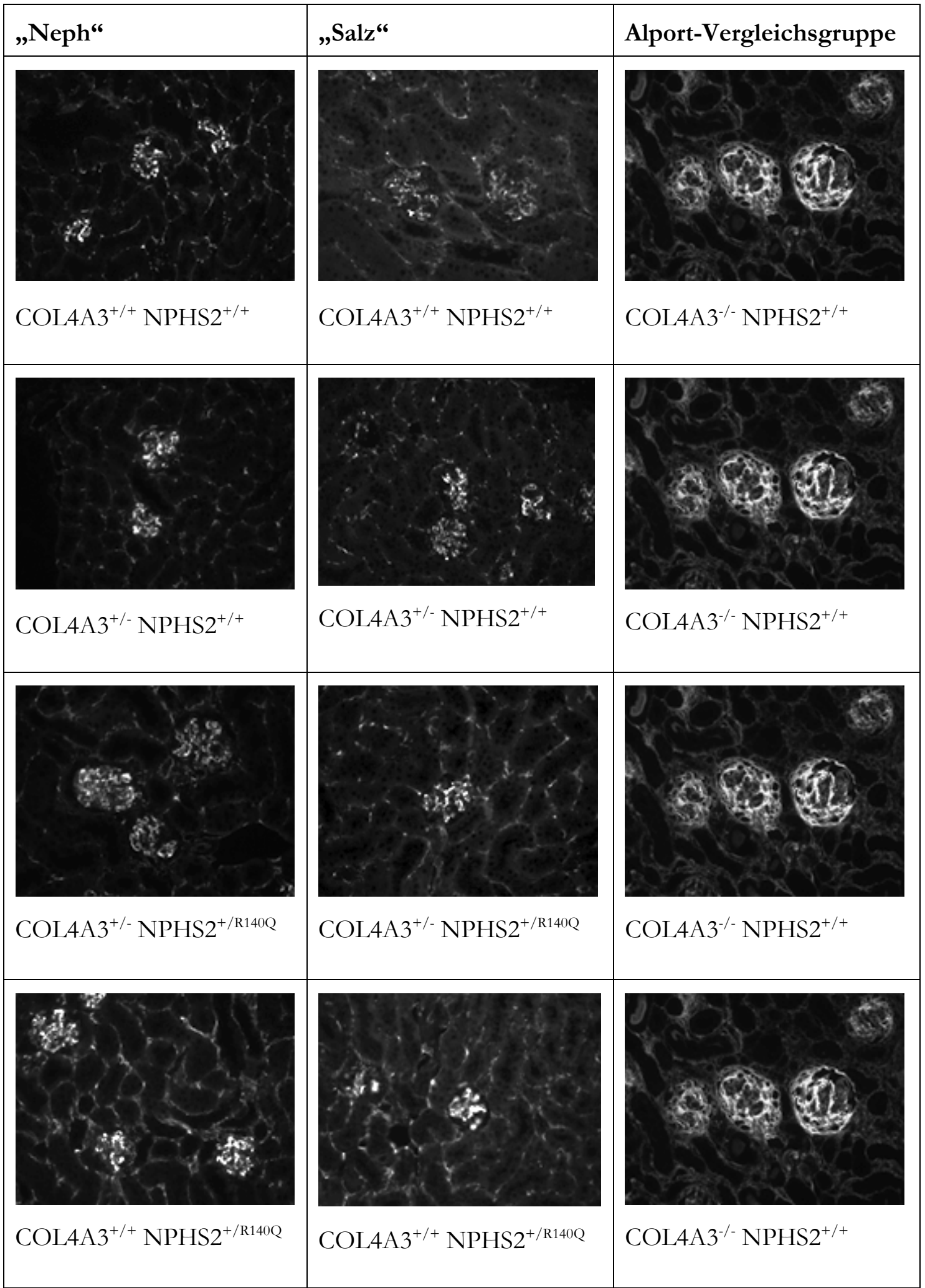

Abbildung 14 - Fibronectinfärbung in 40-facher Vergrößerung; beispielhafte Bilder für jeweilige Behandlungsgruppe und Genotyp. Wildtyp $=$ COL4A3 $3^{+/+} \mathrm{NPHS}^{+/+}-$Tiere; COL4A3 $=$ COL4A $3^{+/-} \mathrm{NPHS}^{+/+}-$Tiere; COL4A3/NPHS2 $=$COL4A3 $^{+/-} \mathrm{NPHS}^{+/ \mathrm{R} 140 \mathrm{Q}-\text { Tiere }}$ NPHS2 $=$

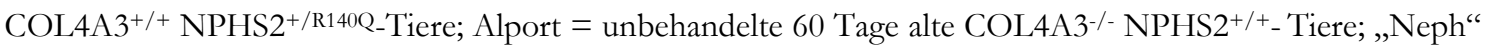
= OP mit Uninephrektomie; „Salz“ = OP mit Uninephrektomie + 0,9\%iger NaCl-Trinkwassergabe. 


\begin{tabular}{|c|c|c|}
\hline „Neph“ & „Salz“ & Alport-Vergleichsgruppe \\
\hline H. & (1) & 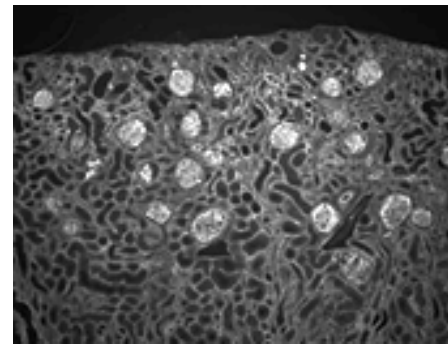 \\
\hline $\mathrm{COL}_{4 A} 3^{+/+} \mathrm{NPHS}^{+/+}$ & $\mathrm{COL}_{4 A} 3^{+/+} \mathrm{NPHS}^{+/+}$ & $\mathrm{COL}_{4 \mathrm{~A}} 3^{-/-} \mathrm{NPHS}_{2}^{+/+}$ \\
\hline 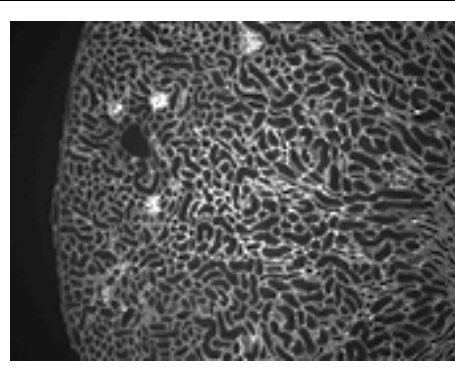 & 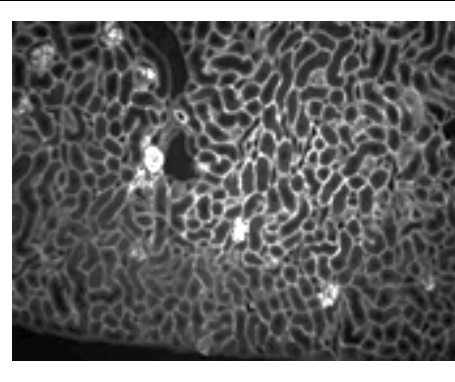 & 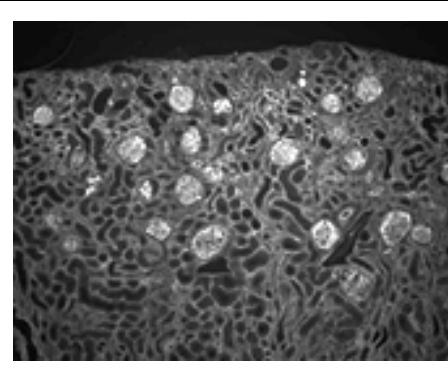 \\
\hline $\mathrm{COL}_{4 \mathrm{~A}} 3^{+/-} \mathrm{NPHS}^{+/+}$ & $\mathrm{COL}_{4} \mathrm{A3}^{+/-} \mathrm{NPHS}^{+/+}$ & $\mathrm{COL}_{4 A 3} 3^{-/-} \mathrm{NPHS}^{+/+}$ \\
\hline (1) & 20 & 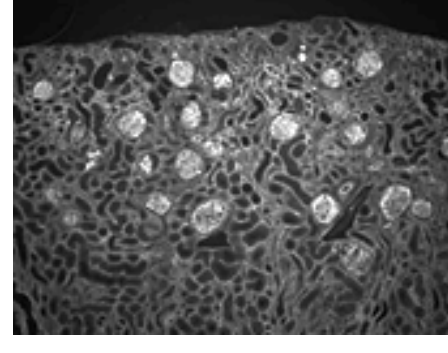 \\
\hline $\mathrm{COL}_{4 A 3} 3^{+/-} \mathrm{NPHS}^{+/ \mathrm{R} 140 \mathrm{Q}}$ & $\mathrm{COL}_{4 \mathrm{~A}} 3^{+/-} \mathrm{NPHS} 2^{+/ \mathrm{R} 140 \mathrm{Q}}$ & $\mathrm{COL}_{4 \mathrm{~A}} 3^{-/-} \mathrm{NPHS}^{+/+}$ \\
\hline 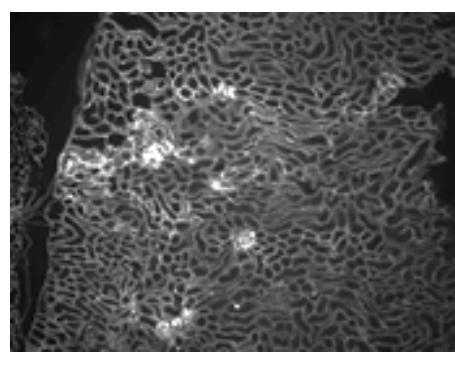 & Mifinge & 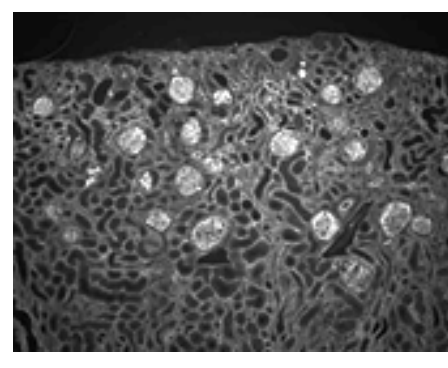 \\
\hline $\mathrm{COL}_{4 A 3^{+/+}} \mathrm{NPHS}^{+/ \mathrm{R} 140 \mathrm{Q}}$ & $\mathrm{COL}_{4} \mathrm{~A}^{+/+} \mathrm{NPHS}^{+/ \mathrm{R} 140 \mathrm{Q}}$ & $\mathrm{COL}_{4} \mathrm{A3}^{-/-} \mathrm{NPHS}^{+/+}$ \\
\hline
\end{tabular}

Abbildung 15 - Lamininfärbung in 10-facher Vergrößerung; beispielhafte Bilder für jeweilige Behandlungsgruppe und Genotyp. Wildtyp $=\mathrm{COL}_{4} 3^{+/+} \mathrm{NPHS}^{+/+}-$Tiere;

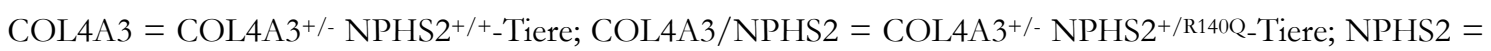

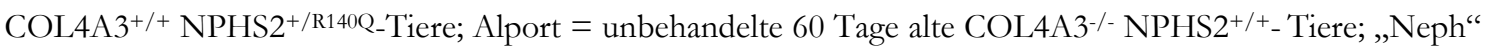
= OP mit Uninephrektomie; „Salz“ = OP mit Uninephrektomie + 0,9\%iger NaCl-Trinkwassergabe. 


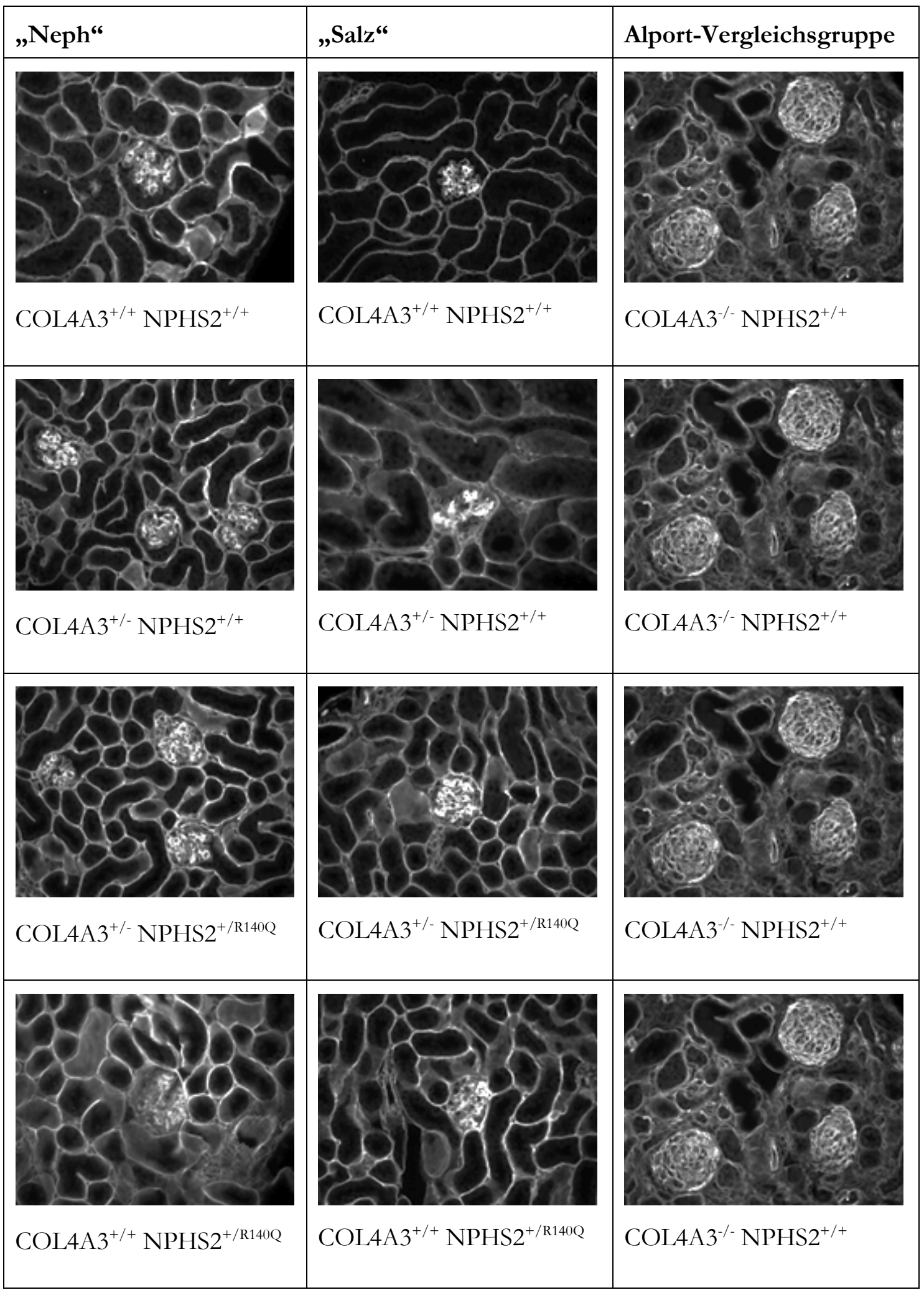

Abbildung 16 - Lamininfärbung in 40-facher Vergrößerung; beispielhafte Bilder für jeweilige Behandlungsgruppe und Genotyp. Wildtyp $=\mathrm{COL}_{4} 3^{+/+} \mathrm{NPHS}^{+/+}-$Tiere; COL4A3 $=$ COL4A3 $^{+/-}$NPHS2 $^{+/+}$-Tiere; COL4A3 $/$NPHS2 $^{2}$ COL4A3 ${ }^{+/-}$NPHS2 $^{+/ R 140 Q}-$ Tiere $;$ NPHS2 $=$

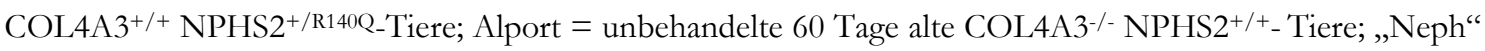
= OP mit Uninephrektomie; „Salz“ = OP mit Uninephrektomie + 0,9\%iger NaCl-Trinkwassergabe. 
Anschließend wurden jeweils sechs Fotos eines Präparates in je 10-facher und 40-facher Vergrößerung angefertigt und drei Scorern verblindet zur Bewertung nach in Tabelle 3 und 4 gezeigten Abstufungen und Anweisungen zur Beurteilung vorgelegt.

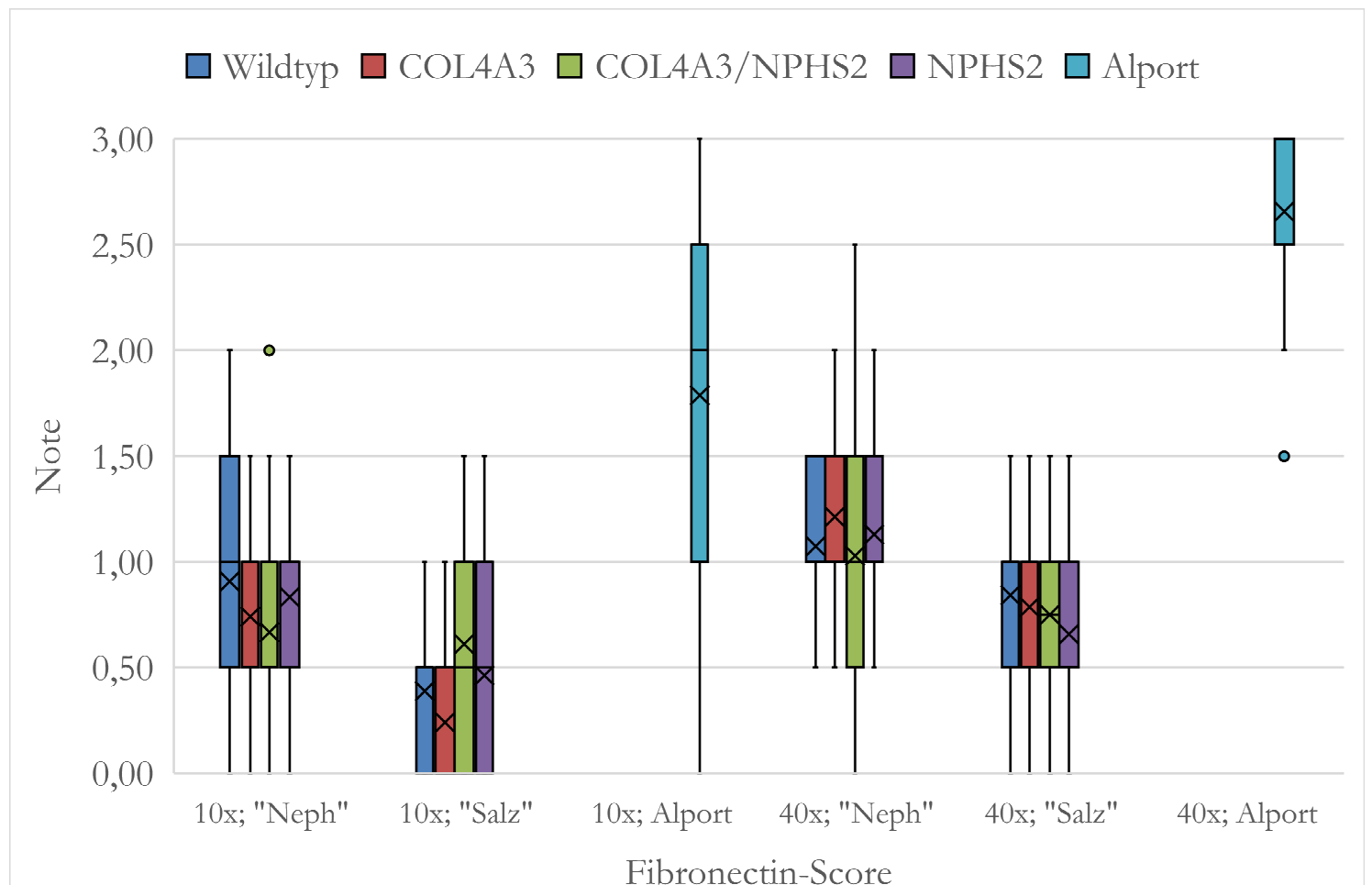

Abbildung 17 - Fibronectin-Score jeweils in 10- und 40-facher Vergrößerung. Wildtyp $=\mathrm{COL}_{4} \mathrm{~A}^{+/+} \mathrm{NPHS}^{+/+-}$Tiere; $\mathrm{COL} 4 \mathrm{~A} 3=\mathrm{COL}_{4} 3^{+/-} \mathrm{NPHS}^{+/+}{ }^{+-}$Tiere$;$COL4A3 $/ \mathrm{NPHS} 2=\mathrm{COL} 4 \mathrm{~A}^{+/-}$

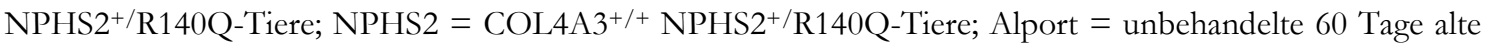
COL4A3\% $\%$ NPHS2 $^{+/+}$-Tiere; „Neph“ = OP mit Uninephrektomie; „Salz“ = OP mit Uninephrektomie + 0,9\%iger NaCl-Trinkwassergabe. Tiere sind jeweils 180 Tage alt. Kreuz zeigt Mittelwert. Punkt zeigt nicht signifikante Ausreißer.

Bei dem Fibronectin-Score fällt im Vergleich der Wildtyp-Tiere ein signifikanter Unterschied zwischen der Behandlungsgruppe „Salz“ und den Alport-Vergleichstieren auf. Im Kruskal-Wallis-Test sind die beiden Gruppen sowohl in der 10-fachen (Mittelwert „Salz“ 0,38; SD \pm 0,19 zu Mittelwert Alport 1,78; SD \pm 0,3) als auch in der 40-fachen Vergrößerung (Mittelwert „Salz“ 0,84; SD \pm 0,26 zu Mittelwert Alport 2,65; SD \pm 0,12) signifikant unterschiedlich. Im Post-hoc-Test nach angepasster Bonferroni-Korrektur konnte dieser Unterschied nur noch für die 10-fache Vergrößerung gezeigt werden.

Es kann zwischen der Behandlungsgruppe „Salz“ ein signifikanter Unterschied für $\mathrm{COL}_{4} \mathrm{~A}^{+/-} \mathrm{NPHS}^{+/+}$-Mäuse zur Alport-Kontrollgruppe in der 10-fachen Vergrößerung (Mittelwert „Salz“ 0,24; SD \pm 0,08) im Kruskal-Wallis-Test in der Fibronectinanfärbung gezeigt werden. Diese Beobachtung bestätigte sich in der 40-fachen Vergrößerung (Mittelwert „Salz“ 0,78; SD \pm 0,08). 


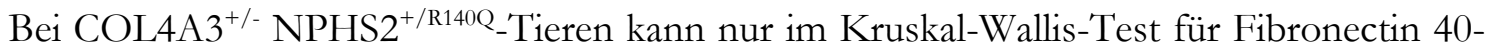
fache Vergrößerung ein signifikanter (Mittelwert „Salz“ 0,75; SD \pm 0,24) Unterschied im Kruskal-Wallis-Test gezeigt werden. In der Post-hoc-Analyse unter angepasster Bonferroni-Korrektur zeigt sich in keiner der Gruppen ein signifikanter Unterschied.

Für den Genotyp COL4A3 ${ }^{+/+} \mathrm{NPHS}^{+/ \mathrm{R} 140 \mathrm{Q}}$ lässt sich wie für die anderen Genotypen ein signifikanter Unterschied im Kruskal-Wallis-Test in beiden Vergrößerungen zwischen der Behandlungsgruppe „Salz“ und der Alport-Vergleichsgruppe (Mittelwert „Salz“ 10-fach 0,46; SD \pm 0,06; Mittelwert „Salz“ 40-fach 0,65; SD $\pm 0,11$ ) ermitteln.

Der Vergleich zwischen „Neph“ und „Salz“ zeigt genauso wie der Vergleich zwischen „Neph“ und den Alport-Vergleichstieren keine signifikanten Ergebnisse. Hierbei ist zu bemerken, dass die Score-Mittelwerte für „Neph“-Tiere bei allen Genotypen höher sind als bei „Salz“-Tieren. „Salz“-Tiere weisen im Fibronectin-Score regelmäßig die besten Scorebewertungen auf.

Auffällig ist weiterhin, dass über alle Genotypen hinweg unabhängig von der Behandlungsgruppe die Schnitte im Mittel bei 40-facher Vergrößerung schlechter bewertet wurden als bei 10-facher Vergrößerung.

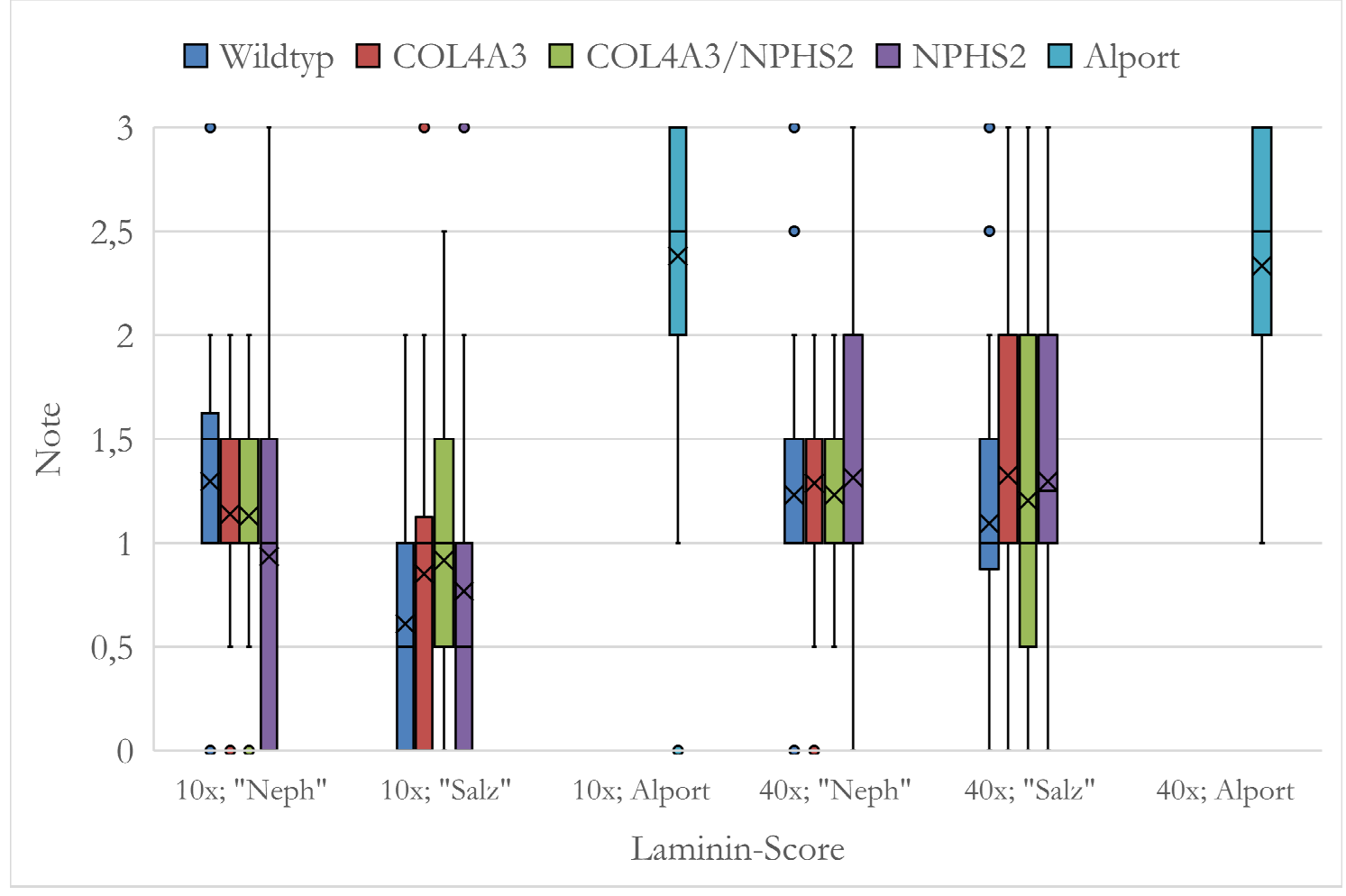

Abbildung 18 - Laminin-Score jeweils in 10- und 40-facher Vergrößerung. Wildtyp =

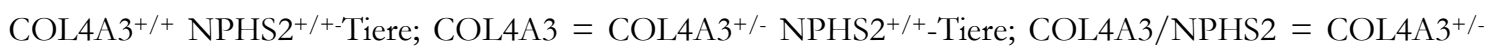
$\mathrm{NPHS2}^{+/ R}$ 140Q-Tiere; NPHS2 $=$ COL4A3 ${ }^{+/+} \mathrm{NPHS}^{+/ R} 140 \mathrm{Q}-$ Tiere; Alport $=$ unbehandelte 60 Tage alte COL4A3-- NPHS2+/+-Tiere; „Neph“ = OP mit Uninephrektomie; „Salz“ = OP mit Uninephrektomie + 0,9\%iger NaCl-Trinkwassergabe. Tiere sind jeweils 180 Tage alt. Kreuz zeigt Mittelwert. Punkt zeigt nicht signifikante Ausreißer. 
Für den Laminin-Score lassen sich folgende Ergebnisse ermitteln:

Beim Wildtyp zeigt sich ähnlich zum Fibronectin-Score eine im Mittel geringere Schädigung in beiden Vergrößerungen für „Salz“-Tiere im Vergleich zu „Neph“-Tieren. In der 10-fachen Vergrößerung ist ein signifikanter Unterschied im Kruskal-Wallis-Test zwischen „Salz“- und Alport-Tieren (Mittelwert „Salz“ 0,61; SD \pm 0,05 und Mittelwert Alport 2,38; $\mathrm{SD} \pm 0,16)$ festzustellen.

Für COL4A3 ${ }^{+/-} \mathrm{NPHS}^{+/+}$-Mäuse ist zu sehen, dass in der 40-fachen Vergrößerung die „Salz“-Tiere (Mittelwert 1,32; SD \pm 0,34) schlechter gescoret wurden als die „Neph“-Tiere (Mittelwert 1,28; SD \pm 0,15). Einen signifikanten Unterschied zwischen zwei Gruppen erbrachte dieser Score nicht.

Für Tiere mit einer COL4A3 ${ }^{+/-}$NPHS2 ${ }^{+/ R 140 Q}-$ Mutation zeigt sich eine bessere Bewertung für „Salz“-Tiere im Vergleich zu „Neph“-Tieren bei beiden Vergrößerungen. Auch hier kann kein signifikanter Unterschied für die Gruppen ermittelt werden. Gleiches gilt für den $\mathrm{COL}_{4} \mathrm{~A} 3^{+/+} \mathrm{NPHS}^{+/ \mathrm{R}_{140 Q}-G e n o t y p}$.

\subsection{Blutserumanalyse}

Es wurden je Genotyp und je Behandlungsgruppe vier Tiere ausgewählt. Das Geschlechterverhältnis war 1:1. Zum Vergleich wurde bei vier Alport-Mäusen das Blutserum auf Cholesterin und Harnstoff-N analysiert. 


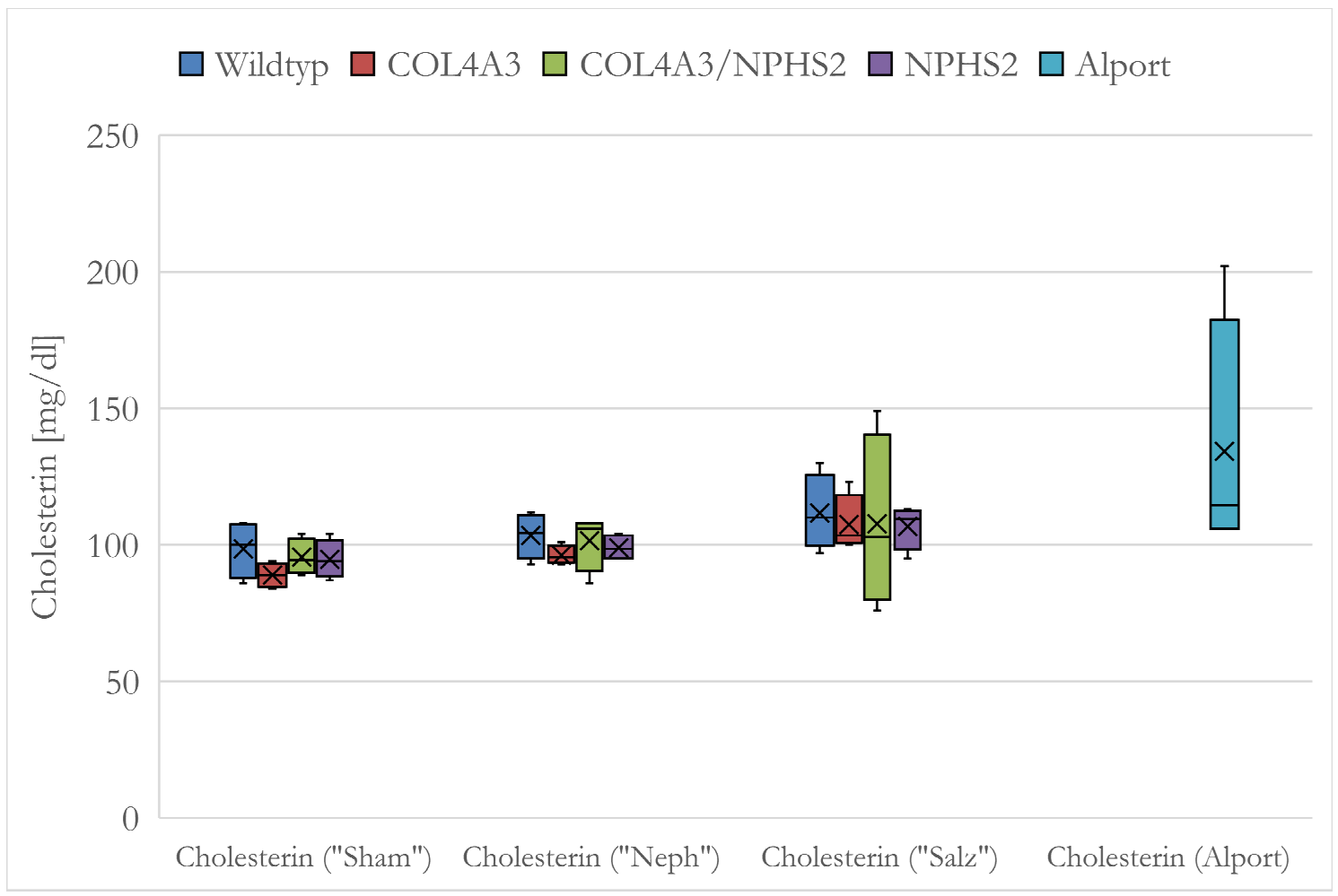

Abbildung 19 - Blutserumanalyse für Cholesterin. Wildtyp $=\mathrm{COL}_{\mathrm{AH}} 3^{+/+} \mathrm{NPHS}^{+/+}-$Tiere; COL4A3 $=$ COL4A3 $3^{+/-} \mathrm{NPHS}^{+/+}{ }_{-}$Tiere $;$COL4A3 $/ \mathrm{NPHS}_{2}=\mathrm{COL}_{\mathrm{A}} 3^{+/-} \mathrm{NPHS}^{+/ \mathrm{R} 140 \mathrm{Q}-\text { Tiere }}$ NPHS2 $=$

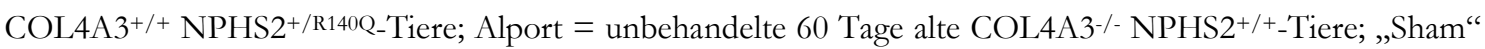
= OP ohne Uninephrektomie; „Neph“ = OP mit Uninephrektomie; „Salz“ = OP mit Uninephrektomie + $0,9 \%$ iger $\mathrm{NaCl}$-Trinkwassergabe. Kreuz zeigt Mittelwert.

Mit Einschluss der Alport-Vergleichsgruppe kommt es zu signifikanten Ergebnissen. So erkennt man in der Behandlungsgruppe „Sham“ einen signifikanten Unterschied im Kruskal-Wallis-Test für Mäuse mit einer $\mathrm{COL}_{4} \mathrm{~A}^{+/-} \mathrm{NPHS}^{+/+}{ }_{-}$Mutation (Mittelwert 89 $\mathrm{mg} /$ Deziliter (dl) mit einer SD \pm 4,39 mg/dl) im Vergleich zur Alport-Kontrollgruppe (Mittelwert 134,25 mg/dl mit einer SD \pm 45,87 mg/dl). Ebenso zeigt sich ein signifikanter Unterschied im Kruskal-Wallis-Test für die Genotypen COL4A3 ${ }^{+/-}$NPHS2 $^{+/ R 140 Q}$ (Mittelwert $95,5 \mathrm{mg} / \mathrm{dl}$ mit einer SD $\pm 6.55 \mathrm{mg} / \mathrm{dl}$ ) und COL4A3 ${ }^{+/+} \mathrm{NPHS}^{+/ \mathrm{R} 140 \mathrm{Q}}$ (Mittelwert $97,25 \mathrm{mg} / \mathrm{dl}$ mit einer SD $\pm 4,78 \mathrm{mg} / \mathrm{dl}$ ). Bei angepasster Bonferroni-Korrektur kann dieser im letzten Fall nicht gezeigt werden. Weiterhin ist zu sehen, dass in dieser Behandlungsgruppe alle Genotypen einen geringeren Cholesterinspiegel im Serum aufweisen als der Wildtyp (COL4A3 ${ }^{+/+} \mathrm{NPHS}^{+/+}$). So haben Tiere mit einer isolierten COL4A3-Mutation einen um 9,6 \% niedrigeren Cholesterinwert im Serum. Für die Genotypen COL4A3 ${ }^{+/-}$ $\mathrm{NPHS}^{+/ \mathrm{R} 140 \mathrm{Q}}(-3 \%)$ und COL4A3 $3^{+/+} \mathrm{NPHS}^{+/ \mathrm{R} 140 \mathrm{Q}}(-1,2 \%)$ ist dieser Unterschied geringer.

Werden die Genotypen der einzelnen Behandlungsgruppen miteinander verglichen, so zeigt beim Wildtyp die „Salz“-Gruppe (Mittelwert 111,75 mg/dl mit einer SD \pm 13,7 $\mathrm{mg} / \mathrm{dl}$ ) einen signifikant höheren Cholesteringehalt im Serum als die „Sham“-Gruppe (Mittelwert 98,5 mg/dl mit einer SD $\pm 10,36 \mathrm{mg} / \mathrm{dl}$ ). Gleiche Signifikanzen haben auch 
COL4A3-mutierte Mäuse („Salz“: Mittelwert 107,5 mg/dl mit einer SD \pm 10,47 mg/dl; „Sham“: Mittelwert $89 \mathrm{mg} / \mathrm{dl}$ mit einer SD \pm 4,39 mg/dl). Die übrigen Genotypen zeigen keine signifikanten Unterschiede untereinander.

Die „Sham“-Gruppe weist immer die geringsten, die „Salz“-Gruppe immer die höchsten Serumcholesterinwerte innerhalb eines Genotyps auf.

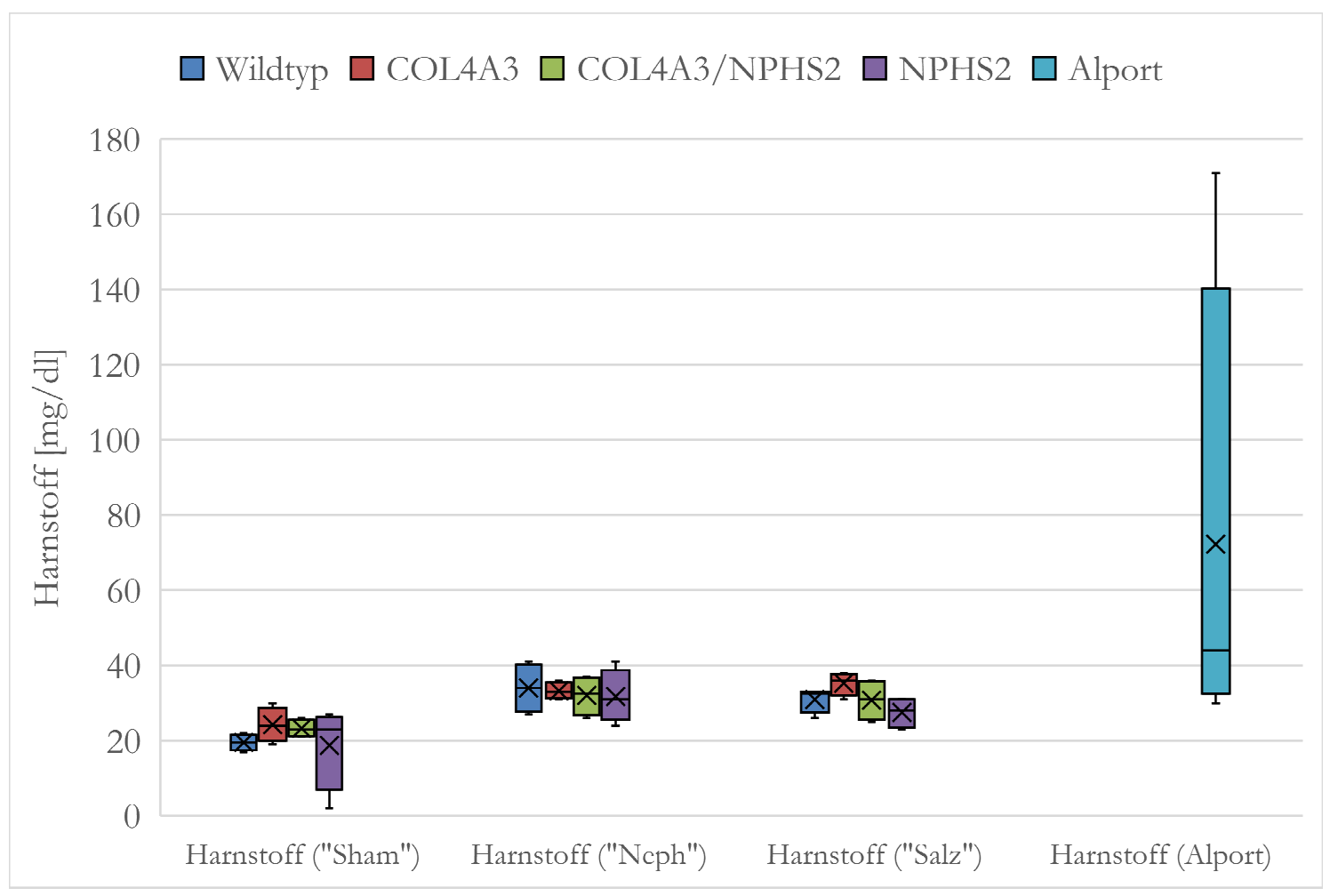

Abbildung 20 - Blutserumanalyse für Harnstoff $\mathbf{N}$. Wildtyp $=$ COL4A3 ${ }^{+/+}$NPHS2 $2^{+/+}-$Tiere; COL4A3 $=$ COL4A $3^{+/-} \mathrm{NPHS}^{+/+}-$Tiere $;$COL4A3 $/ \mathrm{NPHS}_{2}=\mathrm{COL}_{4} 3^{+/-} \mathrm{NPHS}^{+/ \mathrm{R} 140 \mathrm{Q}-\text { Tiere }}$ NPHS2 $=$

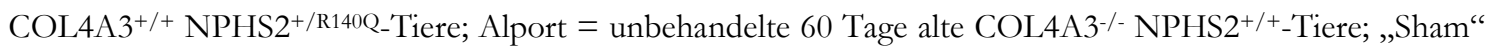
= OP ohne Uninephrektomie; „Neph“ = OP mit Uninephrektomie; „Salz“ = OP mit Uninephrektomie + $0,9 \%$ iger NaCl-Trinkwassergabe. Kreuz zeigt Mittelwert.

Für die Harnstoff N-Analyse ergeben sich signifikante Unterschiede im Vergleich zur Alport-Vergleichsgruppe. Hier erweist sich die Behandlungsgruppe „Sham“ jeweils im Kruskal-Wallis-Test als signifikant unterschiedlich zur Alport-Gruppe. Dieser Unterschied ist vorhanden bei Wildtyp-Tieren (Mittelwert 19,05 mg/dl mit einer SD $\pm 2,08 \mathrm{mg} / \mathrm{dl}$ ), COL4A3 mutierten Tieren $(24,25 \mathrm{mg} / \mathrm{dl}$ mit einer SD \pm 4,57 mg/dl), COL4A3/NPHS2Tieren (Mittelwert 23,25 mg/dl mit einer SD \pm 2,21), sowie NPHS2-Tieren (Mittelwert $24,33 \mathrm{mg} / \mathrm{dl}$ mit einer SD \pm 2,51 mg/dl) im Vergleich zu Alport-Tieren (Mittelwert 72,25 $\mathrm{mg} / \mathrm{dl}$ mit einer SD $\pm 66,24 \mathrm{mg} / \mathrm{dl})$.

Im Vergleich der einzelnen Genotypen innerhalb der verschiedenen Behandlungsgruppen ohne Beachtung der Alport-Vergleichsgruppe zeigt der Wildtyp „Sham“ (Mittelwert 19,5 $\mathrm{mg} / \mathrm{dl}$ mit einer SD $\pm 2,08 \mathrm{mg} / \mathrm{dl}$ ) im Kruskal-Wallis-Test signifikant geringere Harnstoff N-Konzentrationen als der Wildtyp „Neph“ (Mittelwert $34 \mathrm{mg} / \mathrm{dl}$ mit einer SD \pm 6,58 
mg/dl). Für COL4A3-Mäuse zeigen sich für die Gruppen „Neph“ (Mittelwert 33,25 mg/dl mit einer SD $\pm 2,21 \mathrm{mg} / \mathrm{dl}$ ) und „Salz“ (Mittelwert 35,25 mg/dl mit einer SD \pm 3,09 $\mathrm{mg} / \mathrm{dl}$ ) im Kruskal-Wallis-Test signifikant höhere Werte als für die Gruppe „Sham“ (Mittelwert 24,25 mg/dl mit einer SD \pm 4,57 mg/dl). Für die beiden übrigen Genotypen gibt es keine signifikanten Unterschiede.

Es fällt auf, dass Mäuse in den Behandlungsgruppen „Neph“ und „Salz“ stets höhere Mittelwerte aufweisen als ihr Genotyp in der Behandlungsgruppe "Sham“. Lediglich bei COL4A3/NPHS2-mutierten Mäusen hat die Behandlungsgruppe „Salz“ höhere Harnstoff $\mathrm{N}$-Werte im Vergleich zur Behandlungsgruppe „Neph“.

\subsection{Analyse des Körpergewichts der Mäuse}

Das Gewicht der Mäuse wurde nach geschlechterspezifischer und geno- bzw. behandlungstypspezifischer Zuordnung analysiert. Ein Vergleich mit Alport-Tieren erfolgte nicht.

Die Gewichtsveränderungen wurden in Prozent berechnet und für folgende Zeiträume bestimmt und analysiert:

Der erste Zeitraum erstreckt sich vom 60. Lebenstag bis zum Tag der OP. Nachfolgend wurde als zweiter Zeitraum die Postoperationsphase gewählt (OP-Tag - 14 Tage post OP). Der dritte Zeitraum wurde vom 14. bis zum 42. postoperativen Tag (Ende des Versuches) gewählt. Als vierter und letzter Zeitraum wurden die Gewichtsveränderungen vom Tag der OP bis zum Tag des Versuchsendes (42. postoperativer Tag) bestimmt. 


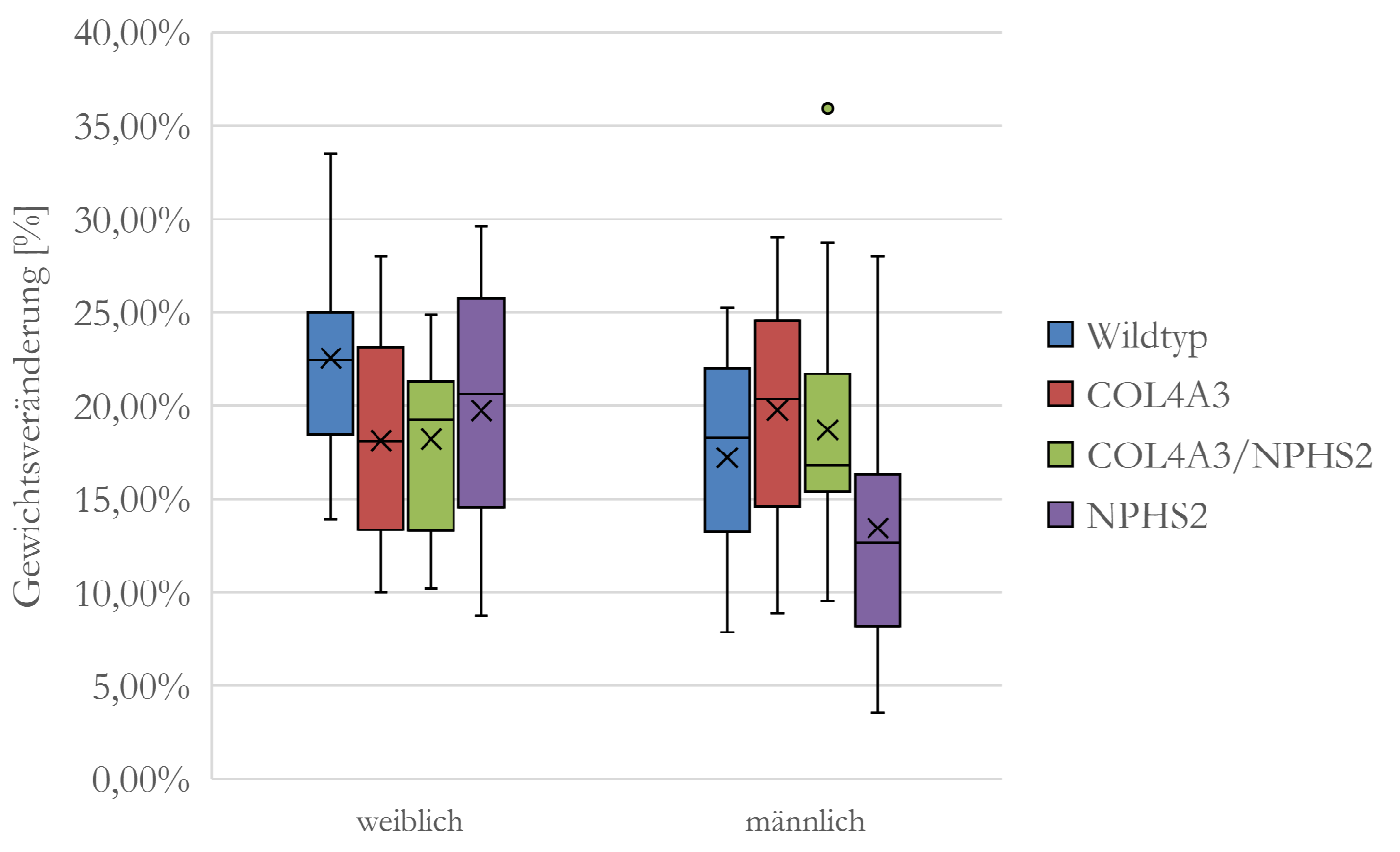

Abbildung 21 - Gewichtsveränderung: 60. Lebenstag bis zur OP. Wildtyp $=$ COL4A3 $3^{+/+}$ NPHS2 $2^{+/+}$-Tiere; COL4A3 $=$COL4A3 $3^{+/}$NPHS2 ${ }^{+/+}{ }_{-}$Tiere; COL4A3 $/ \mathrm{NPHS}=\mathrm{COL}_{4 \mathrm{~A}} 3^{+/}$ $\mathrm{NPHS}^{+/ \mathrm{R} 140 \mathrm{Q}-T i e r e}$ NPHS $=$ COL4A3 ${ }^{+/+}$NPHS2 ${ }^{+/ \mathrm{R} 140 \mathrm{Q}-T i e r e ;}$ Punkt zeigt nicht signifikanten Ausreißer; Kreuz zeigt Mittelwert.

Es ergeben sich keine signifikanten Unterschiede über den präoperativen Zeitraum mit regelhaften Gewichtszunahmen zwischen $15 \%$ und $25 \%$ vom 60 . bis zum 120. Lebenstag. 


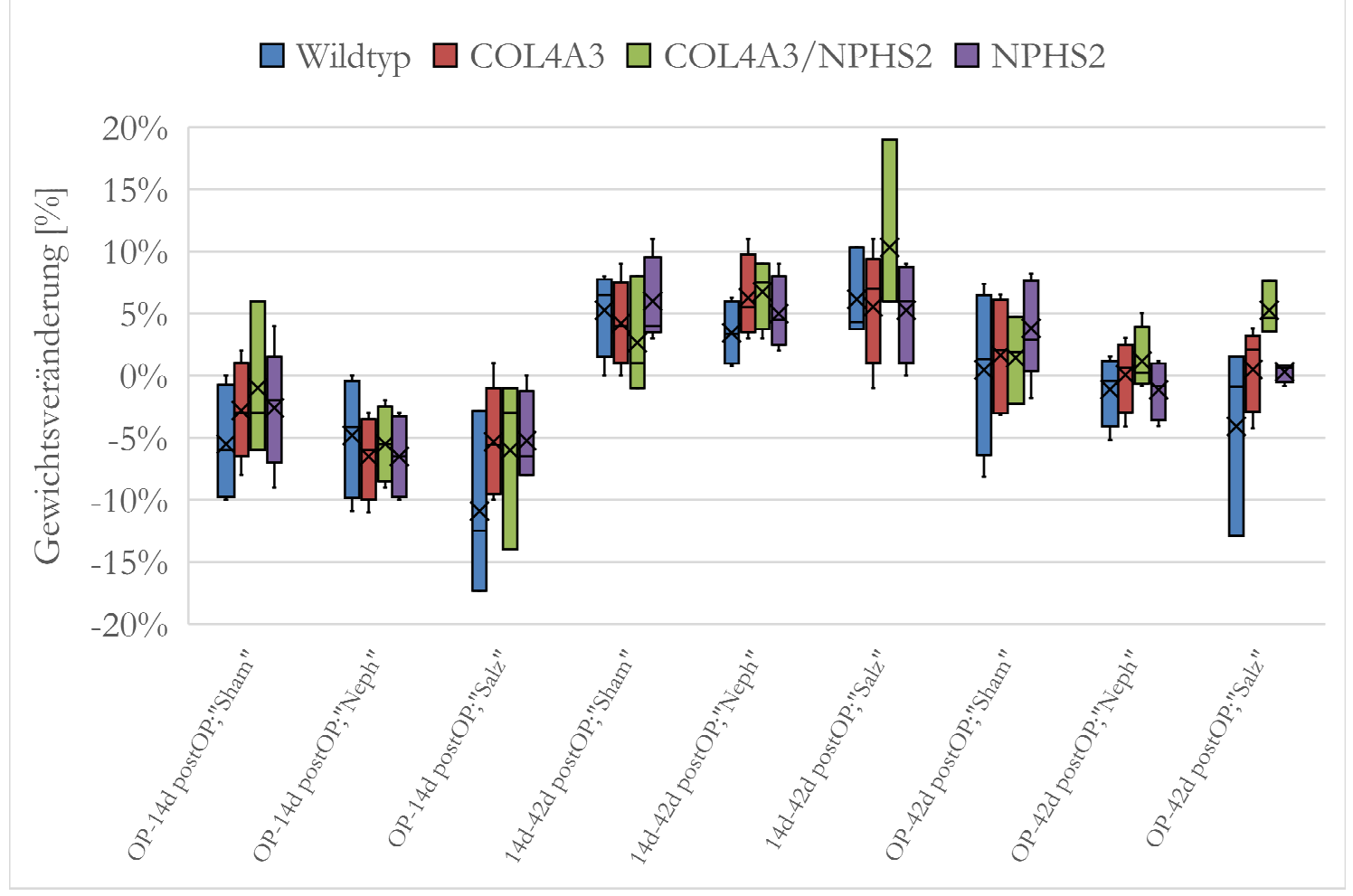

Abbildung 22 - Gewichtsveränderung: ab OP für weibliche Tiere. Wildtyp $=$ COL4A3 $3^{+/+}$ $\mathrm{NPHS}^{+/+}{ }^{+}$Tiere; $\mathrm{COL} 4 \mathrm{~A} 3=\mathrm{COL}_{4} \mathrm{~A}^{+/}{ }^{+} \mathrm{NPHS}^{+/+}{ }_{-}$Tiere; $\mathrm{COL} 4 \mathrm{~A} 3 / \mathrm{NPHS} 2=\mathrm{COL}_{4} 3^{+/-}$

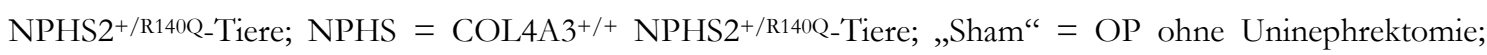
„Neph" = OP mit Uninephrektomie; „Salz“ = OP mit Uninephrektomie + 0,9\%iger NaCl-Trinkwassergabe. Punkt zeigt nicht signifikanten Ausreißer; Kreuz zeigt Mittelwert.

Weibliche Tiere weisen in den ersten 14 postoperativen Tagen nach der OP unabhängig von Behandlungsgruppe oder Genotyp einen Gewichtsverlust auf. In der Phase von 14 bis 42 Tage nach der OP ist bei allen Behandlungsgruppen und Genotypen eine Gewichtszunahme zu sehen. Auffällig erscheint hier die Behandlungsgruppe „Salz“, welche etwas höhere Mittelwerte als die Vergleichsgruppen aufweist. Besonders deutlich wird dies beim Genotypen COL4A3/NPHS2. Im gesamten postoperativen Verlauf kann nur bei COL4A3/NPHS2-mutierten Tieren unter 0,9\%iger Salzgabe über das Trinkwasser eine hohe, allerdings nicht signifikante Gewichtszunahme im Vergleich zu den anderen Behandlungsgruppen nachgewiesen werden.

Ein Nachweis von signifikanten Unterschieden gelingt nicht. 


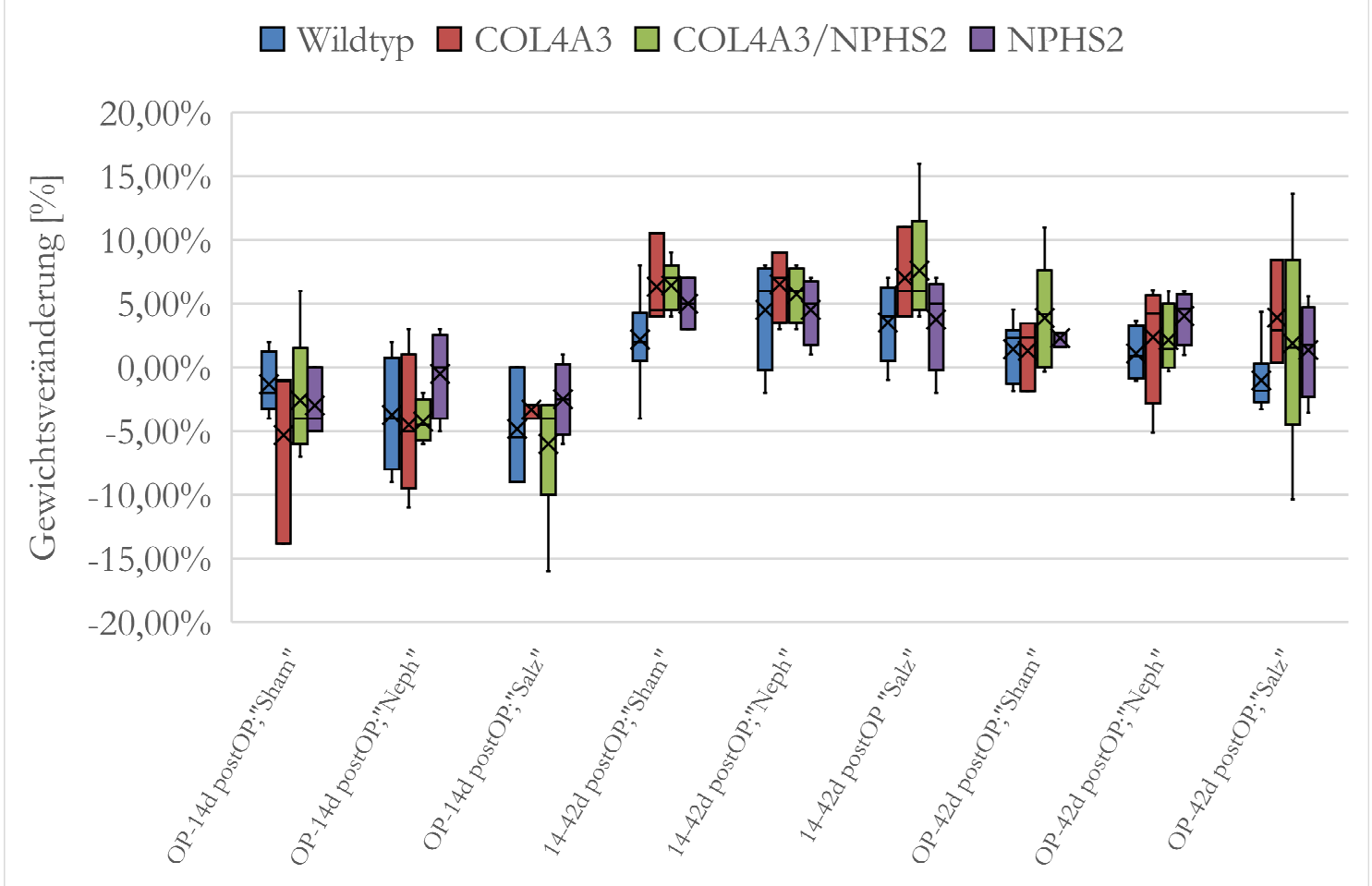

Abbildung 23 - Gewichtsveränderung: ab OP für männliche Tiere. Wildtyp = $\mathrm{COL}_{4} \mathrm{A3}^{+/+} \mathrm{NPHS}^{+/+}-$Tiere; $\mathrm{COL} 4 \mathrm{~A} 3=\mathrm{COL}_{4} \mathrm{~A}^{+/-} \mathrm{NPHS}^{+/+}-$Tiere $;$COL4A3 $/ \mathrm{NPHS} 2=\mathrm{COL}_{4} \mathrm{~A}^{+/-}$

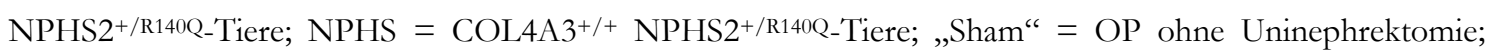
„Neph" = OP mit Uninephrektomie; „Salz" = OP mit Uninephrektomie + 0,9\%iger NaCl-Trinkwassergabe. Punkt zeigt nicht signifikanten Ausreißer; Kreuz zeigt Mittelwert.

Für männliche Mäuse sind ähnliche Gewichtsentwicklungen wie bei weiblichen zu erkennen. Auch hier weist der Genotyp COL4A3/NPHS2 unter Gabe von 0,9\%igem NaClTrinkwasser höhere prozentuale Gewichtszunahmen im Vergleich zu anderen Genotypen und Behandlungsgruppen auf. Ähnlich, wenn auch schwächer, kann dies für den Genotyp COL4A3 beobachtet werden.

Identisch mit den weiblichen Mäusen ergeben sich auch bei den männlichen Tieren keine signifikanten Unterschiede.

\subsection{Intraklassenkorrelationskoeffizient}

Mit Hilfe des Intraklassenkorrelationskoeffizienten wird die Güte des Scores für Fibronectin- und Lamininfärbungen ermittelt. Hierfür wurden alle Bilder eines jeden Scorers betrachtet. Es erfolgte also keine Mittelwertanalyse. Die Rater wurden nicht zufällig ausgewählt. Es handelt sich bei allen Scorern um Ärzte der Klinik für Nephrologie und Rheumatologie an der Universitätsmedizin Göttingen. 
Tabelle 10 - Intraklassenkorrelationskoeffizient.

\begin{tabular}{|l|l|l|l|}
\hline \multirow{2}{*}{ Parameter } & \multirow{2}{*}{$\begin{array}{c}\text { Korrelation inner- } \\
\text { halb der Klasse }\end{array}$} & \multicolumn{1}{c|}{ U5\% Konfidenzintervall } \\
\cline { 3 - 4 } & & 0,251 & \multicolumn{1}{c|}{ Obergrenze } \\
\hline Fibronectin 10x & 0,696 & 0,772 & 0,85 \\
\hline Fibronectin 40x & 0,899 & 0,546 & 0,946 \\
\hline Laminin 10x & 0,693 & 0,482 & 0,788 \\
\hline Laminin 40x & 0,601 & & 0,697 \\
\hline
\end{tabular}

Fibronectin 10x = Fibronectinfärbung, Bilder mit 10-facher Vergrößerung; Fibronectin 40x = Fibronectinfärbung, Bilder mit 40-facher Vergrößerung; Laminin 10x = Lamininfärbung, Bilder mit 10-facher Vergrößerung; Laminin 40x = Lamininfärbung, Bilder mit 40-facher Vergrößerung 


\section{Diskussion}

Ziel der Arbeit war es, im Mausmodell einen negativen Einfluss von salzreicher Ernährung nach einer simulierten Nierenspende bei vorgeschädigter GBM und Parameter, die den fortschreitenden Schaden der GBM anzeigen, zu untersuchen. Hierfür wurden verschiedene Parameter, nämlich die Proteinurie, die Lichtmikroskopie, die Blutserumanalyse sowie das Körpergewicht der Mäuse ausgewählt. Die hierzu in Abschnitt 3 aufgeführten Messergebnisse werden nun kritisch besprochen und in einen Zusammenhang gestellt.

Der hier durchgeführte Versuch ist bisher noch nicht in der Literatur beschrieben worden. Dennoch korrespondieren grundsätzliche Forschungsergebnisse mit den Versuchsergebnissen.

Daten von Spendern nach Nierentransplantation werden zwar erhoben, allerdings finden sich für diese Daten sehr wenige Publikationen. Eine der hierzu aktuellsten Publikationen sieht ein gutes Outcome für Spender (Delanaye et al. 2012).

Das hier verwendete Mausmodell gilt als ein anerkanntes Modell für das Alport-Syndrom (Cosgrove et al. 1996) und für NPHS2-Mutationen (Roselli et al. 2004). Ein Studiendesign wie in diesem Fall wurde bisher noch nicht mit diesem Mausstamm durchgeführt. Trotzdem ist anzunehmen, dass dieses Mausmodell auch ein valides Modell für diesen Versuch darstellt.

\subsection{Grundlegende Überlegungen für die Analyse}

Anhand der Proteinanalyse lassen sich Schäden innerhalb der Niere durch eine Größenzuordnung lokalisieren. Aus diesem Grund spielt die Proteinanalyse in dieser Arbeit eine besondere Rolle. Deren Ergebnisse sollten in Einklang mit den anderen untersuchten Parametern zu bringen sein.

Es wurden Urinproben von vier Alport-Mäusen (weibliche 60 Tage alte COL4A3 ${ }^{-/}$ NPHS2 ${ }^{+/+}$-Tiere) mit Proben von jeweils mindestens drei Mäusen pro Geschlecht und Genotyp $\left(\mathrm{COL}_{4} \mathrm{A3}^{+/+} \mathrm{NPHS}^{+/+}{ }_{-}\right.$; $\mathrm{COL}_{4} 3^{+/-} \mathrm{NPHS}^{+/+}{ }_{-}$; $\mathrm{COL}_{4} 3^{+/-} \mathrm{NPHS}^{+/ \mathrm{R}^{+402}}{ }_{-}$; $\mathrm{COL}_{4} \mathrm{A3}^{+/+} \mathrm{NPHS}^{+/ \mathrm{R} 140 \mathrm{Q}}$ - Tiere) sowie Behandlungsgruppe („Sham“, „Neph“ und „Salz“) analysiert. Die Gesamtzahl der untersuchten Proben stellt eine zu beachtene Limitation der Arbeit dar.

Beim Wildtyp (COL4A3 ${ }^{+/+}$NPHS2 $^{+/+}$) handelt es sich um Mäuse, die einen nierengesunden Patienten simulieren. Somit kann der Wildtyp-Wert als Normalwert angesehen werden. Nur jede nach oben abweichende Veränderung würde auf einen möglichen Einfluss des Genotyps auf die Parameter hinweisen. Im späteren Verlauf der Diskussion sind die Werte 
der Behandlungsgruppe „Sham“-Wildtyp (nach der OP) als normal anzunehmende Werte zu interpretieren.

Auffällig sind die allgemein höheren Proteinuriewerte für männliche im Vergleich zu den weiblichen Tieren. Eine mögliche Erklärung hierfür ist die Verunreinigung der Proben durch Ejakulat, welches bei der Aufbereitung der Proben nicht vollständig beseitigt werden konnte. Weiter ist über einen allgemeinen Unterschied zwischen männlichen und weiblichen Organismen im Sinne der Gendermedizin zu diskutieren.

Zunächst einige grundsätzliche Überlegungen: Bei einem fortschreitenden Nierenschaden kann von einer zunehmenden Proteinurie ausgegangen werden und eine Albuminurie als ein Marker für Nierenerkrankungen angesehen werden (Birn und Christensen 2006). Dementsprechend kann ein erhöhter Proteinuriewert im Vergleich zum Wildtyp für eine Nierenschädigung sprechen. Im Sinne eines progressiven Nierenversagens sollten sich die Werte auch an weiteren Messpunkten als erhöht zeigen. Dies wird dadurch bestätigt, dass beim Voranschreiten von Nierenerkrankungen unter anderem proinflammatorische Prozesse, die durch Albumin ausgelöst werden, eine große Rolle spielen (Birn und Christensen 2006). Nach Tryggvason und Pettersson (2003) spricht das Vorkommen von größeren Proteinen als Albumin im Urin für eine Schädigung der Blut-Harn-Schranke im Glomerulum. Ein primäres Versagen der tubulären Rückresorption würde eine relativ isolierte Albuminurie hervorrufen (Birn und Christensen 2006). Wenn davon ausgegangen wird, dass es sich bei einer Proteinurie beziehungsweise Albuminurie um eine Art „Teufelskreislauf“ handelt, weil erhöhtes Albumin im Primärharn die Niere weiter schädigt und somit steigt das Albumin im Primärharn an (Birn und Christensen 2006), müsste es zu einer stetigen Zunahme der Proteinurie im Verlauf kommen. Weiterhin wurde eine Proteinurie als ein Risikofaktor für die Entstehung einer Fibrose und Glomerulosklerose beschrieben (Remuzzi und Bertani 1998).

Im Rahmen einer chronischen Niereninsuffizienz beziehungsweise eines terminalen Nierenversagens kann es zu einer Wasserüberlagerung mit u.a. peripheren Ödemen kommen (Ellison 2017). Detektierbar ist diese Wasserüberlagerung u.a. durch eine Gewichtszunahme. Daher wurde bei den Mäusen in regelmäßigem Abstand das Gewicht ermittelt. Sollte es zu einem fortschreitenden Nierenversagen kommen, so kann davon ausgegangen werden, dass es zur Ödembildung und somit zur Gewichtszunahme kommt.

Im Rahmen der Lichtmikroskopie wurde versucht, mögliche Messergebnisse einem Korrelat in der Histologie zuzuführen.

Eine andere Arbeitsgruppe konnte zeigen, dass Alport-Mäuse unter erhöhter Salzzufuhr signifikant einen größeren glomerulären Schaden zeigen als Alport-Mäuse ohne eine solche Salzgabe (Meehan et al. 2009). Zu beachten ist hier, dass lediglich die unbehandelte AlportVergleichsgruppe exakt auf diese Ergebnisse zu übertragen ist. Somit kann bei den in diesem Versuch nur heterozygot mutierten Mäusen mit einem verminderten Auftreten der oben beschriebenen Ergebnisse im Vergleich zu den homozygot mutierten Alport-Mäusen 
gerechnet werden. Weiterhin konnte gezeigt werden, dass eine vorgeschädigte Niere auf eine erhöhte Salzzufuhr mit strukturellen Umbauprozessen reagiert (Hamming et al. 2006). In dem hier durchgeführten Versuch wurden die Mäuse nur über einen relativ kurzen Zeitraum von 35 Tagen einer $0,9 \%$ igen $\mathrm{NaCl}$-Trinkwasserexposition ausgesetzt. Allgemein liegt der postoperative Beobachtungszeitraum bei 42 Tagen. So konnten relevante sklerotische Veränderungen nach ähnlicher Salzexposition wie in diesem Versuch bei Mäusen des gleichen Stammes bei $50 \%$ der Tiere nach neun Wochen einer Salzexposition nachgewiesen werden (Smeets et al. 2011). Dies spricht dafür, dass durchaus relevante Veränderungen in einem längeren postoperativen Beobachtungszeitraum möglich sind. Unterstützt wird dies durch bisherige Ergebnisse von Meehan et al. (2009). Diese Arbeitsgruppe stellte dar, dass die Salzgabe bei Mäusen und der daraus mitverursachte erhöhte systolische Blutdruck mit einer erhöhten Albuminurie korrelieren. Diese Ergebnisse konnten nach vier Wochen der Salzgabe gezeigt werden. Smeets et al. (2011) konnten belegen, dass bereits ab 0,5\% $\mathrm{NaCl}$ im Trinkwasser über drei Wochen Veränderungen in der Niere an Mäusen des gleichen Stammes wie in dieser Arbeit zu sehen sind. Folglich dürften bereits in diesem Beobachtungszeitraum auch in dem hier beschriebenen Versuch Unterschiede zwischen den einzelnen Behandlungsgruppen zu erkennen sein.

Nach einer Uninephrektomie ist mit folgenden Veränderungen zu rechnen: Wie von Srivastava et al. (2018) beschrieben, führt der Verlust einer Niere zu einer Hyperfiltration der in situ verbleibenden Niere. Hierdurch kann beim Menschen ein Nierenschaden induziert werden, der je nach genetischer Veranlagung innerhalb von 15 bis 30 Jahren zu einem terminalen Nierenversagen führen kann. Bei Ratten konnte eine Erhöhung der GFR innerhalb von fünf Tagen postoperativ gezeigt werden (Celsi et al. 1989). Ein ähnlicher Mechanismus ist auch bei Mäusen und möglichen Spendern zu erwarten. Daher sollten 12 und 42 Tage postoperativ (Lebenstag 150 und 180) bereits Veränderungen in der Proteinurie bei den Mäusen in diesem Versuch sichtbar sein.

Eine erhöhte Salzzufuhr ist mit erhöhten Cholesterinwerten assoziiert (Slagman et al. 2011). Bis diese allerdings zur Geltung kommen, können Wochen vergehen. Eine kurzfristig erhöhte Salzgabe zeigt keine oder nur geringe Auswirkungen auf den Cholesterinspiegel. Somit sollten in der Analyse hier nur geringe Veränderungen zu erwarten sein. Es ist allerdings zu beachten, dass ein erhöhter Cholesterinspiegel vor einer möglichen Spende mit einer schlechteren Transplantatfunktion korreliert (Issa et al. 2007). Es konnte außerdem gezeigt werden, dass erhöhte Cholesterinwerte mit einem zunehmenden Nierenschaden assoziiert sind (Joles et al. 2000). Umgekehrt stellt aber auch ein Nierenschaden ein erhöhtes Risiko für erhöhte Cholesterinwerte dar (Sharma et al. 2018).

Bei der Harnstoff-N Analyse überschreiten Mäuse dieses Stammes im Gesunden nicht die Konzentration von $25 \mathrm{mg} / \mathrm{dl}$ (Beirowski et al. 2006). Die schädliche Wirkung von Harnstoff auf die Niere mit u.a. mehr freien Radikalen, mehr Apoptose und Produktion von Stoffen, die ihrerseits für biologische Veränderungen sorgen, wird von Vanholder et al. 
(2018) dargestellt. Weiterhin beschrieben Vanholder et al. die Bedeutung von Harnstoff als Urämiemarker bei chronisch Nierenerkrankungen. Somit wäre bei fortschreitender Nierenschädigung durchaus mit einer Erhöhung des Harnstoffes im Serum zu rechnen.

Als weiterer Punkt für eine kritische Auseinandersetzung mit den Versuchsergebnissen ist die postoperative Applikation von Analgetika zu sehen. Trotz der gelegentlichen Assoziation zum akuten Nierenversagen wird Metamizol als ein sicheres Medikament zur kurzfristigen Analgesie angesehen (Hassan et al. 2011; Stueber et al. 2017). Buprenorphin wird nur in geringem Maße renal eliminiert und scheint nach Studien allenfalls nur sehr geringe Auswirkungen bei Kurzzeitanwendungen auf die Niere zu haben (Bellini et al. 2016; Elkader und Sproule 2005). Somit lassen sich einige Ausreißer mit der in diesem Experiment durchgeführten Analgesie erklären. Allgemein sollte die Analgesie allerdings keine Auswirkungen auf die Ergebnisse haben, zumal die Datenlage in Mausexperimenten eher schwach ist.

Kurzfristige Veränderungen der Nierenleistung können ihre mögliche Erklärung hierin finden: Von Zebrafischen ist bekannt, dass tubuläre Epithelzellen in der Lage sind, sich nach einer akuten Nierenschädigung zu regenerieren (Sander und Davidson 2014). Auch in menschlichen Organismus wird eine Regeneration von tubulären und glomerulären Zellen diskutiert (Meyer-Schwesinger 2016).

\section{2 Übertragbarkeit der tierexperimentellen Daten auf den Menschen}

Bei der Interpretation der in Abschnitt 3 dargestellten Ergebnisse ist zunächst zu sehen, dass die Veränderungen der Proteinurie häufig für beide Proteingrößen simultan sind. Dies spricht für eine glomeruläre Veränderung nach den Ergebnissen von Tryggvason und Pettersson (2003). Im Folgenden soll geschlechterspezifisch diskutiert werden, da verschiedene Autoren einen Geschlechterunterschied im Sinne eine stärkeren Progression bzw. eines allgemein höheren Risikos sowohl bei chronischem Nierenversagen (Ricardo et al. 2019) als auch bei akutem Nierenversagen (Neugarten et al. 2018) für das männliche Geschlecht nachgewiesen haben.

\subsubsection{Mäuse vor der OP}

Zunächst wurde untersucht, ob vor einer im Mausmodell simulierten Lebendnierenspende der Genotyp eine Auswirkung auf die Proteinurie hat und somit mögliche Spender deshalb von einer Spende ausgeschlossen werden sollten. Bisher wurden mögliche Spender mit einer heterozygoten Mutation in COL4A3 oder COL4A4 mit Symptomen wie einer Hypertension oder einer Proteinurie von einer Spende ausgeschlossen (Kashtan 2006). 
Bei Betrachtung der Proteinurie von männlichen und weiblichen Tieren weist kein Tier einen signifikant höheren Mittelwert im Vergleich zum Wildtyp (Normalwert) an den ersten drei Beobachtungsterminen auf. Es kommt zwar zu teilweise höheren Mittelwerten als beim Wildtyp, diese bestätigen sich allerdings nicht über den gesamten Zeitraum. Dementsprechend kann hieraus geschlussfolgert werden, dass der Genotyp vor einer Operation keinen Einfluss auf die Proteinurie hat. Aufgrund des relativ geringen Stichprobenumfangs sollten zur besseren Einordnung der Ausreißer und des singulär auftretenden signifikanten Unterschied bei männlichen Mäusen an Lebenstag 90 zwischen COL4A3- und NPHS2mutierten Mäusen weitere Untersuchungen mit größeren Stichprobenumfang erfolgen.

Im Vergleich der Proteinuriewerte zur Alport-Vergleichsgruppe (COL4A3 ${ }^{-/} \mathrm{NPHS}^{+/+}$) zeigen alle Mäuse bis auf einen männlichen Ausreißer an Lebenstag 120 des Genotypen COL4A3/NPHS2 deutlich niedrigere Proteinuriewerte. Dabei ist zu beachten, dass die Messwerte der Alport-Mäuse an Lebenstag 60 bestimmt wurden und die hier vorliegende Untersuchung Mäuse mit einem doppelt so hohen Alter einschließt. Dies unterstützt die Vermutung des fehlenden Einflusses auf die Proteinurie des Genotyps vor einer möglichen Spende.

Zur Gewichtsentwicklung vor der OP fallen keine signifikanten Unterschiede zwischen den Genotypen auf. Bei weiblichen Mäusen zeigt der Wildtyp prozentual die größte Zunahme an Gewicht. Somit kann bei allen anderen Genotypen nicht von einer Gewichtszunahme im Hinblick auf in 4.1 beschriebenen Mechanismus ausgegangen werden. Letztlich dürfte dies auch für männliche Tiere gelten. Zwar zeigen hier COL4A3-Mäuse die prozentual größte Gewichtszunahme, allerdings haben sie in der Regel die geringsten Proteinuriewerte. Daher ist eine Gewichtszunahme im Rahmen von Ödemen auf Grund einer Nierenschädigung eher auszuschließen. Wichtig ist, dass es sich bei dem Ausreißer für die Gewichtsentwicklung von Lebenstag 60 bis zur OP nicht um die gleiche Maus handelt, die bei den gleichen Genotypen auch einen Ausreißer bei der Proteinurie darstellt.

Somit kann im Hinblick auf die Arbeitshypothese zusammengefasst werden, dass es vor einer möglichen Spende keinen negativen Einfluss des Genotyps auf die Proteinurie gibt und ein möglicher Spender nicht auf Grund der hier untersuchten Parameter von der Spende auszuschließen ist.

\subsubsection{Mäuse nach der OP}

Bei den Proteinuriewerten nach der OP ist auffällig, dass die Werte größenunabhängig im Zeitraum von $120 \mathrm{zu} 150$ Lebenstagen häufig zunehmen und dann im Verlauf von $150 \mathrm{zu}$ 180 Lebenstagen wieder abnehmen. Beispielhaft kann hier die Proteinurie sowohl relativ als auch absolut für weibliche Wildtyp-Mäuse der Behandlungsgruppe „Sham“ für Proteine größer als Albumin genannt werden. Als ein möglicher Grund kann der postoperative Stress, der zu einer zeitweisen Niereninsuffizienz mit Proteinurie führen kann, gesehen werden (Edwards 2001; Koch 1998). 


\subsubsection{Betrachtung der Behandlungsgruppe „Sham“}

Bei Betrachtung der relativen Proteinuriewerte der weiblichen Tiere fällt für Proteine gleicher Größe wie Albumin auf, dass relativ zum 120-Tage-Ausgangswert der Wildtyp im Schnitt die größte Proteinuriezunahme aufweist. Werden zusätzlich die Proteinuriewerte für Proteine größer als Albumin berücksichtigt, fällt auf, dass hier der Genotyp NPHS2 eine deutliche Zunahme der Proteinurie erfährt. Dieser Unterschied ist in Bezug auf die relativen Werte als relevant anzusehen. Werden allerdings die absoluten Proteinuriewerte ergänzend hinzugezogen, ist zu erkennen, dass NPHS2-mutierte Mäuse an Lebenstag 180 die größte Spannweite der Proteinuriewerte aufweisen. Weitere Veränderungen im Vergleich zum Wildtyp sind so gering, dass sie als zu vernachlässigend anzusehen sind. Ergänzend hierzu zeigt auch die Gewichtsentwicklung postoperativ keine besonderen Ergebnisse. Ersichtlich ist aber, dass es häufig im Verlauf von 150 zu 180 Lebenstagen zu einer Zunahme der Proteinurie kommt. Dies kann mit einem normalen wechselhaften Verlauf in Einklang gebracht werden. Es könnte allerdings auch der Anfang einer progressiven Steigerung der Proteinurie im Rahmen einer Nierenschädigung sein. Zur Beantwortung dieser Frage könnte ein längerer postoperativer Beobachtungszeitraum aufschlussreiche Ergebnisse bringen.

Die initiale Abnahme der Proteinurie im Vergleich zum Ausgangswert am Lebenstag 120 spricht gegen eine akute Nierenschädigung durch u.a. in 4.1 diskutierte Analgesie. Diese Aussage ist nicht nur für weibliche „Sham“-Mäuse zu treffen, sondern betrifft beide Geschlechter und alle drei Behandlungsgruppen. Als mögliche Erklärung für individuelle Schwankungen und mögliche Anstiege der Proteinurie kann der Einfluss der Analgesie hiermit allerdings nicht vollständig entkräftet werden.

Für männliche Tiere fällt auf, dass COL4A3/NPHS2-Tiere als einziger Genotyp in der relativen Proteinanalyse eine deutliche Zunahme der Proteinurie aufweisen. Auch hier gibt es eine enorme Spannweite der Proteinwerte in der Betrachtung der absoluten Proteinurie mit einem vernachlässigbaren Unterschied bei den Mittelwerten im Vergleich zum Wildtyp. Bei Betrachtung der absoluten Proteinuriewerte ist zu erkennen, dass der Wildtyp in der Regel die höchsten Mittelwerte aufweist. Kleinere Ausnahmen hiervon sind in der Gesamtbetrachtung von untergeordneter Rolle und nur marginal.

Innerhalb der Behandlungsgruppe „Sham“ zeigen sich keine Signifikanzen oder Unterschiede in Bezug auf die Serumanalyse.

Bei der Gewichtsentwicklung ist zu sehen, dass es im Rahmen der OP zu einer Gewichtsabnahme kommt. Diese ist allerdings nach den Abbildungen 18 und 19 nicht signifikant unterschiedlich zu anderen Behandlungsgruppen. Somit lässt sich sagen, dass hier durch eine OP ohne Uninephrektomie der allgemeine Operationsstress gut simuliert werden konnte. 
Zusammenfassend scheint der Genotyp keine Auswirkungen auf einen hier simulierten Operationsstress zu haben.

\subsubsection{Betrachtung der Behandlungsgruppe „Neph“}

Bei der relativen Proteinurie der weiblichen Tiere fällt für den Wildtyp eine Abnahme auf. Allgemein zeigt sich in der relativen Analyse für Proteine größer als Albumin eine Abnahme der Proteinurie bei allen Genotypen. Somit kann nicht von einer höhergradigen Schädigung der GBM nach den Überlegungen in 4.1 ausgegangen werden. Eine stetige Zunahme der Proteinurie von Proteinen gleicher Größe wie Albumin zeigen nur COL4A3-mutierte Mäuse. Diese zeigen sich in ihrem Mittelwert allerdings stets geringer als die Proteinurie des Wildtypen. Dementsprechend ist nach den Vorüberlegungen aus 4.1 kein zunehmender Nierenschaden zu erwarten. Da es ebenfalls keine flächendeckende Erhöhung der Proteinuriewerte zwischen Lebenstag 120 und 150 gibt, ist auch der akute Nierenschaden nicht als genereller Grund von Proteinuriewerterhöhungen zu sehen.

Männliche Tiere haben zwar tendenziell eher einen Anstieg der relativen Proteinurie über alle Genotypen für Proteine gleicher Größe wie Albumin. Für Proteine größer als Albumin gibt es jedoch insbesondere zwischen Lebenstag 150 und 180 eine Abnahme der relativen Proteinurie. Bei Betrachtung der absoluten Proteinuriewerte zeigen sich große Spannweiten und mit Ausnahme von NPHS2 in der Regel niedrigere Mittelwerte als beim Wildtyp. Die Werte für NPHS2 weisen signifikant höhere Werte zur Behandlungsgruppe „Salz“ auf. Hier wäre eine Überprüfung der Werte im Verlauf von Interesse. Da allerdings über alle Genotypen hinweg höhere Mittelwerte bei der Behandlungsgruppe „Neph“ im Vergleich zur „Salz“-Gruppe zu sehen sind, ist dieser Unterschied im Sinne der hier gestellten Fragestellung von untergeordnetem Gewicht.

Wegen der zusätzlichen Parameter sind die Genotypen im Score konstant oder haben nur geringe Mittelwertverschiebungen. Die Blutserumwerte sind zwar nicht in gleichem Maße wie der Score konstant, allerdings weist hier der Wildtyp im Vergleich die höchsten Mittelwerte auf. Hierdurch lassen sich also keine histologischen Korrelate zu den Proteinuriewerten finden.

Auch die allgemeine Stoffwechsellage der Mäuse scheint in den einzelnen Genotypen wenig verändert. Unterstützt werden diese Ergebnisse, die allenfalls als geringfügige Veränderungen zu bezeichnen sind, durch die postoperative Gewichtsentwicklung. Zwar haben hier die Genotypen leicht erhöhte Werte im Vergleich zum Wildtypen. Diese Erhöhungen sind allerdings nicht signifikant untereinander und auch im Vergleich zur Behandlungsgruppe „Sham“ nicht deutlich erhöht.

Damit bleibt festzuhalten, dass der Genotyp nach Uninephrektomie im hier gewählten Simulationsmodell keinen Einfluss auf das Outcome hat. Somit sollte kein möglicher Spender mit einer der hier untersuchten Genmutationen von einer Spende ausgeschlossen werden. 


\subsubsection{Betrachtung der Behandlungsgruppe „Salz“}

Weibliche Tiere zeigen bei der relativen Proteinurie tendenziell über den gesamten Beobachtungszeitraum sinkende Mittelwerte. Somit scheint die Salzgabe hier keinen Einfluss zu haben. Der in Abschnitt 3 dargestellte signifikante Unterschied verliert an Bedeutung unter den tendenziell fallenden Mittelwerten für COL4A3-mutierte Mäuse. Die absolute Proteinurie weist konstante oder abnehmende Mittelwerte auf und unterstützt die Vermutung des fehlenden Einflusses von salzreichem Trinkwasser auf das Outcome der Mäuse.

Die relative Proteinurie für männliche Mäuse hat für den Wildtyp, COL4A3 und COL4A3/NPHS2 steigende Werte bei gleicher Proteingröße wie Albumin und für Wildtyp und COL4A3 bei Proteinen größer als Albumin. Die absolute Proteinurie hilft, diese Werte einzuordnen: Hier zeigt sich bei gleicher Proteingröße wie Albumin der Wildtyp mit den höchsten Mittelwerten. Für Proteine größer als Albumin ist eine sehr große Spannweite der Ergebnisse sowie ein höchster Mittelwert für den Wildtyp an den Lebenstagen 150 und 180 zu erkennen. Der signifikante Unterschied zwischen den Behandlungsgruppen „Neph“ und „Salz“ für NPHS2-mutierte Tiere ist unter der Einschätzung, dass das eigentlich schädlichere Salz (siehe Abschnitt 4.1) einen niedrigeren Wert als die isoliert uninephrektomierten Mäuse aufweisen, als eher nicht kausal zu beurteilen; zumal sich zwischen diesen beiden Gruppen die übrigen Mittelwerte annähern. Zur weiteren Entkräftung des signifikanten Unterschieds ist die Arbeit von Philippe et al. (2008) zu sehen, welche eine fehlende Phänotypentwicklung beim heterozygoten Vorliegen einer NPHS2-Mutation beschrieben.

Unterstützt wird die oben genannte Vermutung des fehlenden negativen Einflusses von Salz auf das Outcome durch den Score. Dieser zeigt tendenziell besser bewertete histologische Bilder als die „Neph“-Behandlungsgruppe. Dass aber ein negativer Einfluss des Salzes nicht auszuschließen ist, zeigen die Cholesterinwerte. Hier zeigen Mäuse unter Salzsubstitution durchgängig höhere Konzentrationen als ihre direkte Vergleichsgruppe „Neph“ oder „Sham“. Für den Harnstoff sind die Werte der Genotypen sehr ähnlich und Unterschiede im Vergleich zur „Neph“ Gruppe sind nicht zu sehen. Die Gewichtsanalyse gibt zwar keine signifikanten Ergebnisse, allerdings ist ersichtlich, dass prozentual die Gruppe COL4A3/NPHS2 deutlich mehr an Gewicht zunimmt als die Vergleichsgruppen. Diese Gruppe hat auch bei der Cholesterinanalyse die größte Spannweite (mehr als doppelt so groß wie der Wildtyp). Somit können hier erste Veränderungen im Stoffwechsel vermutet werden, die eventuell auch mit einer Zunahme des Gewichts in Verbindung zu bringen sind.

Letztlich zeigen sich jedoch bis auf die Gewichtsentwicklung für COL4A3/NPHS2 und Serumgehalt für Cholesterin keine großen Unterschiede innerhalb der Behandlungsgruppe „Salz“ und im Vergleich zur Behandlungsgruppe „Neph“. Dennoch können die Veränderungen als erste Reaktionen auf eine erhöhte Salzgabe gesehen werden. Diese Vermutung muss allerdings in längeren postoperativen Beobachtungszeiträumen bestätigt werden. Sollte tatsächlich das Vorliegen einer NPHS2-Mutation wie in 4.1 beschrieben ein Risiko- 
faktor für schnellere Veränderungen der Niere sein, so sind diese Veränderungen als erste Zeichen der Belastung durchaus interpretierbar. Weitere Untersuchungen sollten allerdings folgen, bei denen sowohl der Beobachtungszeitraum als auch die Stichprobengröße erhöht werden sollte. Weiterhin sollte über eine stärkere Reizung im Sinne einer erhöhten Salzzufuhr über $0,9 \%$ iges $\mathrm{NaCl}$-Trinkwasser nachgedacht werden.

\subsubsection{Vergleich mit Alport-Kontrollgruppe}

Es fallen regelmäßig erhöhte Mittelwerte für Alport-Mäuse (COL4A3 ${ }^{--} \mathrm{NPHS}^{+/+}$) auf. Diese zeigen sich wie in Abschnitt 3 dieser Arbeit dargestellt in der Regel auch als signifikant höher als in den Vergleichsgruppen. Zu beachten ist, dass die Alport-Tiere zum Messzeitpunkt keiner Therapie unterzogen wurden und auch nur ein Drittel des Lebensalters der Vergleichsmäuse aus diesem Versuch aufweisen (60 zu 180 Lebenstage). Dementsprechend kann davon ausgegangen werden, dass bei einem Vergleich von gleichaltrigen Mäusen mit den hier untersuchten Behandlungsgruppen eine noch höhere Differenz auftreten würde. Somit zeigt sich umso mehr, dass eine Organspende für den Spender eine relativ risikoarme Therapieoption handelt.

Es ist bemerkenswert, dass selbst unter der vermeintlich nierenschädigenden Zufuhr (siehe Abschnitt 4.1) von 0,9\% NaCl-Trinkwasser und der Hyperperfusion nach Uninephrektomie keine so hohen Proteinuriewerte erreicht werden konnten wie bei der AlportVergleichsgruppe. Sogar männliche Tiere, die in diesem Versuch eine im Schnitt höhere Proteinurie als ihre weiblichen Vergleichstiere aufweisen konnten und wie in Abschnitt 4.2 gezeigt ein höheres Risiko für Nierenerkrankungen zeigen, haben nicht so hohe Proteinuriewerte wie die weiblichen Alport-Mäuse. Somit kann selbst bei einem erhöhten Salzkonsum nicht grundsätzlich von einer Nierenspende abgeraten werden. Dieses Ergebnis ist unter der Voraussetzung zu verstehen, dass in diesem Versuch nur 42 Tage postoperativ (davon 35 Tage unter erhöhter Salzexposition) beobachtet wurde.

Die teilweise fehlende Signifikanz im Vergleich zur Alport-Gruppe zeigt, dass nicht pauschal vom Genotyp und der Behandlung auf ein besseres oder schlechteres Outcome geschlossen werden kann. So zeigt sich beispielsweise für weibliche „Neph“-Mäuse bei Proteinen gleicher Größe wie Albumin kein signifikanter Unterschied zwischen Wildtyp $\left(\mathrm{COL}_{4} \mathrm{~A}^{+/+} \mathrm{NPHS}^{+/+}\right)$und Alport $\left(\mathrm{COL} 4 \mathrm{A3}^{-/-} \mathrm{NPHS}^{+/+}\right)$. Männliche Tiere des gleichen Genotyps zeigen hier allerdings einen signifikanten Unterschied. Somit wird die aus den anderen Bestandteilen der Diskussion bereits geschlossene Vermutung bestärkt, dass neben dem Genotyp noch weitere individuelle Faktoren auf das Outcome einen Einfluss haben (Voskarides et al. 2012). Weiterhin wird die geschlechterspezifische Betrachtung als sinnvolle Unterscheidung bestätigt.

Auch die sonstigen untersuchten Parameter sind häufig signifikant unterschiedlich zur Alport-Vergleichsgruppe. Somit ist ersichtlich, dass die Mäuse trotz Uninephrektomie und 
teilweiser Salzexposition nicht soweit geschädigt werden können, wie dies beim AlportSyndrom der Fall ist.

\subsubsection{Zusammenführung der Behandlungsgruppen}

Es kann auf Grund einer Zugehörigkeit zu einem Genotyp oder zu einer Behandlungsgruppe keine Prognose über den Verlauf der Proteinurie getroffen werden. Dies bestätigt die Vermutung aus 4.2.2.4, dass es weitere Einflussfaktoren auf das Outcome nach einer möglichen Spende geben muss.

In der Scoreanalyse fallen regelhaft Signifikanzen der Alport-Vergleichsgruppe zur Behandlungsgruppe „Salz“ auf. Die Behandlungsgruppe „Salz“wurde im Schnitt auch als gesünder oder gleich schlecht wie die Behandlungsgruppe „Neph“ gescoret. In Zusammenschau mit der Gewichtsanalyse nach der OP ist auffällig, dass es allenfalls zu größeren Schwankungen und Zunahmen des Gewichts für Mäuse unter salzreicher Ernährung kommt. Dies zeigt sich zwar für keine Gruppe als regelhaft, allerdings kann es, wie in 4.1 diskutiert, durch eine Gewichtszunahme zu Ödemen kommen. Da in dem Score Antigene mit Antikörpern angefärbt werden, kann es bei mehr Ödemen auch zu einem geringeren Vorhandensein von anzufärbenden Antikörpern kommen. Als weiterer möglicher Grund der geringeren Anfärbbarkeit ist das erhöhte Vorkommen von Elektrolyten im Gewebe zu sehen, die eine Antikörperbindung erschweren können. Zur weiteren Klärung wären ein Score für elektronenmikroskopische Bilder oder andere histologische Färbungen notwendig.

Bei der Serumanalyse zeigen sich beim Harnstoff-N alle Werte der „Sham“-Gruppe niedriger als der in 4.1 angegebene Grenzwert für Harnstoff-N. Die beiden anderen Behandlungsgruppen überschreiten diesen Grenzwert. Hier haben die Genotypen der Behandlungsgruppe „Neph“ mit Ausnahme von COL4A3 mit die höchsten Mittelwerte. Signifikanzen werden in Abschnitt 3.3 beschrieben.

Bei der Cholesterinanalyse zeigt der Wildtyp, welcher als Normalfall anzusehen ist, sogar regelhaft die höchsten Mittelwerte innerhalb der jeweiligen Behandlungsgruppe. Die Mittelwerte der „Sham“-Gruppe sind regelmäßig niedriger als die der beiden anderen Behandlungsgruppen. In der Cholesterinanalyse sind zum einen Signifikanzen, wie in Abschnitt 3.3 beschrieben, ersichtlich, zum anderen weisen die Mittelwerte der einzelnen Genotypen einen Anstieg passend zu den Vorüberlegungen in Abschnitt 4.1 auf. Weiterhin ist zu erkennen, dass eine Uninephrektomie durchaus einen Einfluss auf den Stoffwechsel mit u.a. erhöhten Cholesterin und Harnstoff-N-Werten mit ihren schädlichen Einflüssen auf den gesamten Organismus hat. 


\subsection{Reproduzierbarkeit der Ergebnisse (Intraklassenkorrelationskoeffizient)}

Die Beurteilung des Intraklassenkorrelationskoeffizient erfolgt nach Koo und Li (2016), eine der aktuellsten Publikationen zu diesem Thema. Danach haben die Korrelationskoeffizienten für den Fibronectin-Score bei 10-facher Vergrößerung sowie für den LamininScore in beiden Vergrößerungsvarianten eine durchschnittliche Übereinstimmung. Der Fibronectin-Score bei 40-facher Vergrößerung zeigt eine gute Übereinstimmung. Somit sind die Ergebnisse des Scores als durchaus valide anzusehen. Nach Cicchetti (1994) ist der Score sogar noch valider. Danach wird der Intraklassenkorrelationskoeffizient als gut (Fibronectin-Score in 10-facher Vergrößerung sowie die beiden Vergrößerungsstufen des Laminin-Scores) bis sehr gut (Fibronectin-Score in 40-facher Vergrößerung) beschrieben. Dies spricht für eine gute Reproduzierbarkeit der Ergebnisse. Dementsprechend sind die Ergebnisse des Scores gut interpretierbar.

\subsection{Bewertung und Ausblick}

In Zusammenschau aller Ergebnisse kann davon ausgegangen werden, dass eine salzreiche Ernährung (in diesem Fall 0,9\%iges $\mathrm{NaCl}$-Trinkwasser) nach einer Uninephrektomie keinen schädlichen Einfluss auf die Nierenleistung hat, sofern es sich um die hier untersuchten Mutationen handelt (COL4A3, COL4A3/NPHS2 und NPHS2). Als Limitation dieser allgemeinen Aussage ist zu sehen, dass die Tiere nach einer siebentägigen Erholungsphase nach der OP nur 35 Tage eine salzreiche Ernährung bekommen haben. Somit liegt ein Gesamtbeobachtungszeitraum von 42 Tagen nach der OP vor. Wie in der Blutserumanalyse zu erkennen ist, zeigen sich erste negative Auswirkungen bei der Cholesterinspiegelbestimmung für „Salz“-Mäuse im Vergleich zu „Sham“- und „Neph“-Mäusen. Auch in der Harnstoff-N-Analyse sind schädliche Auswirkungen der Uninephrektomie mit und ohne zusätzliche Salzgabe sichtbar. Daher wäre ein längerer Beobachtungszeitraum überlegenswert. Des Weiteren handelt es sich hier um eine relativ kleine Beobachtungsgruppe. Bei größeren Beobachtungsgruppen würde die Validität der Aussagen zunehmen. Um das allgemeine Studiendesign zu überprüfen, würde sich eine stärkere Reizung mit erhöhten Salzkonzentrationen anbieten.

Dennoch bleibt festzuhalten, dass diese Arbeit den Kreis von möglichen Nierenspendern keinesfalls einschränkt.

Die in dieser Arbeit gezeigten Ergebnisse erweisen sich als passend zu den bisherigen Patientenstudien, die die Möglichkeit einer Lebendspende als Therapieoption bei AlportPatienten untermauern (Kashtan 2018).

Trotz der hier gezeigten Ergebnisse sollte Patienten nach einer Uninephrektomie weiterhin empfohlen werden, eine restriktive Ernährung im Bezug auf Salz einzunehmen. 
Diese Arbeit rechtfertigt die Annahme, eine geschlechterspezifische Untersuchung im Bezug auf eine Nierenspende im Rahmen des Alport-Syndroms voranzutreiben.

In der Gesamtschau der Ergebnisse kann die in dieser Arbeit gewählte Arbeitshypothese als widerlegt angesehen werden. 


\section{$5 \quad$ Zusammenfassung}

Die Filtrationsfunktion der Niere im Glomerulum wird durch einen dreiteiligen Filter gewährleistet. Der Filter besteht aus den Endothelzellen auf der Blutseite und den Podozyten auf der Urinseite. Dazwischen liegt die GBM. Kollagen IV ist neben Laminin, Nidogen und Heperansulfatproteoglykanen ein Hauptbestandteil der GBM.

Homozygote Mutationen in dem Typ IV Kollagen (COL4A3, COL4A4 und COL4A5) führen zum Alport-Syndrom. Heterozygoten Mutationen führen zum heterozygoten Alport-Syndrom (ehemals: thin basement membran nephropathie oder benigne familiäre Hämaturie). Eine Variante im Podocin-Gen (NPHS2, hier der R229Q) kann zu einer schlechteren Prognose bei beiden Erkrankungen führen. Podocin ist ein Verbindungsmolekül zwischen Podozyt und Schlitzmembran.

Patienten mit Alport-Syndrom erlangen früh in ihrem Leben eine terminale Niereninsuffizienz. Um diese und die damit verbundene Dialysepflichtigkeit möglichst lange hinauszuzögern, stellen ACE-Inhibitoren die aktuelle Therapie der Wahl dar.

Die Nierenspende ist eine weitere Säule der Therapie. In Deutschland ist neben der Entnahme der Organe bei hirntoten Patienten nur die Lebendspende unter strengen Voraussetzungen möglich. Für eine Spende kommen oft nur die Eltern von betroffenen Patienten in Frage. Bei diesen liegt häufig eine heterozygote Mutation vor, welche ihrerseits im Alter ebenfalls zu einer Niereninsuffizienz führen kann.

In dieser Arbeit wurde das Spenden einer Niere in einem Mausmodell (SvJ-129-Maus) simuliert. Hierzu wurden den Mäusen mit unterschiedlichen Genotypen (Wildtyp-Mäuse oder COL4A3-mutierte-Mäuse $\left(\mathrm{COL} 4 \mathrm{~A} 3^{+/-} \mathrm{NPHS}^{+/+}\right.$) sowie COL4A3/NPHS2- $\left(\mathrm{COL} 4 \mathrm{~A} 3^{+/-}\right.$ $\mathrm{NPHS}^{+/}$) oder NPHS2- $\left(\mathrm{COL} 4 \mathrm{A3}^{+/+} \mathrm{NPHS}^{+/-}\right.$) mutierte-Tiere) im Alter von 138 Lebenstagen eine Niere entfernt. Als Kontrolle dienten scheinoperierte Tiere („Sham“). Zusätzlich wurde ein Teil der Tiere mit übermäßigem Salzkonsum („Salz“) belastet.

Die Gabe von $\mathrm{NaCl}$ im Trinkwasser begann sieben Tage nach der Operation. 42 Tage nach der Operation wurden die Mäuse zur Organentnahme für die weitere Analyse getötet.

Die Arbeit sollte die Frage beantworten, welchen Einfluss haben Modifiergene (hier NPHS2), eine erhöhte Salzzufuhr und eine Hyperfiltration auf eine vorgeschädigte Basalmembran der Niere. Weiterhin wurden mögliche prognostische Marker einer Nierenschädigung wie Proteinurie, Cholesterin- und Harnstoff-N-Gehalt im Serum sowie die Gewichtsentwicklung und die Nierenhistologie untersucht.

Zur Untersuchung der Hypothese, dass Salzbehandlung nach einer Uninephrektomie zu einer Aggravierung des Nierenschadens führt, wurden der Urin und das Gewicht der Mäu- 
se alle 30 Tage überprüft. Die Urine wurden semiquantitativ mittels Gel-Elektrophorese auf Proteine gleicher Größe wie Albumin und größer als Albumin als Marker für einen glomerulären Schaden untersucht. Weiterhin wurde nach der Tötung Blut zur Blutserumanalyse auf den Cholesterin- und Harnstoff-N-Gehalt gewonnen. Die Nieren wurden histologisch aufgearbeitet und auf Fibronectin und Laminin-1 gefärbt. Hierbei wurde auf eine geschlechtsspezifische Untersuchung geachtet.

Die Ergebnisse zeigen, dass es zwischen den Behandlungsgruppen keine generellen Unterschiede in Bezug auf die einzelnen Genotypen gibt. Einzig die Cholesterin-Analyse zeigt erste dezente Veränderungen im Sinne einer Nierenschädigung durch Uninephrektomie und/oder salzreicher Ernährung an, die sich allerdings als nicht signifikant erweisen. Im Vergleich zur homozygoten Alport-Kontrollgruppe (COL4A3-Knockout) weisen die unterschiedlichen Genotypen jedoch oft signifikant bessere bzw. dem Nierengesunden ähnliche Ergebnisse auf.

Auf Grund dieser Ergebnisse kann der Rahmen für mögliche Nierenspender erweitert werden. Spender mit einer der hier untersuchten Mutationen sollten nicht generell von einer Spende ausgeschlossen werden. Diese Aussage wäre in einer retrospektiven Arbeit zu bestätigen oder mit einer größeren Anzahl von Mäusen in einem Tierversuch mit längerem postoperativen Beobachtungszeitraum zu bestätigen.

Gleichwohl sollte Patienten wegen des Ergebnisses anderer Arbeitsgruppen nach einer Spende weiterhin geraten werden, nicht übermäßig viel Salz zu konsumieren.

Als Erweiterung der Forschung sind weitere bisher unbeachtete molekulare Einflüsse zu diskutieren.

In dieser Arbeit konnte gezeigt werden, dass es keine klaren präoperativen Prognosemarker gibt und die Mäuse ein gutes Outcome nach einer simulierten Nierenspende haben. Somit bestätigt diese Arbeit Ergebnisse von retrospektiven Studien, die bei Menschen ebenfalls eine Nierenspende als eine gute Therapiealternative neben den gebräuchlichen Medikamenten zeigen.

Ein weiterer interessanter Ansatzpunkt für weitere Forschung ist die Untersuchung der geschlechterspezifischen Unterschiede in diesem speziellen Fall.

Zusammenfassend kann die Arbeitshypothese als widerlegt angesehen werden: Es gibt keinen Einfluss von NPHS2 als Modifiergen auf die vorgeschädigte Basalmembran. Des Weiteren haben die hier untersuchten Einflüsse (0,9\%ige NaCl-Trinkwassergabe und eine Hyperperfusion nach Uninephrektomie) keinen signifikant negativen Effekt auf die Nierenleistung. Zusätzlich stieg die Proteinurie nicht generell nach einer Uninephrektomie an. Auch eine darüber hinaus gehende Steigerung der Proteinurie durch Salzgabe blieb aus. Dennoch ist eine nachfolgende, mäßige Nierenschädigung nicht sicher auszuschließen, auch wenn sich darauf anhand der Parameter Gewicht, Histologie und Serumgehalt von Cholesterin und Harnstoff-N keine Hinweise fanden. 


\section{$6 \quad$ Anhang}

\subsection{Materialienzusammensetzung}

Tabelle A 1 - Geräte

\begin{tabular}{|c|c|c|}
\hline Gerät & Hersteller & Verwendung bei \\
\hline $\begin{array}{l}\text { Eppendorf Thermomi- } \\
\text { xer Compact }\end{array}$ & $\begin{array}{l}\text { Sigma-Aldrich Chemie } \mathrm{GmbH} \text { München } \\
\text { (heute Firma MERCK) }\end{array}$ & $\begin{array}{l}\text { Genotypisierung; } \\
\text { Chloroform-Methanol- } \\
\text { Fällung }\end{array}$ \\
\hline $\begin{array}{l}\text { Labtherm TR-L } 288 \\
\text { (Heizblock) }\end{array}$ & Liebisch, 33649 Bielefeld, Deutschland & $\begin{array}{l}\text { Genotypisierung; } \\
\text { Chloroform-Methanol- } \\
\text { Fällung }\end{array}$ \\
\hline Biometra TProfessional & Analytik Jena AG 07745 Jena & Genotypisierung \\
\hline $\begin{array}{l}\text { Mikro200R Hettich } \\
\text { Zentrifuge }\end{array}$ & $\begin{array}{l}\text { Andreas Hettich GmbH \& Co.KG } \\
\text { Föhrenstr.12 } \\
\text { D-78532 Tuttlingen }\end{array}$ & $\begin{array}{l}\text { Genotypisierung; Bluta- } \\
\text { nalyse; } \\
\text { Chloroform-Methanol- } \\
\text { Fällung }\end{array}$ \\
\hline UV-Transsimulator & $\begin{array}{l}\text { Bio Doc Analyze Biometra; Analytik Jena } \\
\text { AG } \\
\text { Konrad-Zuse-Straße } 1 \\
\text { 07745 Jena }\end{array}$ & Genotypisierung \\
\hline Centrifuge $5424 \mathrm{R}$ & $\begin{array}{l}\text { Eppendorf AG } \\
\text { Barkenhausenweg } 1 \\
22339 \text { Hamburg }\end{array}$ & $\begin{array}{l}\text { Chloroform-Methanol- } \\
\text { Fällung }\end{array}$ \\
\hline $\begin{array}{l}\text { IKA: Vortex Schüttler } \\
\text { VF2 }\end{array}$ & $\begin{array}{l}\text { W. Krannich GmbH + Co. KG } \\
\text { Göttingen, Deutschland }\end{array}$ & $\begin{array}{l}\text { Genotypisierung; } \\
\text { Chloroform-Methanol- } \\
\text { Fällung }\end{array}$ \\
\hline
\end{tabular}

Tabelle A 2 - Genotypisierung

\begin{tabular}{|c|c|c|}
\hline Substanz & Stoffmenge & Hersteller \\
\hline DirectPCR (Tail) & $200 \mu l$ & $\begin{array}{l}\text { VIAGEN, } \\
\text { Los Angeles, CA 90010, USA }\end{array}$ \\
\hline Proteinase $\mathrm{K}$ & $4 \mu \mathrm{l}$ & $\begin{array}{l}\text { VWR International GmbH } \\
64295 \text { Darmstadt }\end{array}$ \\
\hline \multicolumn{3}{|c|}{ Top Taq PCR für COL4 } \\
\hline 10 x Puffer (TopTaq PCR Puffer, 10 x) & $2,5 \mu \mathrm{l}$ & $\begin{array}{l}\text { QIAGEN GmbH } \\
40724 \text { Hilden }\end{array}$ \\
\hline $10 \times$ Corel Load ${ }^{\mathrm{TM}}$ (Concentrate, $10 \mathrm{x}$ ) & $2,5 \mu \mathrm{l}$ & $\begin{array}{l}\text { QIAGEN GmbH } \\
40724 \text { Hilden }\end{array}$ \\
\hline $\begin{array}{l}\text { Primer } 1 \text { forward } \\
\text { (CCA GGC TTA AAG GGA AAT } \\
\text { CC) }\end{array}$ & $0,5 \mu \mathrm{l}$ & $\begin{array}{l}\text { Eurofins Genomics } 85560 \\
\text { Ebersber }\end{array}$ \\
\hline $\begin{array}{l}\text { Primer } 2 \text { reverse } \\
\text { (CCT GCT AAT ATA GGG TTC } \\
\text { GAG A) }\end{array}$ & $0,5 \mu \mathrm{l}$ & $\begin{array}{l}\text { Eurofins Genomics } 85560 \\
\text { Ebersber }\end{array}$ \\
\hline $\begin{array}{l}\text { Primer } 3 \text { mutant } \\
\text { (AAT CGC CAA TGA CAA GAC G) }\end{array}$ & $0,5 \mu \mathrm{l}$ & $\begin{array}{l}\text { Eurofins Genomics } 85560 \\
\text { Ebersber }\end{array}$ \\
\hline
\end{tabular}




\begin{tabular}{|c|c|c|}
\hline Substanz & Stoffmenge & Hersteller \\
\hline Nukleotide (je $10 \mathrm{mM}$ ) & $0,5 \mu \mathrm{l}$ & $\begin{array}{l}\text { Thermo Fisher Scientific } \\
168 \text { Third Avenue } \\
\text { Waltham, MA USA } 02451\end{array}$ \\
\hline Taq & $0,1 \mu \mathrm{l}$ & $\begin{array}{l}\text { QIAGEN GmbH } \\
40724 \text { Hilden }\end{array}$ \\
\hline $\mathrm{dH}_{2} \mathrm{O}$ & $\operatorname{Ad} 25 \mu \mathrm{l}(17,4 \mu \mathrm{l})$ & \\
\hline \multicolumn{3}{|c|}{ Top Taq PCR für Podocin } \\
\hline 10 x Puffer (TopTaq PCR Puffer, 10 x) & $2,5 \mu l$ & $\begin{array}{l}\text { QIAGEN GmbH } \\
40724 \text { Hilden }\end{array}$ \\
\hline $10 \mathrm{x}$ Corel Load ${ }^{\mathrm{TM}}$ (Concentrate, $10 \mathrm{x}$ ) & $2,5 \mu \mathrm{l}$ & $\begin{array}{l}\text { QIAGEN GmbH } \\
40724 \text { Hilden }\end{array}$ \\
\hline $\begin{array}{l}\text { Podocin } 3 \text { forward } \\
\text { (TAA TTA TAG GGC CGG TTG) }\end{array}$ & $0,5 \mu \mathrm{l}$ & $\begin{array}{l}\text { Eurofins Genomics } 85560 \\
\text { Ebersber }\end{array}$ \\
\hline $\begin{array}{l}\text { Podocin } 3 \text { reverse } \\
\text { (TGC CTC TTC TCC CAA CTA) }\end{array}$ & $0,5 \mu \mathrm{l}$ & $\begin{array}{l}\text { Eurofins Genomics } 85560 \\
\text { Ebersber }\end{array}$ \\
\hline Nukleotide (je $10 \mathrm{mM}$ ) & $0,5 \mu \mathrm{l}$ & $\begin{array}{l}\text { Thermo Fisher Scientific } \\
168 \text { Third Avenue } \\
\text { Waltham, MA USA } 02451\end{array}$ \\
\hline Taq & $0,1 \mu \mathrm{l}$ & $\begin{array}{l}\text { QIAGEN GmbH } \\
40724 \text { Hilden }\end{array}$ \\
\hline $\mathrm{dH}_{2} \mathrm{O}$ & Ad $25 \mu \mathrm{l}(17,9 \mu \mathrm{l})$ & \\
\hline \multicolumn{3}{|c|}{ DNA - Gelelketrophorese $\rightarrow$ 1,5\% iges Gel } \\
\hline TAE $1 \mathrm{x}$-Puffer & $30 \mathrm{ml}$ & \\
\hline \multicolumn{3}{|c|}{ Ansatz für 50xTAE (Tris-Acetat-EDTA) } \\
\hline$-2 \mathrm{M}$ Tris & $242 \mathrm{~g}$ & $\begin{array}{l}\text { Roche Diagnostics GmbH } \\
\text { Mannheim, Germany }\end{array}$ \\
\hline $\begin{array}{l}-50 \text { mM EDTA-Tetra-natriumsalz- } \\
\text { tetrahydrat }\end{array}$ & $22,6 \mathrm{~g}$ & $\begin{array}{l}\text { SIGMA-Aldrich } \\
\text { Jetzt: } \\
\text { MERCK KGaA } 64271 \text { Darm- } \\
\text { stadt }\end{array}$ \\
\hline -1 M Essigsäure & $57,1 \mathrm{ml}$ & $\begin{array}{l}\text { MERCK KGaA } 64271 \text { Darm- } \\
\text { stadt }\end{array}$ \\
\hline Agarose & $\sim 0,45 \mathrm{~g}$ & $\begin{array}{l}\text { Biozym Scientific GmbH } \\
31833 \text { Hess. Oldendorf }\end{array}$ \\
\hline Ethidiumbromidlösung $(10 \mathrm{mg} / \mathrm{ml})$ & $10 \mu \mathrm{l}$ & $\begin{array}{l}\text { Carl Roth GmbH + Co. KG } \\
\text { Schoemperlenstraße 1-5 } \\
76185 \text { Karlsruhe,_Deutschland }\end{array}$ \\
\hline
\end{tabular}

Tabelle A 3 - Analgesie

\begin{tabular}{|l|l|l|}
\hline \multicolumn{1}{|c|}{ Substanz } & \multicolumn{1}{|c|}{ Stoffmenge } & \multicolumn{1}{c|}{ Hersteller } \\
\hline \multicolumn{3}{|c|}{ Metamizol (Vetalgin) $200 \mathrm{mg} / \mathrm{kg}$} \\
\hline $\begin{array}{l}\text { Metamizol-Natrium } 1 \mathrm{H}_{2} \mathrm{O} \\
(500 \mathrm{mg} / \mathrm{ml})\end{array}$ & $0,4 \mathrm{ml}(200 \mathrm{mg})$ & $\begin{array}{l}\text { Intervet Deutschland GmbH } \\
\text { Ein Unternehmen der MSD } \\
\text { Tiergesundheit } \\
\text { Feldstraße 1a } \\
85716 \text { Unterschleißheim }\end{array}$ \\
\hline $\mathrm{NaCl}(0,9 \%)$ & Ad $5 \mathrm{ml}(4,6 \mathrm{ml})$ & $\begin{array}{l}\text { B. Braun Melsungen AG } \\
\text { Carl-Braun-Straße 1 } \\
\text { 34212 Melsungen }\end{array}$ \\
\hline \multicolumn{2}{|c|}{ Metamizol (Vetalgin) $200 \mathrm{mg} / \mathrm{kg} \&$ Buprenorphin (Temgesic) 0,1 mg/kg } \\
\hline
\end{tabular}




\begin{tabular}{|l|l|l|}
\hline \multicolumn{1}{|c|}{ Substanz } & \multicolumn{1}{|c|}{ Stoffmenge } & \multicolumn{1}{c|}{ Hersteller } \\
\hline Metamizol-Natrium $1 \mathrm{H}_{2} \mathrm{O}$ & $0,4 \mathrm{ml}(200 \mathrm{mg})$ & $\begin{array}{l}\text { Intervet Deutschland GmbH } \\
\text { Ein Unternehmen der MSD } \\
\text { Tiergesundheit } \\
\text { Feldstraße 1a } \\
85716 \text { Unterschleißheim }\end{array}$ \\
\hline Buphrenorphinhydrochlorid & $0,324 \mathrm{mg} / \mathrm{ml}$ & $\begin{array}{l}\text { Indivior Inc. } \\
\text { North Chesterfield, } \\
\text { Virginia, USA }\end{array}$ \\
\hline $\mathrm{NaCl}(0,9 \%)$ & Ad $5 \mathrm{ml}(4,267 \mathrm{ml})$ & $\begin{array}{l}\text { B. Braun Melsungen AG } \\
\text { Carl-Braun-Straße 1 } \\
\text { 34212 Melsungen }\end{array}$ \\
\hline
\end{tabular}

Tabelle A 4 - Salzreiches Trinkwasser für die Mäuse

\begin{tabular}{|l|l|l|}
\hline \multicolumn{1}{|c|}{ Substanz } & \multicolumn{1}{|c|}{ Stoffmenge } & \multicolumn{1}{c|}{ Hersteller } \\
\hline Natriumchlorid & $9 \mathrm{~g}$ & $\begin{array}{l}\text { Carl Roth GmbH + Co. KG } \\
\text { Schoemperlenstraße 1-5 } \\
76185 \text { Karlsruhe } \\
\text { Deutschland }\end{array}$ \\
\hline Wasser & $1 \mathrm{~L}$ & \\
\hline
\end{tabular}

Tabelle A 5 - Urin

\begin{tabular}{|c|l|}
\hline \multicolumn{1}{|c|}{ Material } & \multicolumn{1}{|c|}{ Hersteller } \\
\hline Biozym Reaktionsgefäße $1.6 \mathrm{ml}$ & Biozym Biotech Trading GbmH \\
& A-1200 Wien \\
\hline
\end{tabular}

Tabelle A 6 - Präparation der Mäuse für Paraffinschnitte

\begin{tabular}{|c|c|c|}
\hline Material / Substanz & Stoffmenge & Hersteller \\
\hline Omnican 40 & & $\begin{array}{l}\text { B.Braun Meslungen AG } \\
34212 \text { Melsungen }\end{array}$ \\
\hline Einmalspritzen $1 \mathrm{ml}$ & & $\begin{array}{l}\text { Transcoject GmbH } \\
\text { Rügenstraße } 8 \\
\text { D-24539 Neumünster }\end{array}$ \\
\hline $\begin{array}{l}\text { Sterican Kanülen } 0,55 \text { x } 25 \\
\text { mm }\end{array}$ & & $\begin{array}{l}\text { B.Braun Meslungen AG } \\
34212 \text { Melsungen }\end{array}$ \\
\hline $\begin{array}{l}\text { Biozym Reaktionsgefäße } 1.6 \\
\text { ml }\end{array}$ & & $\begin{array}{l}\text { Biozym Biotech Tradining } \\
\text { GbmH } \\
\text { A-1200 Wien }\end{array}$ \\
\hline \multicolumn{3}{|c|}{ Aufbewahren der Nieren } \\
\hline Einbettkasette-Universal & & $\begin{array}{l}\text { K.Lutz Bahnhofsstr. } 10 \\
97877 \text { Wertheim }\end{array}$ \\
\hline Ethanol vergällt & $70 \%$ & $\begin{array}{l}\text { Th. Geyer GmbH \& Co.KG } \\
71272 \text { Renningen }\end{array}$ \\
\hline \multicolumn{3}{|c|}{ Herstellung PFA, pH 7,4-7,6 } \\
\hline IKA RH basic Magnetrührer & 2 Std auf $80^{\circ} \mathrm{C}$ & $\begin{array}{l}\text { IKA Werke GmbH\&CoKG } \\
79219 \text { Staufen }\end{array}$ \\
\hline $\mathrm{pH}-$ Streifen Universalindikator & & $\begin{array}{l}\text { MERCK KGaA } \\
\text { 64293 Darmstadt }\end{array}$ \\
\hline
\end{tabular}




\begin{tabular}{|c|c|c|}
\hline Material / Substanz & Stoffmenge & Hersteller \\
\hline Paraformaldehyd & $40 \mathrm{~g}$ & $\begin{array}{l}\text { SIGMA } \\
\text { 63178 St. Louis USA }\end{array}$ \\
\hline $1 \times \mathrm{PBS}$ & Herstellung s.u. & \\
\hline \multicolumn{3}{|c|}{ Herstellung PBS $(10 \mathrm{x}), \mathrm{pH} 7,4$} \\
\hline Kaliumchlorid & $4 \mathrm{~g}$ & $\begin{array}{l}\text { Fluka Chemie GmbH CH-9471 } \\
\text { Buchs }\end{array}$ \\
\hline Natriumchlorid & $160 \mathrm{~g}$ & $\begin{array}{l}\text { MERCK KGaA } \\
\text { 64293 Darmstadt }\end{array}$ \\
\hline Dinatriumhydrogenphosphat & $28,4 \mathrm{~g}$ & $\begin{array}{l}\text { MERCK KGaA } \\
\text { 64293 Darmstadt }\end{array}$ \\
\hline Kaliumdihydrogenphosphat & $4,8 \mathrm{~g}$ & $\begin{array}{l}\text { MERCK KGaA } \\
\text { 64293 Darmstadt }\end{array}$ \\
\hline $\mathrm{dH}_{2} \mathrm{O}$ & Ad $2000 \mathrm{ml}$ & \\
\hline
\end{tabular}

Tabelle A 7 - Chloroform-Methanol-Fällung / Urin-Elektrophorese

\begin{tabular}{|c|c|c|}
\hline Gerät / Material / Substanz & Stoffmenge & Hersteller \\
\hline Safe-Lok Tubes 1,5 ml & & $\begin{array}{l}\text { Eppendorf AG } \\
22331 \text { Hamburg }\end{array}$ \\
\hline Methanol & $1200 \mu \mathrm{l}$ & $\begin{array}{l}\text { MERCK KGaA } \\
\text { 64271 Darmstadt }\end{array}$ \\
\hline Chloroform & $100 \mu \mathrm{l}$ & $\begin{array}{l}\text { MERCK KGaA } \\
\text { 64271 Darmstadt }\end{array}$ \\
\hline $\mathrm{dH}_{2} \mathrm{O}$ & $300 \mu \mathrm{l}$ & \\
\hline \multicolumn{3}{|c|}{ Probenpuffer $(1,2 \mathrm{ml})$} \\
\hline $\begin{array}{l}2 \times \text { Tris-Glycine SDS Sample } \\
\text { Buffer (Invitrogen) }\end{array}$ & $600 \mu \mathrm{l}$ & $\begin{array}{l}\text { Thermo Fisher Scientific } \\
168 \text { Third Avenue } \\
\text { Waltham, } \\
\text { MA USA } 02451\end{array}$ \\
\hline $\begin{array}{l}10 \text { x NuPAGE Sample Reduc- } \\
\text { ing Agent (Invitrogen) }\end{array}$ & $120 \mu \mathrm{l}$ & $\begin{array}{l}\text { Thermo Fisher Scientific } \\
168 \text { Third Avenue } \\
\text { Waltham, } \\
\text { MA USA } 02451\end{array}$ \\
\hline $\mathrm{dH}_{2} \mathrm{O}$ & $480 \mu \mathrm{l}$ & \\
\hline \multicolumn{3}{|c|}{ Probepufferansatz/BSA } \\
\hline $\begin{array}{l}2 \times \text { Tris-Glycine SDS Sample } \\
\text { Buffer (Invitrogen) }\end{array}$ & $6,25 \mu l$ & $\begin{array}{l}\text { Thermo Fisher Scientific } \\
168 \text { Third Avenue } \\
\text { Waltham, } \\
\text { MA USA } 02451\end{array}$ \\
\hline BSA-Standard $300 \mathrm{ng} / 5 \mu \mathrm{l}$ & $5 \mu \mathrm{l}$ & \\
\hline $\begin{array}{l}10 \text { x NuPAGE Sample Reduc- } \\
\text { ing Agent (Invitrogen) }\end{array}$ & $1,25 \mu l$ & $\begin{array}{l}\text { Thermo Fisher Scientific } \\
168 \text { Third Avenue } \\
\text { Waltham, } \\
\text { MA USA } 02451\end{array}$ \\
\hline \multicolumn{3}{|c|}{ Herstellung BSA-Standard $300 \mathrm{ng} / 5 \mu \mathrm{l}$ (Angaben für $10 \mathrm{ml}$ Standard) } \\
\hline BSA & $0,3 \mathrm{mg}$ & $\begin{array}{l}\text { MERCK KGaA } \\
64271 \text { Darmstadt }\end{array}$ \\
\hline $\mathrm{dH}_{2} \mathrm{O}$ & $10 \mathrm{ml}$ & \\
\hline \multicolumn{3}{|c|}{ Gelelektrophorese } \\
\hline $\begin{array}{l}\text { Novex WedgeWell Tris-Glycine } \\
\text { Gel (Invitrogen) }\end{array}$ & & $\begin{array}{l}\text { Thermo Fisher Scientific } \\
168 \text { Third Avenue } \\
\text { Waltham, } \\
\text { MA USA } 02451\end{array}$ \\
\hline $\begin{array}{l}\text { ProSieve QuadColor Protein } \\
\text { Marker, 4,6-300 kDa }\end{array}$ & & $\begin{array}{l}\text { Lonza Rockland Inc. } \\
191 \text { Thomaston St, Rockland, ME 04841, USA }\end{array}$ \\
\hline
\end{tabular}




\begin{tabular}{|c|c|c|}
\hline Gerät / Material / Substanz & Stoffmenge & Hersteller \\
\hline XCell SureLock Mini-Cell & & $\begin{array}{l}\text { Thermo Fisher Scientific } \\
168 \text { Third Avenue } \\
\text { Waltham, } \\
\text { MA USA } 02451\end{array}$ \\
\hline $\begin{array}{l}\text { Hamilton } 700 \text { Serie Microliter } \\
\# 705\end{array}$ & & $\begin{array}{l}\text { Hamilton Bonaduz AG } \\
7402 \text { Bonaduz, Schweiz }\end{array}$ \\
\hline $\begin{array}{l}\text { GE Healthcare EPS } 301 \text { Elec- } \\
\text { trophoresis Power Supply }\end{array}$ & & $\begin{array}{l}\text { Thermo Fisher Scientific } \\
168 \text { Third Avenue } \\
\text { Waltham, } \\
\text { MA USA } 02451\end{array}$ \\
\hline Duomax 1030 & & $\begin{array}{l}\text { Heidolph Instruments GmbH \& CO. } \\
\text { Walpersdorfer Str. 12, } 91126 \text { Schwabach }\end{array}$ \\
\hline $\begin{array}{l}\text { Novex Tris-Glycine-SDS Run- } \\
\text { ning Buffer }(10 \mathrm{x})\end{array}$ & & $\begin{array}{l}\text { Thermo Fisher Scientific } \\
168 \text { Third Avenue } \\
\text { Waltham, } \\
\text { MA USA } 02451\end{array}$ \\
\hline InstantBlue ${ }^{\mathrm{TM}}$ & & $\begin{array}{l}\text { Expedeon Ltd. } \\
25 \text { Norman Way, Over, Cambridge CB24 5QE, } \\
\text { Vereinigtes Königreich }\end{array}$ \\
\hline \multicolumn{3}{|c|}{ Auswertung der Uringele } \\
\hline Bio Rad & $\begin{array}{l}\text { Bio Rad } \\
\text { Model No.: } \\
\text { Universal } \\
\text { Hood III }\end{array}$ & $\begin{array}{l}\text { Bio-Rad Laboratories GmbH } \\
\text { Heidemannstr. } 164 \\
80939 \text { München }\end{array}$ \\
\hline Image Lab Software & & $\begin{array}{l}\text { Bio-Rad Laboratories GmbH } \\
\text { Heidemannstr. } 164 \\
80939 \text { München }\end{array}$ \\
\hline
\end{tabular}

Tabelle A 8 - Einbettung der Präparate für Paraffinschnitte

\begin{tabular}{|l|l|}
\hline \multicolumn{1}{|c|}{ Gerät } & \multicolumn{1}{c|}{ Hersteller } \\
\hline Einbettautomat & Leica Biosystems Nussloch GmbH \\
Leica HistoCore Pearl & Heidelberger Straße 17-19 \\
& 69226 Nussloch \\
\hline Ausgießstation & Leica Biosystems Nussloch GmbH \\
Leica EG 1150H & Heidelberger Straße 17-19 \\
& 69226 Nussloch \\
\hline Kühlplatte & Leica Biosystems Nussloch GmbH \\
Leica EG 1150C & Heidelberger Straße 17-19 \\
& 69226 Nussloch \\
\hline
\end{tabular}

Tabelle A 9 - Anfertigung Paraffinschnitte

\begin{tabular}{|l|l|}
\hline \multicolumn{1}{|c|}{ Gerät / Material } & \multicolumn{1}{c|}{ Hersteller } \\
\hline $\begin{array}{l}\text { Objektträger } \\
\text { Thermo SCIENTIFIC } \\
\text { MENZEL-GLÄSER SU- } \\
\text { PERFROST PLUS }\end{array}$ & $\begin{array}{l}\text { Gerhard Menzel B.V. \& Co. KG Saarbrückener Str. 248 } \\
\text { 38116 Braunschweig }\end{array}$ \\
\hline $\begin{array}{l}\text { Klingen } \\
\text { Feather MICROTOME } \\
\text { BLADE STAINLESS } \\
\text { STEEL S35 }\end{array}$ & $\begin{array}{l}\text { FEATHER SAFETY RAZOR CO., LTD. 3-70, OHYODO- } \\
\text { MINAMI 3-CHome, KITA-KU, OSAKA 531-0075, JAPAN }\end{array}$ \\
\hline $\begin{array}{l}\text { Rotationsmikrotom } \\
\text { LEICA RM 2165 }\end{array}$ & $\begin{array}{l}\text { Leica Biosystems Nussloch GmbH Heidelberger Straße 17-19 } \\
\text { 69226 Nussloch }\end{array}$ \\
\hline
\end{tabular}




\begin{tabular}{|l|l|}
\hline \multicolumn{1}{|c|}{ Gerät / Material } & \multicolumn{1}{c|}{ Hersteller } \\
\hline Wärmeplatte & MEDAX Nagel GmbH Kiel \\
Typ 12801 & Friedrich-Wöhler-Straße 46 \\
& 24536 Neumünster \\
\hline Wasserbad & Gesellschaft für Labortechnik GmbH \\
Typ 1052 & Schulze-Delitzsch-Straße 4 \\
& 30938 Burgwedel \\
\hline Wärmeschrank & SANYO Eletric Co., Ltd. \\
SANYO Convection Oven & 2-1-61 Shiromi, Chuou-ku, Osaka City, \\
Model MOV-112F & Osaka 540-6226, Japan \\
\hline
\end{tabular}

\section{Tabelle A 10 - Lamininfärbung}

\begin{tabular}{|c|c|c|}
\hline Gerät / Material / Substanz & Stoffmenge & Hersteller \\
\hline $\begin{array}{l}\text { Inkubationsschrank } \\
\text { Panasonic CO2 Incubator } \\
\text { MCO-19AIC(UV)-PE }\end{array}$ & & $\begin{array}{l}\text { Panasonic Healthcare Co.,Ltd } \\
\text { 1-1-1 Sakata, } \\
\text { Oizumi-Machi } \\
\text { Ora-Gunma 370-0596 Japan }\end{array}$ \\
\hline Färbekasten Hellendahl & & $\begin{array}{l}\text { Th. Geyer GmbH \& Co. KG } \\
\text { Dornierstr. } 4-6 \\
71272 \text { Renningen }\end{array}$ \\
\hline $\begin{array}{l}\text { Färbegestell Bestellnummer: } \\
2481\end{array}$ & & $\begin{array}{l}\text { Th. Geyer GmbH \& Co. KG } \\
\text { Dornierstr. } 4 \text { - } 6 \\
71272 \text { Renningen }\end{array}$ \\
\hline $\begin{array}{l}\text { Deckglas } \\
\text { MENZEL-GLÄSER Deckglä- } \\
\text { ser } 24 \text { x } 40 \mathrm{~mm}\end{array}$ & & $\begin{array}{l}\text { Gerhard Menzel B.V. \& Co. KG Saarbrücke- } \\
\text { ner Str. } 24838116 \text { Braunschweig }\end{array}$ \\
\hline $\begin{array}{l}\text { Fluoreszenz Mounting Medi- } \\
\text { um }\end{array}$ & & $\begin{array}{l}\text { Dako Fluorescent Mounting Medium ; Dako } \\
\text { North America, Inc. } 6392 \text { Via Real } \\
\text { Carpinteria, CA } 93013 \text { USA }\end{array}$ \\
\hline Ethanol (99\% vollvergällt) & & $\begin{array}{l}\text { Th.Geyer GmbH \& Co. KG } \\
\text { Dornierstr. } 4-6 \\
71272 \text { Renningen }\end{array}$ \\
\hline Xylol z.A. Min. $96 \%$ & & $\begin{array}{l}\text { Th.Geyer GmbH \& Co. KG } \\
\text { Dornierstr. } 4 \text { - } 6 \\
71272 \text { Renningen }\end{array}$ \\
\hline KIMTECH Science & & $\begin{array}{l}\text { KIMBERLY-CLARK GmbH } \\
\text { Carl-Spaeter-Str. } 17 \\
56070 \text { Koblenz / Rheinhafen }\end{array}$ \\
\hline \multicolumn{3}{|c|}{ Herstellung Tris- $\mathrm{HCl}$} \\
\hline Tris & $0,303 \mathrm{~g}$ & Roche Diagnostics GmbH 68305 Mannheim \\
\hline $\mathrm{HCl}$ & $\begin{array}{l}\text { Dosieren } \mathrm{zu} \mathrm{pH} \\
7,6 \text { ad } 50 \mathrm{ml} \\
\mathrm{dH}_{2} \mathrm{O}\end{array}$ & $\begin{array}{l}\text { MERCK KGaA } \\
64271 \text { Darmstadt }\end{array}$ \\
\hline Dako Proteinase K & & $\begin{array}{l}\text { Dako North America, Inc. } 6392 \text { Via Real } \\
\text { Carpinteria, CA } 93013 \text { USA }\end{array}$ \\
\hline BSA & & $\begin{array}{l}\text { PAA Laboratories GmbH Haldmannweg } 9 \\
\text { A-4061 Pasching }\end{array}$ \\
\hline \multicolumn{3}{|c|}{ Herstellung TBS $10 \times \mathrm{pH} 7,6$} \\
\hline Tris & $121 \mathrm{~g}$ & Roche Diagnostics GmbH 68305 Mannheim \\
\hline Natriumchlorid & $175 \mathrm{~g}$ & MERCK KGaA 64271 Darmstadt \\
\hline $\mathrm{dH}_{2} \mathrm{O}$ & Ad $2000 \mathrm{ml}$ & \\
\hline
\end{tabular}




\begin{tabular}{|l|l|l|}
\hline Gerät / Material / Substanz & Stoffmenge & \multicolumn{1}{|c|}{ Hersteller } \\
\hline 1. Antikörper & & Discovery Drive, Cambridge Biomedical \\
Laminin-Ak & & Campus, Cambridge, CB2 0AX, UK \\
Rb pAb to Laminin (Abcam) & & \\
Ab11575 rabbit IgG & & \\
\hline 2. Antikörper & & Thermo Fisher Scientific \\
Goat anti Rabbit Alexa488 & & 168 Third Avenue \\
A11008 & & Waltham, MA USA 02451 \\
& & \\
\hline
\end{tabular}

\section{Tabelle A 11 - Fibronectinfärbung}

Gleiches Vorgehen wie bei der Lamininfärbung. Veränderte Antikörper

\begin{tabular}{|l|l|}
\hline \multicolumn{1}{|c|}{ Substanz } & \multicolumn{1}{c|}{ Hersteller } \\
\hline 1. Antikörper & Discovery Drive, Cambridge Biomedical Cam- \\
Fibronectin-Ak & pus, Cambridge, CB2 0AX, UK \\
ab2413 anti-Fibronectin rabbit + polyclonal & \\
\hline 2. Antikörper & \\
Goat anti rabbit Cy3 (Bestell-Nr: 111-165-144) & WIANOVA GmbH \\
& Warburgstraße 45 \\
\hline
\end{tabular}

Tabelle A 12 - Lichtmikroskopie

\begin{tabular}{|l|l|}
\hline \multicolumn{1}{|c|}{ Gerät } & \multicolumn{1}{c|}{ Hersteller } \\
\hline ZEISS Axiocam 503 mono & Carl Zeiss AG \\
Für Laminin: FITC44 Filter & Carl-Zeiss-Straße 22 \\
Für Fibronectin: TexRed & 73447 Oberkochen \\
\hline Computerprogramm: Zen2.6 blue pro & Carl Zeiss AG \\
& Carl-Zeiss-Straße 22 \\
& 73447 Oberkochen \\
\hline
\end{tabular}




\section{$7 \quad$ Literaturverzeichnis}

Abrahamson DR (1985): Origin of the glomerular basement membrane visualized after in vivo labeling of laminin in newborn rat kidneys. J Cell Biol 100, 1988-2000

Abrahamson DR, Prettyman AC, Robert B, St John PL (2003): Laminin-1 reexpression in Alport mouse glomerular basement membranes. Kidney Int 63, 826-834

Abrahamson DR, Hudson BG, Stroganova L, Borza DB, St John PL (2009): Cellular origins of type IV collagen networks in developing glomeruli. J Am Soc Nephrol 20, 14711479

Abrahamson DR, Isom K, Roach E, Stroganova L, Zelenchuk A, Miner JH, St John PL (2007): Laminin compensation in collagen alpha3(IV) knockout (Alport) glomeruli contributes to permeability defects. J Am Soc Nephrol 18, 2465-2472

Alport AC (1927): Hereditary Familial Congenital Haemorrhagic Nephritis. Br Med J 1, 504-506

Bader BL, Smyth N, Nedbal S, Miosge N, Baranowsky A, Mokkapati S, Murshed M, Nischt R (2005): Compound genetic ablation of nidogen 1 and 2 causes basement membrane defects and perinatal lethality in mice. Mol Cell Biol 25, 6846-6856

Beirowski B, Weber M, Gross O (2006): Chronic renal failure and shortened lifespan in COL4A3+/- mice: an animal model for thin basement membrane nephropathy. J Am Soc Nephrol 17, 1986-1994

Bekheirnia MR, Reed B, Gregory MC, McFann K, Shamshirsaz AA, Masoumi A, Schrier RW (2010): Genotype-phenotype correlation in X-linked Alport syndrome. J Am Soc Nephrol 21, 876-883

Bellini L, Vadori M, De Benedictis GM, Busetto R (2016): Effects of opioids on proximal renal tubular cells undergoing ATP depletion. J Pharmacol Sci 131, 288-291

Birn H, Christensen EI (2006): Renal albumin absorption in physiology and pathology. Kidney Int $\underline{69}, 440-449$

Bouchireb K, Boyer O, Gribouval O, Nevo F, Huynh-Cong E, Moriniere V, Campait R, Ars E, Brackman D, Dantal J et al. (2014): NPHS2 mutations in steroid-resistant nephrotic syndrome: a mutation update and the associated phenotypic spectrum. Hum Mutat $\underline{35}$, 178-186 
Boute N, Gribouval O, Roselli S, Benessy F, Lee H, Fuchshuber A, Dahan K, Gubler MC, Niaudet P, Antignac C (2000): NPHS2, encoding the glomerular protein podocin, is mutated in autosomal recessive steroid-resistant nephrotic syndrome. Nat Genet 24, 349354

Calles-Escandon J, Cipolla M (2001): Diabetes and endothelial dysfunction: a clinical perspective. Endocr Rev 22, 36-52

Carter DC, He XM, Munson SH, Twigg PD, Gernert KM, Broom MB, Miller TY (1989): Three-dimensional structure of human serum albumin. Science (New York, N.Y.) 244, $1195-1198$

Celsi G, Larsson L, Seri I, Savin V, Aperia A (1989): Glomerular adaptation in uninephrectomized young rats. Pediatr Nephrol (Berlin, Germany) $\underline{3}$, 280-285

Cheng H, Harris RC (2014): Renal endothelial dysfunction in diabetic nephropathy. Cardiovasc Hematol Disord Drug Targets $\underline{14}$, 22-33

Chew C, Lennon R (2018): Basement Membrane Defects in Genetic Kidney Diseases. Frontiers in pediatrics $\underline{6}, 11$

Cicchetti DV (1994): Guidelines, criteria, and rules of thumb for evaluating normed and standardized assessment instruments in psychology. Psychol Assess $\underline{6}$, 284-290

Cosgrove D, Liu S (2017): Collagen IV diseases: A focus on the glomerular basement membrane in Alport syndrome. Matrix Biol 57-58, 45-54

Cosgrove D, Meehan DT, Grunkemeyer JA, Kornak JM, Sayers R, Hunter WJ, Samuelson GC (1996): Collagen COL4A3 knockout: a mouse model for autosomal Alport syndrome. Genes \& development 10, 2981-2992

Cosgrove D, Rodgers K, Meehan D, Miller C, Bovard K, Gilroy A, Gardner H, Kotelianski V, Gotwals P, Amatucci A, et al. (2000): Integrin alpha1beta1 and transforming growth factor-beta1 play distinct roles in alport glomerular pathogenesis and serve as dual targets for metabolic therapy. Am J Pathol 157, 1649-1659

Delanaye P, Weekers L, Dubois BE, Cavalier E, Detry O, Squifflet J-P, Krzesinski J-M (2012): Outcome of the living kidney donor. Nephrol Dial Transplant 27, 41-50

Deltas C, Savva I, Voskarides K, Papazachariou L, Pierides A (2015): Carriers of Autosomal Recessive Alport Syndrome with Thin Basement Membrane Nephropathy Presenting as Focal Segmental Glomerulosclerosis in Later Life. Nephron 130, 271-280 
Ding F, Wickman L, Wang SQ, Zhang Y, Wang F, Afshinnia F, Hodgin J, Ding J, Wiggins RC (2017): Accelerated podocyte detachment and progressive podocyte loss from glomeruli with age in Alport Syndrome. Kidney Int 2, 1515-1525

Edwards BF (2001): Postoperative renal insufficiency. Med Clin North Am 모, 1241-1254

Elkader A, Sproule B (2005): Buprenorphine: clinical pharmacokinetics in the treatment of opioid dependence. Clin Pharmacokinet 44, 661-680

Ellison DH (2017): Treatment of Disorders of Sodium Balance in Chronic Kidney Disease. Adv Chronic Kidney Dis 24, 332-341

Fox JW, Mayer U, Nischt R, Aumailley M, Reinhardt D, Wiedemann H, Mann K, Timpl R, Krieg T, Engel J, et al. (1991): Recombinant nidogen consists of three globular domains and mediates binding of laminin to collagen type IV. EMBO J 10, 3137-3146

Funk SD, Lin MH, Miner JH (2018): Alport syndrome and Pierson syndrome: Diseases of the glomerular basement membrane. Matrix Biol 71-72, 250-261

Gillion V, Dahan K, Cosyns JP, Hilbert P, Jadoul M, Goffin E, Godefroid N, De Meyer M, Mourad M, Pirson Y, et al. (2018): Genotype and Outcome After Kidney Transplantation in Alport Syndrome. Kidney Int Rep $\underline{3}$, 652-660

Grahammer F, Schell C, Huber TB (2013): Molecular understanding of the slit diaphragm. Pediatr Nephrol (Berlin, Germany) 28, 1957-1962

Gross O, Netzer KO, Lambrecht R, Seibold S, Weber M (2003): Novel COL4A4 splice defect and in-frame deletion in a large consanguine family as a genetic link between benign familial haematuria and autosomal Alport syndrome. Nephrology, dialysis, transplantation : official publication of the European Dialysis and Transplant Association - European Renal Association 18, 1122-1127

Gross O, Beirowski B, Harvey SJ, McFadden C, Chen D, Tam S, Thorner PS, Smyth N, Addicks K, Bloch W, et al. (2004): DDR1-deficient mice show localized subepithelial GBM thickening with focal loss of slit diaphragms and proteinuria. Kidney Int 66, 102-111

Gross O, Licht C, Anders HJ, Hoppe B, Beck B, Tonshoff B, Hocker B, Wygoda S, Ehrich JH, Pape L, et al. (2012): Early angiotensin-converting enzyme inhibition in Alport

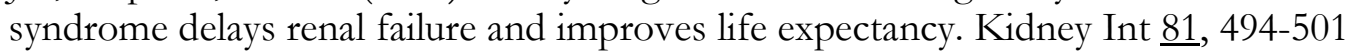


Gunwar S, Ballester F, Noelken ME, Sado Y, Ninomiya Y, Hudson BG (1998): Glomerular basement membrane. Identification of a novel disulfide-cross-linked network of alpha3, alpha4, and alpha5 chains of type IV collagen and its implications for the pathogenesis of Alport syndrome. J Biol Chem $\underline{273}$, 8767-8775

Hamano Y, Grunkemeyer JA, Sudhakar A, Zeisberg M, Cosgrove D, Morello R, Lee B, Sugimoto H, Kalluri R (2002): Determinants of vascular permeability in the kidney glomerulus. J Biol Chem 277, 31154-31162

Hamming I, Navis G, Kocks MJ, van Goor H (2006): ACE inhibition has adverse renal effects during dietary sodium restriction in proteinuric and healthy rats. J Pathol $\underline{209}, 129$ 139

Haraldsson B, Nystrom J, Deen WM (2008): Properties of the glomerular barrier and mechanisms of proteinuria. Physiol Rev $\underline{88}, 451-487$

Harvey SJ, Jarad G, Cunningham J, Rops AL, van der Vlag J, Berden JH, Moeller MJ, Holzman LB, Burgess RW, Miner JH (2007): Disruption of glomerular basement membrane charge through podocyte-specific mutation of agrin does not alter glomerular permselectivity. Am J Pathol 171, 139-152

Hassan K, Khazim K, Hassan F, Hassan S (2011): Acute kidney injury associated with metamizole sodium ingestion. Renal failure $\underline{33}, 544-547$

Heidet L, Cai Y, Guicharnaud L, Antignac C, Gubler MC (2000): Glomerular expression of type IV collagen chains in normal and X-linked Alport syndrome kidneys. Am J Pathol 156, 1901-1910

Huber TB, Simons M, Hartleben B, Sernetz L, Schmidts M, Gundlach E, Saleem MA, Walz G, Benzing T (2003): Molecular basis of the functional podocin-nephrin complex: mutations in the NPHS2 gene disrupt nephrin targeting to lipid raft microdomains. Human molecular genetics $\underline{12}, 3397-3405$

Hudson BG (2004): The molecular basis of Goodpasture and Alport syndromes: beacons for the discovery of the collagen IV family. J Am Soc Nephrol 15, 2514-2527

Issa N, Stephany B, Fatica R, Nurko S, Krishnamurthi V, Goldfarb DA, Braun WE, Dennis VW, Heeger PS, Poggio ED (2007): Donor factors influencing graft outcomes in live donor kidney transplantation. Transplantation $\underline{83}$, 593-599 
Jais JP, Knebelmann B, Giatras I, De Marchi M, Rizzoni G, Renieri A, Weber M, Gross O, Netzer KO, Flinter F, et al. (2003): X-linked Alport syndrome: natural history and genotype-phenotype correlations in girls and women belonging to 195 families: a "European Community Alport Syndrome Concerted Action" study. J Am Soc Nephrol 14, 2603-2610

Joles JA, Kunter U, Janssen U, Kriz W, Rabelink TJ, Koomans HA, FLOEGE J (2000): Early mechanisms of renal injury in hypercholesterolemic or hypertriglyceridemic rats. J Am Soc Nephrol 11, 669-683

Kalluri R, Shield CF, Todd P, Hudson BG, Neilson EG (1997): Isoform switching of type IV collagen is developmentally arrested in X-linked Alport syndrome leading to increased susceptibility of renal basement membranes to endoproteolysis. J Clin Invest 99, 2470-2478

Kang JS, Colon S, Hellmark T, Sado Y, Hudson BG, Borza DB (2008): Identification of noncollagenous sites encoding specific interactions and quaternary assembly of alpha 3 alpha 4 alpha 5(IV) collagen: implications for Alport gene therapy. J Biol Chem 283, 3507035077

Kanwar YS, Danesh FR, Chugh SS (2007): Contribution of proteoglycans towards the integrated functions of renal glomerular capillaries: a historical perspective. Am J Pathol $\underline{171}, 9-13$

Kashtan CE (2003): Alport Syndrome and Thin Basement Membrane Nephropathy: Diseases Arising from Mutations in Type IV Collagen. Saudi journal of kidney diseases and transplantation : an official publication of the Saudi Center for Organ Transplantation, Saudi Arabia 14, 276-289

Kashtan CE (2004): Familial hematuria due to type IV collagen mutations: Alport syndrome and thin basement membrane nephropathy. Current opinion in pediatrics $\underline{16}$, $177-181$

Kashtan CE (2006): Renal transplantation in patients with Alport syndrome. Pediatr Transplant $\underline{10}$, 651-657

Kashtan CE (2018): Renal transplantation in patients with Alport syndrome: patient selection, outcomes, and donor evaluation. Int J Nephrol Renovasc Dis $\underline{11}$, 267-270

Kashtan CE, McEnery PT, Tejani A, Stablein DM (1995): Renal allograft survival according to primary diagnosis: a report of the North American Pediatric Renal Transplant Cooperative Study. Pediatr Nephrol (Berlin, Germany) 2, 679-684 
Kashtan CE, Kim Y, Lees GE, Thorner PS, Virtanen I, Miner JH (2001): Abnormal glomerular basement membrane laminins in murine, canine, and human Alport syndrome: aberrant laminin alpha2 deposition is species independent. J Am Soc Nephrol 12, 252-260

Kashtan CE, Ding J, Gregory M, Gross O, Heidet L, Knebelmann B, Rheault M, Licht C (2013): Clinical practice recommendations for the treatment of Alport syndrome: a statement of the Alport Syndrome Research Collaborative. Pediatr Nephrol (Berlin, Germany) $\underline{28}, 5-11$

Kashtan CE, Ding J, Garosi G, Heidet L, Massella L, Nakanishi K, Nozu K, Renieri A, Rheault M, Wang F, et al. (2018): Alport syndrome: a unified classification of genetic disorders of collagen IV alpha345: a position paper of the Alport Syndrome Classification Working Group. Kidney Int 로, 1045-1051

Kerjaschki D (2001): Caught flat-footed: podocyte damage and the molecular bases of focal glomerulosclerosis. J Clin Invest $\underline{108}, 1583-1587$

Koch T (1998): Origin and mediators involved in sepsis and the systemic inflammatory response syndrome. Kidney Int Suppl 64, S66-69

Koo TK, Li MY (2016): A Guideline of Selecting and Reporting Intraclass Correlation Coefficients for Reliability Research. J Chiropr Med 15, 155-163

Kruegel J, Rubel D, Gross O (2013): Alport syndrome--insights from basic and clinical research. Nature reviews. Nephrology $\underline{9}, 170-178$

Lüllmann-Rauch R: Taschenlehrbuch Histologie, 4. Auflage; Georg Thieme Verlag, Stuttgart 2012

Machuca E, Hummel A, Nevo F, Dantal J, Martinez F, Al-Sabban E, Baudouin V, Abel L, Grunfeld JP, Antignac C (2009): Clinical and epidemiological assessment of steroidresistant nephrotic syndrome associated with the NPHS2 R229Q variant. Kidney Int $\underline{75}$, $727-735$

Meehan DT, Delimont D, Cheung L, Zallocchi M, Sansom SC, Holzclaw JD, Rao V, Cosgrove D (2009): Biomechanical strain causes maladaptive gene regulation, contributing to Alport glomerular disease. Kidney Int $\underline{76}$, 968-976

Meyer-Schwesinger C (2016): The Role of Renal Progenitors in Renal Regeneration. Nephron 132, 101-109

Miner JH (1998): Developmental biology of glomerular basement membrane components. Curr Opin Nephrol Hypertens 7, 13-19 
Miner JH (1999): Renal basement membrane components. Kidney Int 6, 2016-2024

Miner JH (2005): Building the glomerulus: a matricentric view. J Am Soc Nephrol $\underline{16}$, 857861

Miner JH (2011): Organogenesis of the kidney glomerulus: focus on the glomerular basement membrane. Organogenesis $\underline{7}, 75-82$

Miner JH (2012): The glomerular basement membrane. Exp Cell Res 318, 973-978

Miner JH, Sanes JR (1994): Collagen IV alpha 3, alpha 4, and alpha 5 chains in rodent basal laminae: sequence, distribution, association with laminins, and developmental switches. J Cell Biol 127, 879-891

Miner JH, Sanes JR (1996): Molecular and functional defects in kidneys of mice lacking collagen alpha 3(IV): implications for Alport syndrome. J Cell Biol 135, 1403-1413

Miner JH, Li C (2000): Defective glomerulogenesis in the absence of laminin alpha5 demonstrates a developmental role for the kidney glomerular basement membrane. Developmental biology 217, 278-289

Miosge N, Sasaki T, Timpl R (2002): Evidence of nidogen-2 compensation for nidogen-1 deficiency in transgenic mice. Matrix Biol 21, 611-621

Murshed M, Smyth N, Miosge N, Karolat J, Krieg T, Paulsson M, Nischt R (2000): The absence of nidogen 1 does not affect murine basement membrane formation. Mol Cell Biol 20, 7007-7012

Neugarten J, Golestaneh L, Kolhe NV (2018): Sex differences in acute kidney injury requiring dialysis. BMC nephrology $\underline{19}, 131$

Noakes PG, Miner JH, Gautam M, Cunningham JM, Sanes JR, Merlie JP (1995): The renal glomerulus of mice lacking s-laminin/laminin beta 2: nephrosis despite molecular compensation by laminin beta 1 . Nat Genet $\underline{10}$, 400-406

Pavenstadt H, Kriz W, Kretzler M (2003): Cell biology of the glomerular podocyte. Physiological reviews $\underline{83}$, 253-307

Philippe A, Weber S, Esquivel EL, Houbron C, Hamard G, Ratelade J, Kriz W, Schaefer F, Gubler MC, Antignac C (2008): A missense mutation in podocin leads to early and severe renal disease in mice. Kidney Int $\underline{73}$, 1038-1047 
Pierides A, Voskarides K, Athanasiou Y, Ioannou K, Damianou L, Arsali M, Zavros M, Pierides M, Vargemezis V, Patsias C, et al. (2009): Clinico-pathological correlations in 127 patients in 11 large pedigrees, segregating one of three heterozygous mutations in the COL4A3/ COL4A4 genes associated with familial haematuria and significant late progression to proteinuria and chronic kidney disease from focal segmental glomerulosclerosis. Nephrology, dialysis, transplantation : official publication of the European Dialysis and Transplant Association - European Renal Association 24, 27212729

Poschl E, Schlotzer-Schrehardt U, Brachvogel B, Saito K, Ninomiya Y, Mayer U (2004): Collagen IV is essential for basement membrane stability but dispensable for initiation of its assembly during early development. Development (Cambridge, England) 131, 16191628

Pozzi A, Yurchenco PD, Iozzo RV (2017): The nature and biology of basement membranes. Matrix Biol 57-58, 1-11

Pricam C, Humbert F, Perrelet A, Amherdt M, Orci L (1975): Intercellular junctions in podocytes of the nephrotic glomerulus as seen with freeze-fracture. Lab Invest $\underline{33}, 209-218$

Remuzzi G, Bertani T (1998): Pathophysiology of progressive nephropathies. N Engl J Med $\underline{339}, 1448-1456$

Rennke HG, Venkatachalam MA (1977): Glomerular permeability: in vivo tracer studies with polyanionic and polycationic ferritins. Kidney Int 11, 44-53

Rennke HG, Cotran RS, Venkatachalam MA (1975): Role of molecular charge in glomerular permeability. Tracer studies with cationized ferritins. J Cell Biol 67, 638-646

Ricardo AC, Yang W, Sha D, Appel LJ, Chen J, Krousel-Wood M, Manoharan A, Steigerwalt S, Wright J, Rahman M, et al. (2019): Sex-Related Disparities in CKD Progression. J Am Soc Nephrol 30, 137-146

Rodewald R, Karnovsky MJ (1974): Porous substructure of the glomerular slit diaphragm in the rat and mouse. J Cell Biol $\underline{60}, 423-433$

Roselli S, Heidet L, Sich M, Henger A, Kretzler M, Gubler MC, Antignac C (2004): Early glomerular filtration defect and severe renal disease in podocin-deficient mice. Mol Cell Biol 24, 550-560

Sampson NS, Ryan ST, Enke DA, Cosgrove D, Koteliansky V, Gotwals P (2001): Global gene expression analysis reveals a role for the alpha 1 integrin in renal pathogenesis. J Biol Chem 276, 34182-34188 
Sander V, Davidson AJ (2014): Kidney injury and regeneration in zebrafish. Semin Nephrol 34, 437-444

Savige J, Rana K, Tonna S, Buzza M, Dagher H, Wang YY (2003): Thin basement membrane nephropathy. Kidney Int 64, 1169-1178

Savige J, Gregory M, Gross O, Kashtan C, Ding J, Flinter F (2013): Expert guidelines for the management of Alport syndrome and thin basement membrane nephropathy. J Am Soc Nephrol 24, 364-375

Savige J, Ars E, Cotton RG, Crockett D, Dagher H, Deltas C, Ding J, Flinter F, PontKingdon G, Smaoui N, et al. (2014): DNA variant databases improve test accuracy and phenotype prediction in Alport syndrome. Pediatr Nephrol (Berlin, Germany) 29, 971-977

Schymeinsky J, Nedbal S, Miosge N, Poschl E, Rao C, Beier DR, Skarnes WC, Timpl R, Bader BL (2002): Gene structure and functional analysis of the mouse nidogen-2 gene: nidogen-2 is not essential for basement membrane formation in mice. Mol Cell Biol 22, $6820-6830$

Sethi S, Haas M, Markowitz GS, D'Agati VD, Rennke HG, Jennette JC, Bajema IM, Alpers CE, Chang A, Cornell LD, et al. (2016): Mayo Clinic/Renal Pathology Society Consensus Report on Pathologic Classification, Diagnosis, and Reporting of GN. J Am Soc Nephrol 27, $1278-1287$

Sharma D, Hill AE, Christopher MM (2018): Hypercholesterolemia and hypertriglyceridemia as biochemical markers of disease in companion rabbits. Vet Clin Pathol 47, 589-602

Slagman MC, Waanders F, Hemmelder MH, Woittiez AJ, Janssen WM, Lambers Heerspink HJ, Navis G, Laverman GD (2011): Moderate dietary sodium restriction added to angiotensin converting enzyme inhibition compared with dual blockade in lowering proteinuria and blood pressure: randomised controlled trial. BMJ (Clinical research ed.) $\underline{343}, \mathrm{~d} 4366$

Smeets B, Kuppe C, Sicking EM, Fuss A, Jirak P, van Kuppevelt TH, Endlich K, Wetzels JF, Grone HJ, Floege J, et al. (2011): Parietal epithelial cells participate in the formation of sclerotic lesions in focal segmental glomerulosclerosis. J Am Soc Nephrol 22, 1262-1274

Srivastava T, Hariharan S, Alon US, McCarthy ET, Sharma R, El-Meanawy A, Savin VJ, Sharma M (2018): Hyperfiltration-mediated Injury in the Remaining Kidney of a Transplant Donor. Transplantation 102, 1624-1635

St John PL, Abrahamson DR (2001): Glomerular endothelial cells and podocytes jointly synthesize laminin-1 and -11 chains. Kidney Int 60, 1037-1046 
Strom EH, Banfi G, Krapf R, Abt AB, Mazzucco G, Monga G, Gloor F, Neuweiler J, Riess R, Stosiek P, et al. (1995): Glomerulopathy associated with predominant fibronectin deposits: a newly recognized hereditary disease. Kidney Int 4ㅁ, 163-170

Stueber T, Buessecker L, Leffler A, Gillmann HJ (2017): The use of dipyrone in the ICU is associated with acute kidney injury: A retrospective cohort analysis. Eur J Anaesthesiol 34, 673-680

Suleiman H, Zhang L, Roth R, Heuser JE, Miner JH, Shaw AS, Dani A (2013): Nanoscale protein architecture of the kidney glomerular basement membrane. eLife $\underline{2}$, e01149

Tabatabaeifar M, Wlodkowski T, Simic I, Denc H, Mollet G, Weber S, Moyers JJ, Bruhl B, Randles MJ, Lennon R, et al. (2017): An inducible mouse model of podocin-mutationrelated nephrotic syndrome. PloS one $\underline{12}$, e0186574

Tonna S, Wang YY, Wilson D, Rigby L, Tabone T, Cotton R, Savige J (2008): The R229Q mutation in NPHS2 may predispose to proteinuria in thin-basement-membrane nephropathy. Pediatr Nephrol (Berlin, Germany) 23, 2201-2207

Tryggvason K, Pettersson E (2003): Causes and consequences of proteinuria: the kidney filtration barrier and progressive renal failure. J Intern Med 254, 216-224

Tryggvason K, Wartiovaara J (2005): How does the kidney filter plasma? Physiology (Bethesda, Md.) 20, 96-101

Tsukaguchi H, Sudhakar A, Le TC, Nguyen T, Yao J, Schwimmer JA, Schachter AD, Poch E, Abreu PF, Appel GB, et al. (2002): NPHS2 mutations in late-onset focal segmental glomerulosclerosis: R229Q is a common disease-associated allele. J Clin Invest $\underline{110}, 1659$ 1666

Vanholder R, Gryp T, Glorieux G (2018): Urea and chronic kidney disease: the comeback of the century? (in uraemia research). Nephrology, dialysis, transplantation : official publication of the European Dialysis and Transplant Association - European Renal Association $\underline{33}, 4-12$

Voskarides K, Arsali M, Athanasiou Y, Elia A, Pierides A, Deltas C (2012): Evidence that NPHS2-R229Q predisposes to proteinuria and renal failure in familial hematuria. Pediatr Nephrol (Berlin, Germany) 27, 675-679

Voskarides K, Damianou L, Neocleous V, Zouvani I, Christodoulidou S, Hadjiconstantinou V, Ioannou K, Athanasiou Y, Patsias C, Alexopoulos E, et al. (2007): COL4A3/COL4A4 mutations producing focal segmental glomerulosclerosis and renal failure in thin basement membrane nephropathy. J Am Soc Nephrol 18, 3004-3016 
Wickman L, Hodgin JB, Wang SQ, Afshinnia F, Kershaw D, Wiggins RC (2016): Podocyte Depletion in Thin GBM and Alport Syndrome. PloS one 11, e0155255

Yurchenco PD, O'Rear JJ (1994): Basal lamina assembly. Curr Opin Cell Biol $\underline{6}$, 674-681 


\section{Danksagung}

Mein Dank gilt in erster Linie Herrn Prof. Dr. med. Oliver Gross, welcher mir diese Dissertation unter seiner Leitung in seiner Arbeitsgruppe ermöglicht hat und mir stets mit Rat und Tat zur Seite stand. Seine immer freundliche Begleitung der Arbeit, insbesondere bei den regelmäßig unter seiner Leitung durchgeführten Laborgesprächen waren für mich eine wertvolle Hilfe. Des Weiteren stand Herr Prof. Dr. med. Oliver Gross mir als Scorer für die histologischen Bilder zur Verfügung.

Weiterhin möchte ich mich bei Frau Diplom-Biologin Diana Rubel bedanken. Frau Rubel hat mich stets bei den Versuchen unterstützt und stand mir neben ihrer Funktion als Versuchsleiterin stets beratend zur Seite. Des Weiteren führte Frau Rubel die Operationen an den Mäusen durch.

Die Betreuung des Mausstammes wäre ohne die Unterstützung von Frau Karoline Czeranski und Herrn Markus Konstantin Brüggemann nicht möglich gewesen. Ich möchte mich für die stets kollegiale Unterstützung herzlich bedanken.

Ebenfalls möchte ich mich bei meinem zweiten Betreuer für diese Arbeit bedanken, Herrn PD Dr. rer. nat. Krick.

Darüber hinaus gilt mein Dank Frau Dr. med. Ann-Kathrin Schäfer und Herrn Jan Simon Böckhaus, welche ebenfalls die histologischen Bilder gescoret haben.

Weiter gilt mein Dank auch Herrn Prof. Dr. med. Michael Zeisberg, welcher als kommissarischer Leiter der Klinik diese Forschung auch ermöglicht hat. 